\title{
DIE SOGENANN'TEN REDUPLICIERENDEN VERBA IM GERMANISCHEN.
}

\section{Iiteratur.}

Scherer, Zur geschichte der deutschen sprache ${ }^{2}$, s. $267 \mathrm{ff}$.

- Zs. f. d. östr. gymn. 24 (1873), s. $295 \mathrm{ff}$.

Sievers, Beitr. 1, $504 \mathrm{ff}$.

Pokorny, Ueber die redupl. praeterita der germ. sprachen u.s.w., Wissenschaftl. abhandlungen, Wien $u$. Leipzig (1874).

Schmidt, Vocalismus $\Pi$, s. $428 \mathrm{ff}$.

H off or $y$, Die redupl. praeterita im altnordischen, Kuhns Zs. 27, $593 \mathrm{ff}$.

Hol tha a sen, Die redupl. verba im germanischen, Kuhns Zs. 27, $618 \mathrm{ff}$.

Os th off, Zur reduplicationslehre, Beitr. 8, $540 \mathrm{ff}$.

Ljungstedt, Anmärkningar till det starka preteritum i germanska språk, Upsala 1887.

Ottmann, Die redupl. praeterita in den germ. sprachen (Jahresbericht der realschule zu Alzei, 1890), Leipzig 1890.

Holz, Urgerm. geschlossenes $\ddot{e}$ und verwantes, Leipzig 1890.

Lichtenberger, De verbis quae redupl. praet. etc. exhibebant, Nancy 1891 (Berger-Levrault \& Cie).

Zarncke, Beitr. 15, 350 ff.

Brugmann, IF. 6, 89 ff.

Franck, Zs. fda. 40, 24 ff.

Bethge in Dieters Laut- $u$. formenlehre der altgerm. dialekte, s. $361 \mathrm{ff}$. Hoffmann, $\boldsymbol{\Gamma E P} A \boldsymbol{\Sigma}$ : Abh. z. idg. sprachgeschichte. Festschrift zu A. Ficks 70. geburtstag, Göttingen 1903, s. 33 ff. (citiert: Hoffmann, $r$.).

L o ewe, Kuhns Zs. 40, 266 ff.

J anko, IF. 20, 229 ff. (hier findet man eine ganz ausführliche aufzählung der einschlägigen literatur).

Einschlägige arbeiten, die sich nicht ausschliesslich mit unserm gegenstand beschäftigen, sind an der in betracht kommenden stelle dieser abhandlung angeführt. 
Uebersicht über die reduplicierenden

\begin{tabular}{|c|c|c|c|c|}
\hline & Urgerm. & Gotisch & Altisländ'isch & Altschwed. \\
\hline & $\begin{array}{l}\text { aikan } z u- \\
\text { sprechen }\end{array}$ & af-aikan, =aiaik, & & \\
\hline & aikan rasen & &,,-- eikenn & \\
\hline & alpan &,,-- us-alpans &,-- , aldenn & \\
\hline & *aran, arjan & ar̀jăn, 一, 一 & & \\
\hline & aukan & aukan, - aiauk, - & $\begin{array}{l}\text { auka, iók, pl. iukom, } \\
\text { aukenn }\end{array}$ & \\
\hline & ausan & & $\begin{array}{l}\text { ausa, iós, } p l \text { iusom, } \\
\text { ausenn }\end{array}$ & \\
\hline 7) & aupan & &,- , auđenn & \\
\hline & bannan & & & \\
\hline & bauan & & $\begin{array}{l}\text { búa, bió,pl. biuggom, } \\
\text { búenn }\end{array}$ & \\
\hline 10) & bautan & & bauta, -, -bautenn & \\
\hline 11) & bēgan & & & \\
\hline 12) & bēsan & & & \\
\hline 13) & blandan & blandan,,-- & $\begin{array}{l}\text { blanda, blett, blan- } \\
\text { denn }\end{array}$ & \\
\hline 14) & blēan & & & \\
\hline 15) & blēsan &,- , uf-blēsans & blása, blés, blásenn & \\
\hline 16) & blōan & & & \\
\hline 17) & blōtan & blōtan, 一, 一 & blóta, blét, blótenn & \\
\hline & b-nauan & b-nauan, 一, - & 一, b-nere (3.sg.), - & \\
\hline 19) & brēdan & & & brāpa, 一, brāpin \\
\hline 20) & brokan & & & \\
\hline
\end{tabular}


verbon des germanischen.

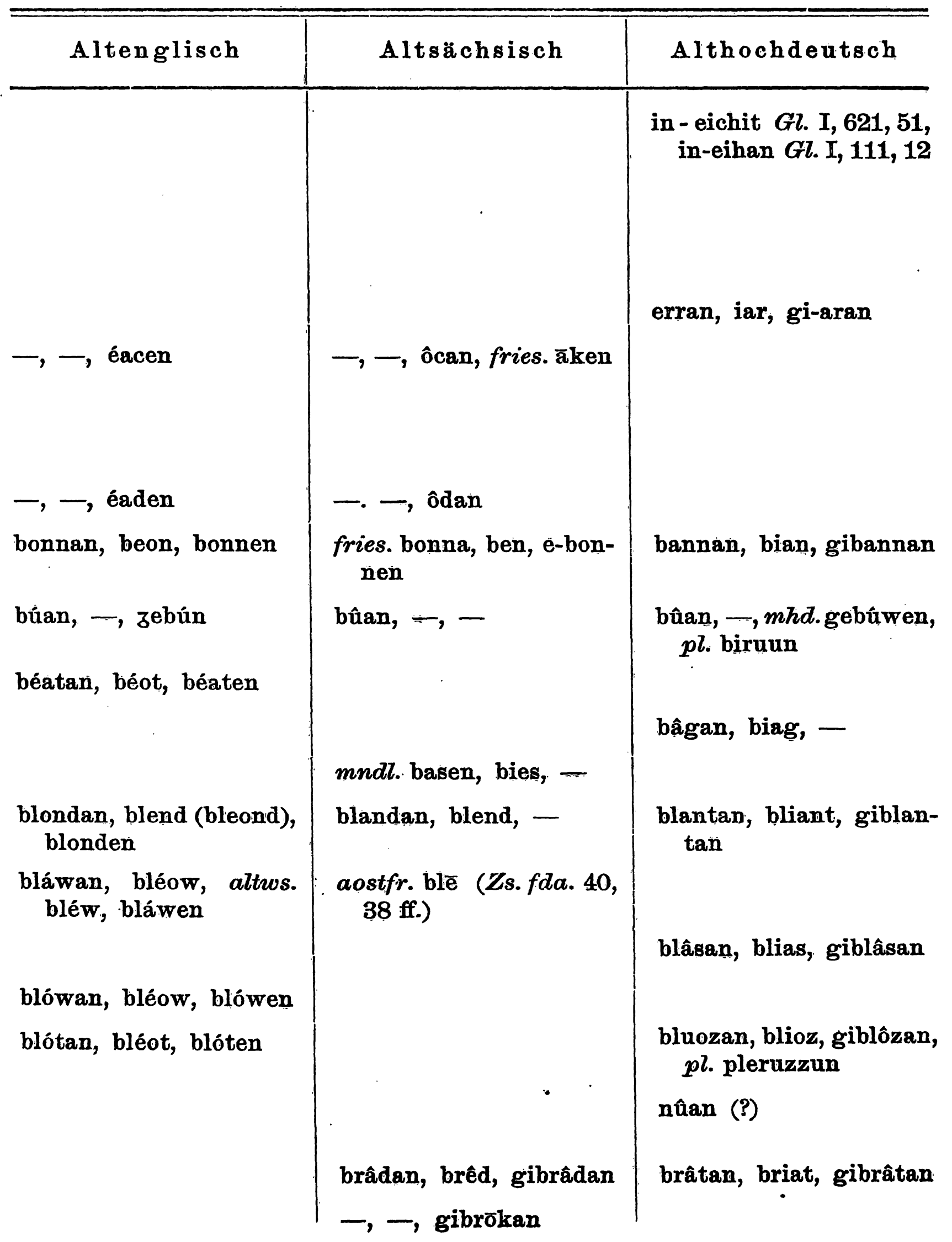




\begin{tabular}{|c|c|c|c|}
\hline Urgerm. & Gotisch & Altisländisch & Altschwed. \\
\hline 21) drēdan & & 1 & \\
\hline 22) fāhan & fahan, faifäh, - & $\begin{array}{l}\text { fá, fekk, pl. fingom, } \\
\text { fangenn }\end{array}$ & $\begin{array}{l}\text { fā, fik (faek), pl. } \\
\text { fingo, fangin }\end{array}$ \\
\hline 23) fallan & & falla, fell, fallenn & $\begin{array}{l}\text { falla, fiol (fael, } \\
\text { fal), fallin }\end{array}$ \\
\hline 24) falpan & -, faifalp, - & falda, felt, faldenn & \\
\hline 25) fējan (?) & faian,,-- & & \\
\hline 26) flōan & & & \\
\hline 27) flōkan & -, faiflok,- & 一; 一, flókenn & \\
\hline 28) fraisan & fraisan, faifrais, & & \\
\hline 29) gangan & $\begin{array}{l}\text { gaggan, -, us- } \\
\text { gag'gans }\end{array}$ & $\begin{array}{l}\text { gang’a, gekk, pl. gin- } \\
\text { gom, gingenn }\end{array}$ & $\begin{array}{l}\text { ganga, gik (aschro. } \\
\text { gaek), gangin }\end{array}$ \\
\hline $\begin{array}{l}\text { 30) g-nauan vgl. } \\
\text { no. } 18\end{array}$ & & gnúa, gnera, gnúenn & \\
\hline 31) grētan & grētan, gaigrōt, & $\begin{array}{l}\text { gráta, grét (greit), } \\
\text { grátenn }\end{array}$ & $\begin{array}{l}\text { gräta, graet, } \\
\text { (grēt, pl.grito): } \\
\text { grātin }\end{array}$ \\
\hline 32) grōan & & gróa, grera, gróenn & \\
\hline 33) hāhan & hahan, -haihah, & $\begin{array}{l}\text { hanga, hekk, pl. hen- } \\
\text { gom, hangenn }\end{array}$ & \\
\hline 34) haitan & haitan, haihait, & $\begin{array}{l}\text { heita, hét (heit, hei- } \\
\text { tom), heitenn }\end{array}$ & $\begin{array}{l}\text { hèta, hāet, hë- } \\
\text { tinn (run. hai- } \\
\text { ta; agutn. hit, } \\
\left.\text { mschw. hēt) }{ }^{1}\right)\end{array}$ \\
\hline 35) haldan & $\begin{array}{l}\text { haldan, -, hal- } \\
\text { dans }\end{array}$ & $\begin{array}{l}\text { halda, helt (wn. heilt) } \\
\text { haldenn }\end{array}$ & $\begin{array}{l}\text { halda, hiolt(haelt, } \\
\text { halt), haldin }\end{array}$ \\
\hline
\end{tabular}

1) Runschwed. perf. ait ist wol als hait aufzufassen (Noreen, Altschwed. gramm. s. 444). 


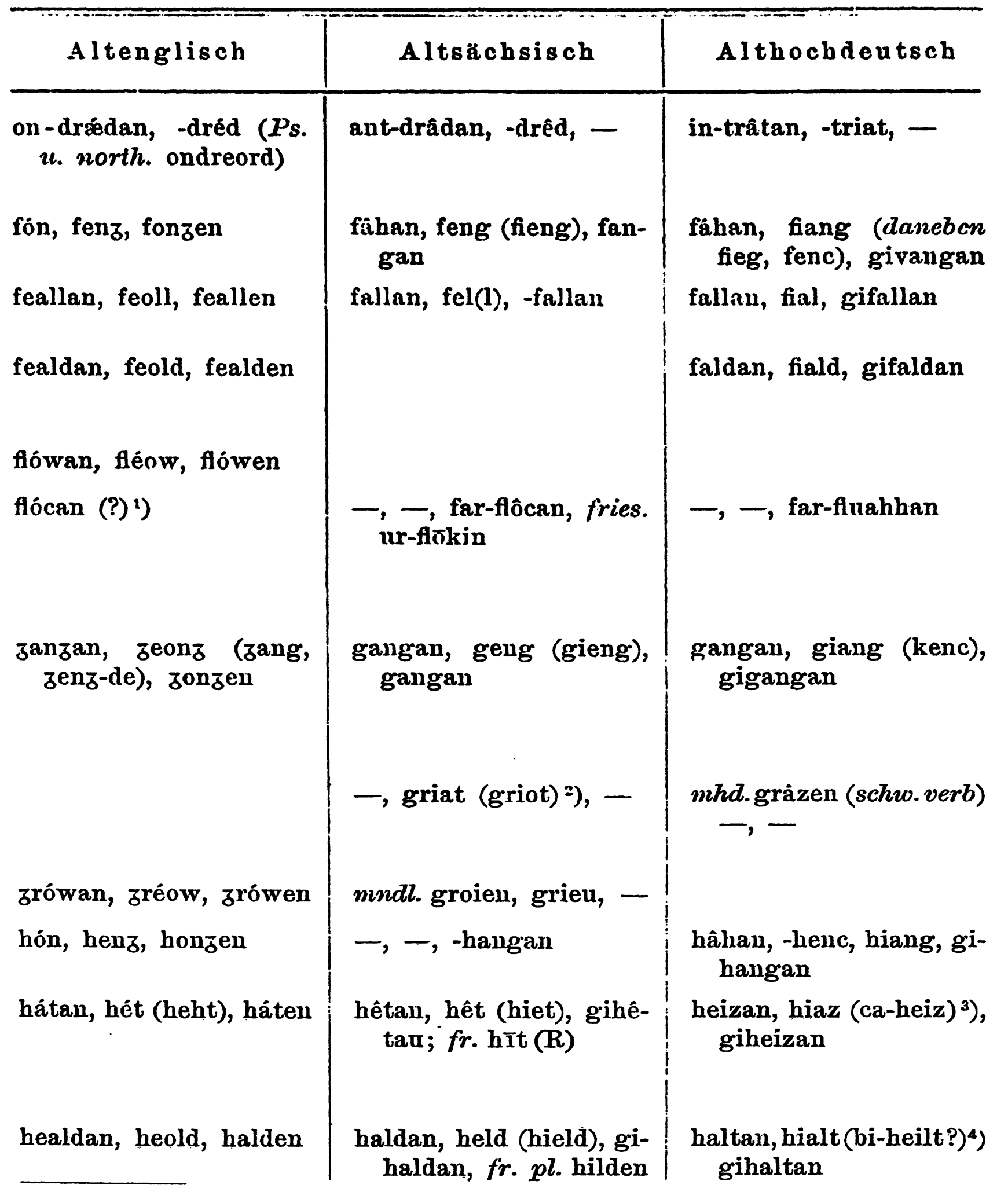

1) Vgl. Sievers, Beitr. 9, 287.

2) Oder eher zu griotan, greotan = aé. zréotan, perf. zréat? (Hoffmann, $\Gamma$. s. 56). Anders Roediger, Zs. fda. 20, 243 und Janko, IF. 20, $283 \mathrm{f}$.

3) Vgl. Singer, Beitr. 11, 294 und Janko, IF. 20, 270.

4) Vgl. Singer a.a.o. ei-formen finden sich z. b. im text B der Fuldaer beichte, daneben aber auch ie-formen: furleiz neben furlieze. 


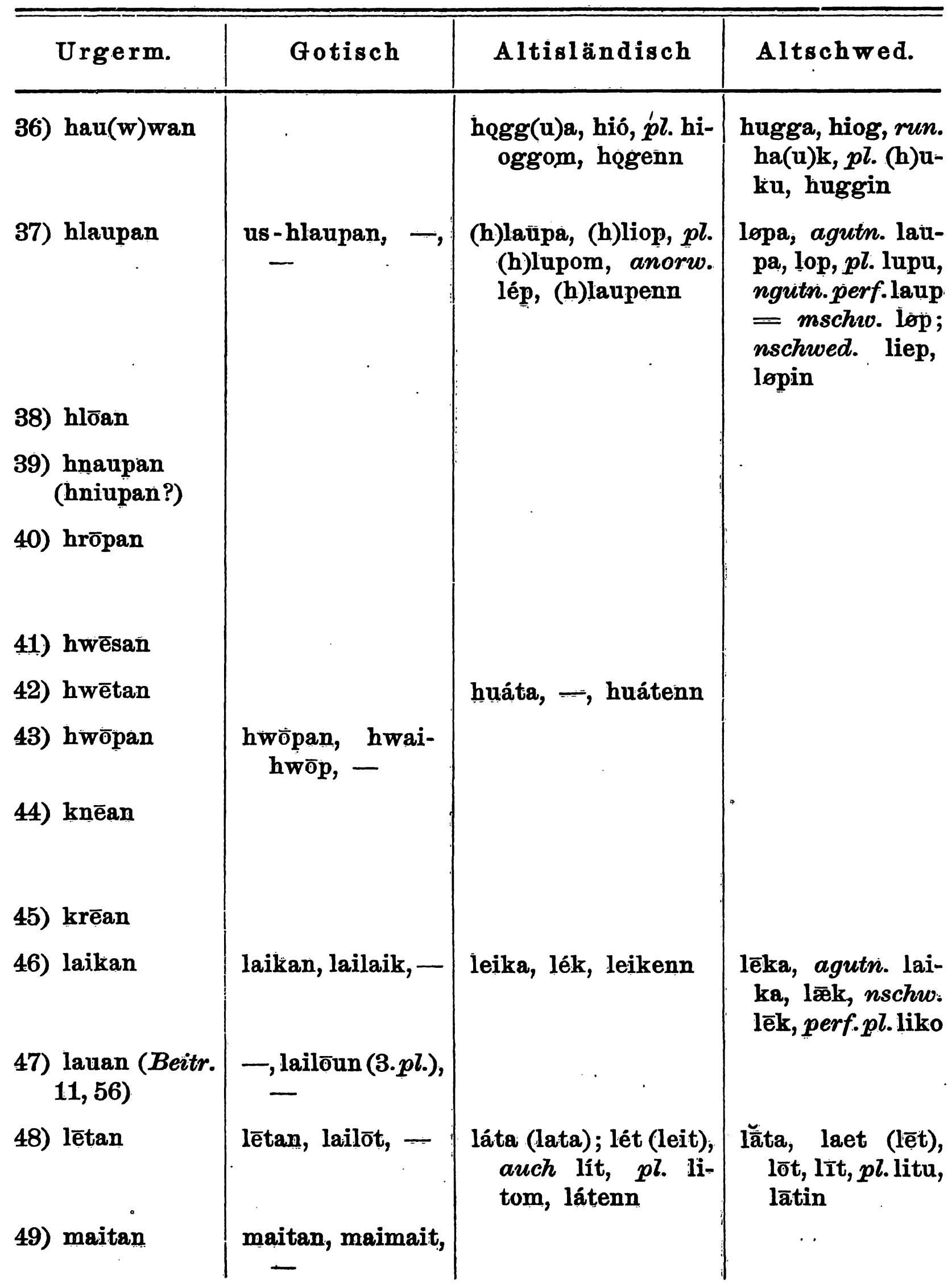




\begin{tabular}{|c|c|c|}
\hline Altenglisch & Altsächsisch & Althochdeutsch \\
\hline héawan, héow, héawen & $\begin{array}{l}\text { ha(u)wan, -heu, gihau- } \\
\left.\text { wan }{ }^{2}\right) \text {, perf. mnal. } \\
\text { hieu, pl. hieuwen }\end{array}$ & $\begin{array}{l}\text { houwan, hio (hin), pl. } \\
\text { hiowun (hiuwun), gi- } \\
\text { houwan }\end{array}$ \\
\hline $\begin{array}{r}\text { hléapan, hléop, hléapen, } \\
\text { pl. hlupon ( } \alpha \dot{\alpha} \pi . \lambda \dot{\varepsilon} \gamma \text {.) }\end{array}$ & $\begin{array}{l}\text { (-hlôpan), -hliepun, -hli- } \\
\text { opun, fr. hlâpa, hlêp, } \\
\text { opt. hliope }\end{array}$ & $\begin{array}{l}\text { (b)loufan, leof (liof, liaf), } \\
\text { mhd. pl. luffen, gilou- } \\
\text { fan }\end{array}$ \\
\hline \multicolumn{3}{|l|}{$\begin{array}{l}\text { hlówan, hléow, - } \\
\text { a-hnéapan (oder hneó- } \\
\text { pan?), hnéop, -hnéapeu }\end{array}$} \\
\hline hrópan, hréop, - & $\begin{array}{l}\text { hrôpan, hriop (hreop), } \\
\text { fr. roep, by-(h)rōpen }\end{array}$ & hruofan, hriof (hriuf), - \\
\hline \multicolumn{3}{|l|}{ hwésan 1), hwéos, - } \\
\hline \multicolumn{3}{|l|}{$\begin{array}{l}\text { cnáwan, cnéow, north. } \\
\text { cnǽw, altwos. cnéw, } \\
\text { cnáwen }\end{array}$} \\
\hline $\begin{array}{l}\text { cráwan, créow, cráwen } \\
\text { lácan, léc, north. leolc, } \\
\text { lácen }\end{array}$ & mndl. craien, crieu, - & \\
\hline $\begin{array}{l}\text { lǽtan, lét, north. leort, } \\
\text { lǽten }\end{array}$ & lâtan, lêt (liet), gilâtan & $\begin{array}{l}\text { lâzan, liaz, -leiz, gilâzan } \\
\text { meizan, miaz, gameizan }\end{array}$ \\
\hline $\begin{array}{l}\text { 1) Oder eher hwods } \\
\text { 2) Fries. } h \bar{a}(u) w e n .\end{array}$ & 2? Sievers a.a. 0 & $\cdot$ \\
\hline
\end{tabular}




\begin{tabular}{|c|c|c|c|}
\hline Urgerm. & Gotisch & Altisländisch & Altschwed. \\
\hline 50) mēan & & $i$ & \\
\hline 51) prangan & $\begin{array}{l}- \text {, -, ana-prag- } \\
\text { gans }\end{array}$ & - & \\
\hline 52) rēdan & $\begin{array}{r}\text { ga-rèdan, -rairōp, } \\
\text { - (ga-rapans) }\end{array}$ & $\begin{array}{l}\text { ráđa, réđ (reiđ), rá- } \\
\text { đenn }\end{array}$ & $\begin{array}{l}\text { rāpa, rǣp (rēp), } \\
\text { rāpin }\end{array}$ \\
\hline 53) rōan & & róa, rera, róenn & \\
\hline 54) saltan & $\begin{array}{l}\text { saltan, }- \text { un- } \\
\text { saltans }\end{array}$ & & \\
\hline 55) sējan & saian, saiso, & sá, sera, sáenn & \\
\hline 56) skaipan & $\begin{array}{l}\text { skaidan, skai- } \\
\text { skaip, - }\end{array}$ & & \\
\hline 57) skaldan & & & \\
\hline 58) skēpan & & & \\
\hline 59) skrautan & & & \\
\hline 60) slēpan & $\begin{array}{l}\text { slēpan, saislēp, } \\
\text {-saizlēp, - }\end{array}$ & & \\
\hline 61) snauan & & snúa, snera, snúenn & \\
\hline 62) sōan & & sóa, 一, sóenn & \\
\hline 63) spaldan & & & \\
\hline 64) spannan & & & \\
\hline 65) spōan & & & \\
\hline 66) staldan & $\begin{array}{l}\text { ga-staldan, stai- } \\
\text { stald, - }\end{array}$ & & \\
\hline 67) stautan & stautan, - , - & & \\
\hline 68) swaipan & & $\begin{array}{l}\text { sueipa, sueip, suei- } \\
\text { penn }\end{array}$ & \\
\hline
\end{tabular}




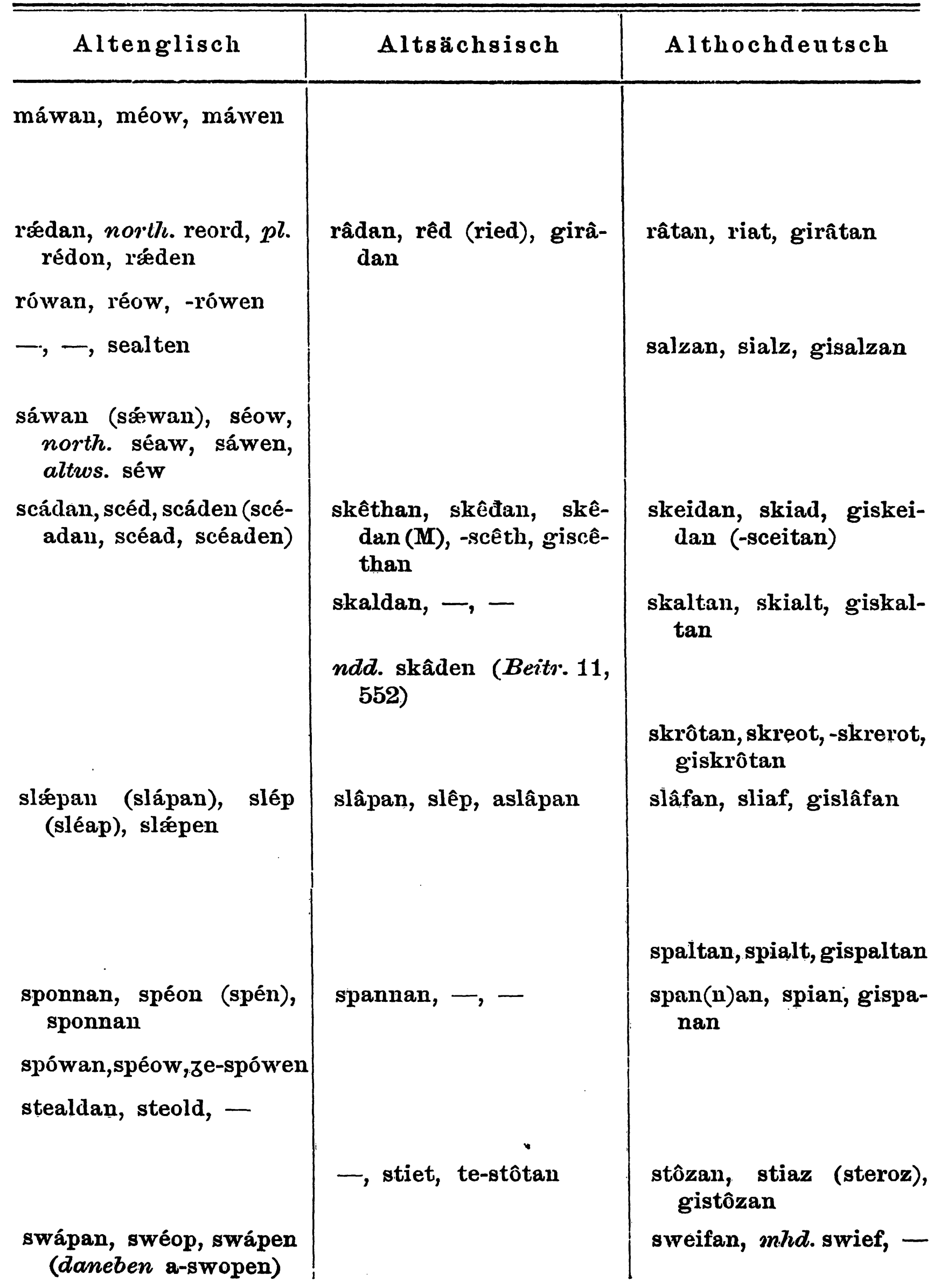




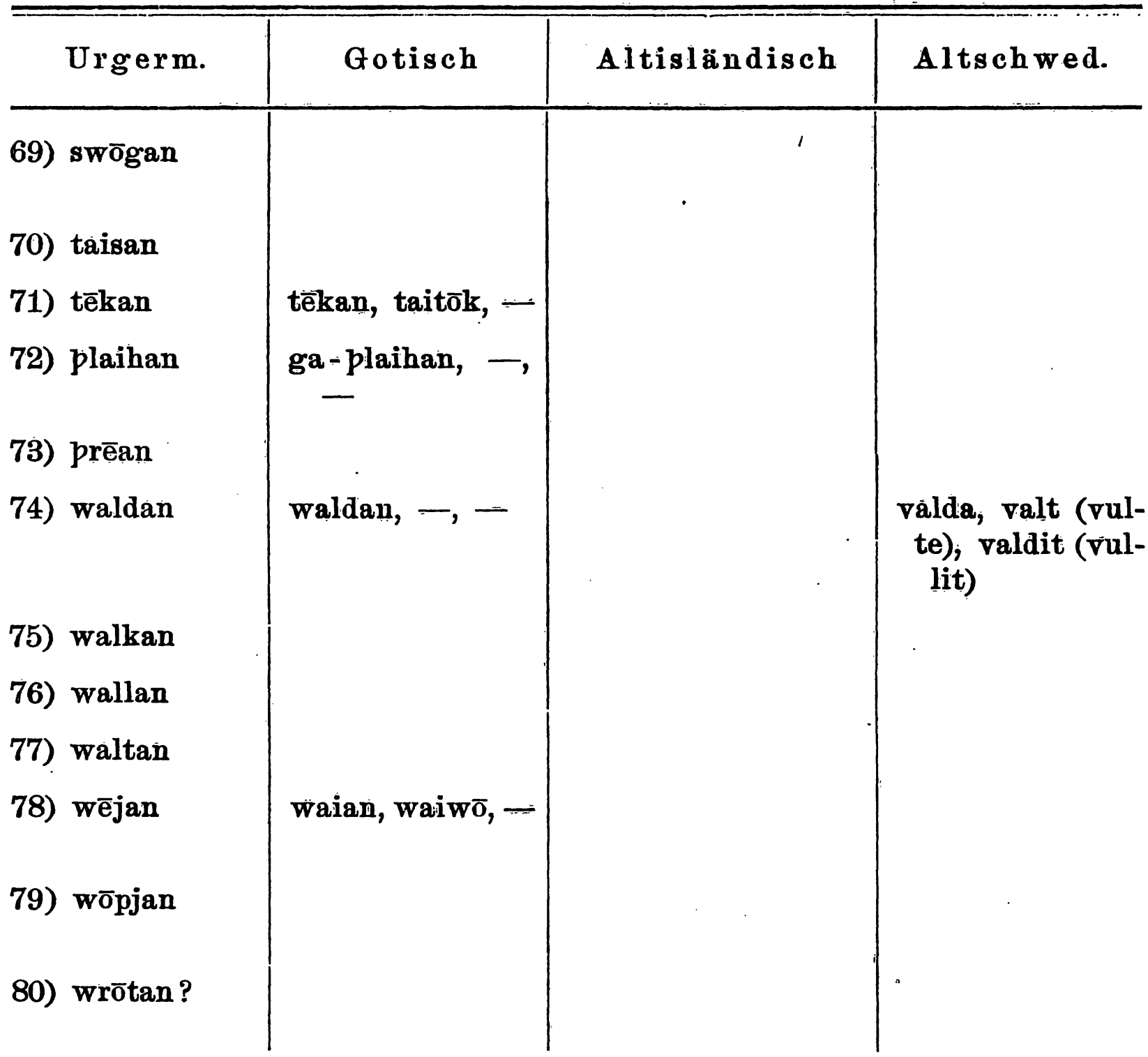

Vereinzelte formen des altenglischen: 1) á-blonzne (Lind. Matth. 26, 8); 2) á-bréot 'er tötete' (Beow. 2931); 3) héof, héofon zu héofan, as. hioban, ahd.hiuban, got. pl.hufum; á-hnéop 'pflückte ab' (Leg. of Gúðlác); ze-néop (Exod. 475) zu got. dishniupan, dishmupnan, aschwed. nyūpa 'kneife'; onvéod 'inbuit' (Corpus Gloss. 1129) zu ae. hréodan 'schmücken', part. hroden = aisl. hrodenn 'gefärbt'. - Auch déoz (Beow. 851)? Vgl. Hoffmann, $\Gamma$. s. 55 und Sievers, Ags. gramm. ${ }^{3} \S 396$, anm. 5, s. 223: - Vereinzelte form des altsächsischen: anskiann C $5798=$ ae. sción Beow. 303 (?).

Die red. verba nach ihren praesensvocalen geordnet:

1) $a$-Stämme (20):

albän, arjan, bannan, blandan, fallan, falban, fa(n)han, gangan, haldan, ha(n)han, prangan, saltan, skaldan, spaldan, spannan, staldan, waldan, walkàn, wallan, waltan. 


\begin{tabular}{|c|c|c|}
\hline Altenglisch & Altsüchsisch & Althochdeutsch \\
\hline swózan, swéoz, swúzen & $\begin{array}{c}\text { 8wôgan (vgl. Beitr. 11, } \\
\text { 286) }\end{array}$ & zeisan, zias, - \\
\hline $\begin{array}{l}\text { oráwnn, oréow, oráwen } \\
\text { wealdan, weold, weal- } \\
\text { den }\end{array}$ & $\begin{array}{l}\text { thrâan, -, - } \\
\text { waldan, -weld (-wield), } \\
\quad \text { - }\end{array}$ & waltan, wialt, - \\
\hline $\begin{array}{l}\text { wealcan, weolc, wealcen } \\
\text { weallan, weoll, weallen }\end{array}$ & wallan, wel(1), - & $\begin{array}{l}\text { walkan, -, giwalchen } \\
\text { wallan, wial, - } \\
\text { walzan, wialz (?), - }\end{array}$ \\
\hline wáwan, wéow, wáwen & $\begin{array}{l}\text { mnal. wâien, wiey, woei, } \\
\text { —, awfries. wē }\end{array}$ & \\
\hline $\begin{array}{l}\text { wépan, wéop (wép), } \\
\text { wópen } \\
\text { wrótan }\end{array}$ & $\begin{array}{l}\text { wôpian, wiop (weop, } \\
\text { wiep), wêpin }\end{array}$ & wuofan, wiof (wiuf), \\
\hline
\end{tabular}

2) ai-Stämme (10):

aikan (2 mal), fraisan, haitan, laikan, maitan, skaipan, swvaipan taisan, plaihan.

3) au-Stämme (14):

aukan, ausan, aupan, bautan, hauwan. Inlaupan, hnaupan (?), skrautan, stautan; bauan, bnauan, gnauan, lauan, snauan.

4) $\bar{e}$-Stämme (21):

bègan, bēsan, blēsan, brēedan, drēdan, gr•ētan, havessan, hwētan, lētan,

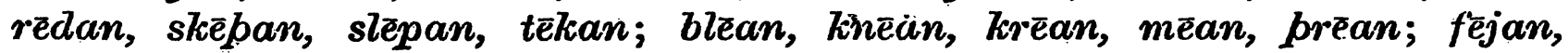
sejan, ఒvējan.

5) $\overline{0}$-Stämme (15):

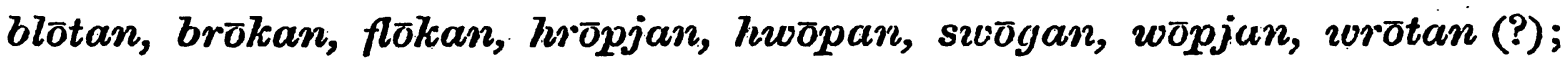
blöan, flöin, gröän, hlockn, v'öin, sōan, spōan. 


\section{Einleitung. - Das idg. perfect.}

Die frage nach der weiterentwickelung des indogerm. perfects im germanischen war seit der mitte der neunziger jahre des vorigen jahrhunderts für längere zeit aus dem vordergrunde der germanistischen forschung zurückgetreten; sie hat indes in den letzten jahren wider eine erhöhte beachtung gefunden. Kurz hintereinander haben A. Hoffmann, $\boldsymbol{I}$. (1903), R. Loewe in Kuhns Zs. 40,266 ff. (1906) und endlich J. Janko, IF. 20, $229 \mathrm{ff}$. (1906) den sogenannten reduplicierenden verben des germanischen zum teil sehr eingehende untersuchungen gewidmet. Im letzten grunde spitzt sich jede untersuchung, die auf diesem äusserst verwickelten gebiete angestellt wird, auf folgenden punkt zu: haben die verben des sog. $\bar{e}^{2}$ - bez. eo-typus im perfect in den nordisch-westgerm. mundarten einstmals ein redupliciertes perfect wie die entsprechenden zeitwörter des gotischen besessen, oder sind diese perfecta aus einer anderen grundform erwachsen? Während bis auf Brugmanns aufsatz, IF , 6,89 ff. (1896) allgemein angenommen wurde, dass alle germ. dialekte einmal reduplicierte perfecta aufzuweisen hatten, aus denen die ablautenden perfecta des $\vec{e}^{2-}$ und eo-typus herzuleiten sind, hat der genannte gelehrte die behauptung aufgestellt, dass in ihnen alte reduplicationslose praeterita. zu erblicken sind, die teils lautgesetzlich, teils analogisch auf hochstufenformen mit $\bar{e} i$ und $\bar{e} u$ als stammvocal zurückgehen. Gleichzeitig mit Brugmann hat ein amerikanischer gelehrter, Wood in den Germanic Studies 2, 27 ff. (Chicago 1896), denselben weg zur erklärung der nordisch-westgerm. perfectbildungen beschritten. Dagegen wante sich Hoffmann in dem genannten aufsatz und wies durch eingehende etymologische untersuchungen nach, dass zu keinem der praesentia mit -ai- und -au- als wurzelvocal stammesformen mit $\bar{e} i$ und $\bar{e} u$ sicher nachzuweisen sind. Indes nimmt er für die verben mit $\bar{e}$ im praesensstamm (létan) ein von diesem verschiedenes $\bar{e}$ im perfect (an. lét) an, das er aus geschleifter idg. betonung entstehen lässt, während ersteres idg. stosston besessen habe. Im anschluss daran lässt er aus einem urgerm. aorist *léilie (zu got. lailian) und *stéute (zu got. stautan) mit verlust der letzten silbe geschleift betonte delinstufige formen

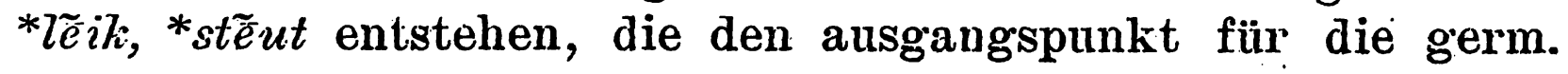


perfecta des $e^{2}$ - und eo-typus darstellen sollten. Auf dasselbe ziel, aber unter anderen voraussetzungen steuert Janko zu, der anstatt geschleift betonter urformen, deren zulässigkeit er bestreitet, solche mit $\bar{e}$ - und $\bar{\delta}$-ablaut statuiert, also *hëitc, *høita, gekürzt urgerm. *haita und *hlenp)a, *hloupa, gekürzt *hlaıp)a; das $e^{2}$ des perfects in *let lässt er in minder betonter silbe *lélit entstanden sein und gestuitzt durch ein lautgesetzlich erwachsenes $\bar{c}^{2}$ in *heta aus *heita in die haupttonige stelle iibertragen werden. Alle diese forscher sind also einig in dem punkte, dass die $\ddot{i}^{2}$. und eo-typen bei den sog. reduplicierenden verben auf reduplicationslose grundformen (Hoffmann bezeichnet sie als aoriste, Janko nennt sie praeterita) zurückgehen. In der erklärung des ursprungs dieser grundformen gehen sie indes ganz verschiedene weg.e. ${ }^{1}$ )

Auf dem älteren standpunkt, die perfecta des $\bar{e}^{2}$ - und eo-typus aus reduplicierten formen $z u$ erklären, belıar't dagegen Loewe in dem erwähnten aufsatz. Obwol er in manclien einzelheiten, wie auch Janko a.a.o. s. 307 anerkennt, das richtige trifft, so kann ich ihm trotzdem in der hauptsache, in seiner erklärung des verlustes der reduplication nicht beistimmen. $\mathrm{Er}$ sieht als dessen ursache eine 'haplologische' dissimilation an, $d$. h. von zwei gleichlautenden silben wird die eine, in unserm falle die erste, die reduplicationssilbe, unterdrückt. Beispiele für die haplologie gibt es, wie Loewe selbst in Kuhns Zs. 35, 609 ff. ausführt, vereinzelt in allen idg. sprachen: ai. çérgrdhas aus *çêra-v?dhas 'lieb, wert' (Brugmann, Kurze vgl. gramm. der idg:

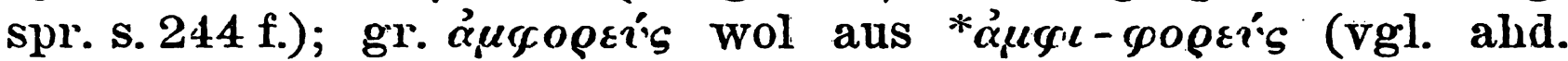
zubar, zwibar 'zuber') 'zweihenkliger krug'; got. awistr wol aus *awi-wist. (vgl. ahd. wist 'aufenthalt, wolnnung') 'schafstall'; nhd. falter aus mhd. vîvalter (daneben bayr. feifalter, auch vielfach volksetymologisch umgedeutet), u. ähnl. m. Im letzteren falle ist die veranlassung des haplologischen schwundes der ersten silbe wol der umstand, dass der nebenton auf der zweiten silbe vîvàlter zum hauptton wurde, wie in nhd. lebéndig, hollúnder, wachılólder u. a., und zunächst $\hat{\imath} \mathrm{zu} i$ gekürzt, dann zu lautschwachem $\ni$ wurde, das endlich schwand.

Aber die haplologische dissimilation, die sich in grösserem

1) Näheres iiber Hoffmanns und Jankos erklärungsversuche s. w. u. Eeiträge zur gesshichte der deutschen sprache. XXXII. 
umfang im keltischen sprachgebiet nachweisen lässt, ist auf germanischem boden immer nur eine vereinzelte erscheinung geblieben. Auch tritt sie in der regel nur bei solchen wörtern auf, deren etymologische beziehungen dem sprachbewusstsein verdunkelt oder entschwunden sind; bei bildungen aber, deren zugehörigkeit $\mathrm{zu}$ einer umfangreichen und productiven formenkategorie klar empfunden werden musste, wie dies bei den reduplicierten perfectformen der fall war, kann eine so durchgreifende unterdrückung eines charakteristischen bestandteils aus lautmechanischen gründen nicht zugegeben werden. Denn die verhältnisse im neugriechischen, wo $\delta a ́ \sigma x \alpha \lambda o s$ für $* \delta \iota \delta a ́ \sigma-$

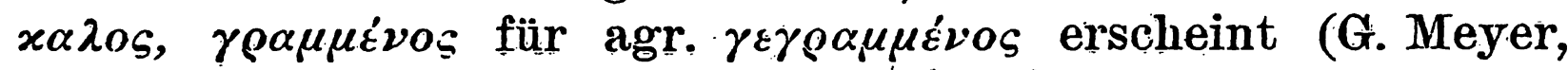
Gr. gramm. ${ }^{3} \S 549$, s. 629), dürfen nicht ohnë weiteres mit denjenigen in den altgermanischen dialekten verglichen werden, da hier eine weit ältere und von fremden idiomen anscheinend nicht wesentlich beeinflusste sprachstufe vorliegt. Eher schon könnte das baltisch-slavische zum vergleich herangezogen werden, wo bei dem einzig erhaltenen particip des sonst untergegangenen perfects die reduplication fehlt (ich sage nicht: verloren ist): aksl. črbţ (= lit. kiñtẹs) 'zu črbta 'ich schneide' ai. cakrvtvás - (Brugmann, Kurze vgl. gramm. s. 547). Aber vereinzelte 'restformen' (über den ausdruck vgl. E. Hermann, Kuhns Zs. 39, 609) einer kategorie sollten gerade infolge ihrer isolierung ihre ursprüngliche gestalt bewahren. ${ }^{1)}$ Statt also bei den baltisch-slavischen part. perf. angleichung an den verbalstamm des praesens oder mit Loewe haplologische dissimilation anzunehmen, vermute ich (mit Lorentz, IF. 8, 73 oder Bethge in Dieters Laut- und formenlehre der altgerm. dialekte s. 376), dass im indogerm. die reduplication bei dem sog. part. perf. überhaupt gefehlt hat, da der anschluss dieser adjectivbildung an das perfectsystem erst secundär erfolgt ist; vgl. formen wie

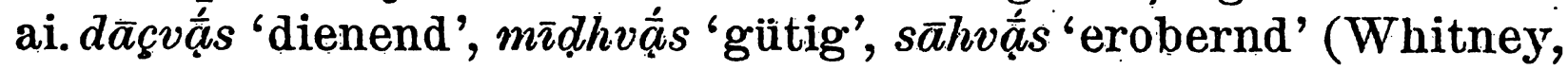

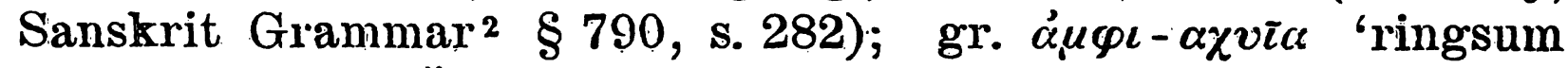

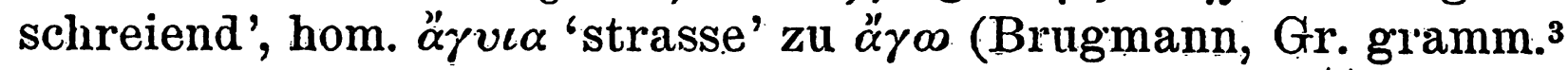

1) Vgl. J. Erdmann, Zs. f. d. mundarten, 1906, s. 151 ff. und passim, w.o isolierte wörter in altertïmlicher lautgestaltung aus des verf. mundart (Bingen a. Rh.) angeführt werden. - Auch für ältere sprachperioden lässt sich aus diesen tatsïchlichèn belegen anscheinend unregelmïssiger lautgestaltung mancherlei aufklärung erzielen. 
s. 324); ähnlich beim part. perf. pass. auf der alten inschrift

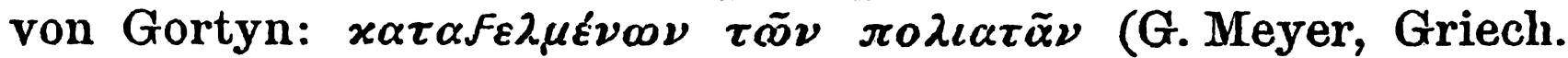
gramm. ${ }^{3} § 549$, s. 629); vgl. auch die isolierten formen got.

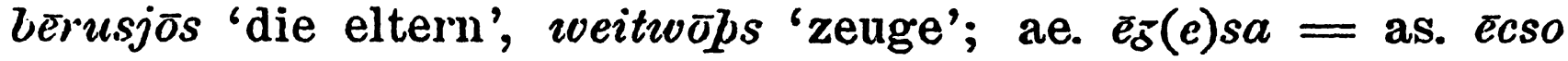
'besitzer' (zu got. aih, aigum aus *aigusja?), u. ä. m.

Auch im indicativ perfecti hat bekanntlich im indogermanischen die reduplication vereinzelt gefelılt, vgl. ai. vécla, gr. oí $\delta \alpha$, got. wait, abulg. vědé (mit medialer endung) 'ich weiss', apreuss. waidimai (plural), lat. $v \bar{\imath} d \bar{\imath}$ (?) oder ai. $\bar{\imath} g \bar{e}$ 'hat im besitz' = got. aih zu gr. jon. oỉxe 'ist gleich' (Brugmann, Grundriss $2,2,1212)$, vielleicht auch ai. $\dot{a} d l a$, lat. $\bar{e} d \bar{\imath}$, got. fr-èt 'ass', lit. $\dot{e} d$-usi (part. perf.). ')

Aus den einzelsprachen lassen sich die beispiele für das fehlen der reduplication im perfect noch vermehren; so fehlt sie im indischen in der älteren wie in der jüngeren sprache sehr häufig: ai. sárpa neben sasárpa (vgl. Brugmann a.a.o. und Whitney, Sanskrit Grammar ${ }^{2} \S 790$, s. 282); ebenso im

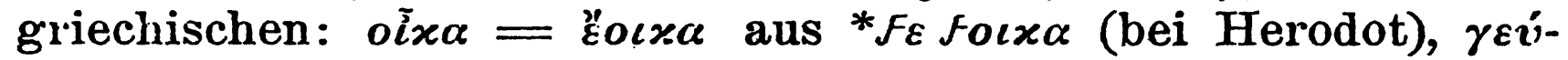

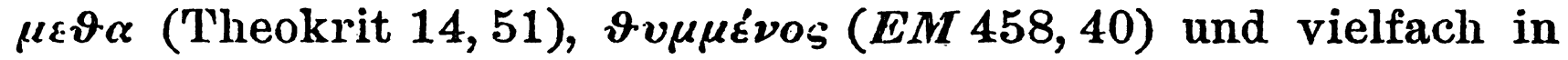
den glossen des Hesych, deren formen vielleicht der volkssprache entlehnt sind, die die reduplication, gleichwie das mittel- und neugriechische, in weiterem umfang entbehrt haben mag (G. Meyer, Gr. gramm.3 § 549, s. 628 f.). Ganz erloschen ist die reduplication im armenischen und baltisch-slavischen und auch das keltische bewahrt nur im irischen einige reste (s. w. u. s. 472), ebenso in gall. dede = lat. dedit oder mcymr. ciglef 'ich hörte'.

Ein beispiel der fehlenden reduplication geht scheinbar durchs indische, lateinische und germanische, nämlich ai. sêdimá = lat.sēdinus = got. sètum 'sassen'. Vielfach wird ein *sēdəmé schon für das indogerm. vorausgesetzt; man dachte an eine schon idg. ersatzdehnung * sēsdomé, *sezdamé, *sēdamé. Dagegen bemerkt Loewe a.a. o. s. 290 mit recht, dass $z$ vor $d$ nur im indischen und allenfalls im lateinischen schwinden konnte; ai. $n \bar{\imath} d a ́ s=$ lat. nìdus, aber ahd. nest aus *nizdom; ebenso av. hazdyāt aus *sazdyāt (opt. perf. zur wzl. sed, vgl. Hübschmann,

1) So Hirt, Idg. ablaut s. 194. Anders Lorentz, IF. 8, 71 ff., der reduplication annimmt, jedenfalls im singular. 
Kuhns Zs. 26, 325); arm. ost $=$ gr. ő $\zeta o s=$ got. asts aus idg. *ozdos, u.s.w. Aber der versuch Loewes, die form *sēdamé doch für das indogerm. zu retten, indem er folgendes lautgesetz aufstellt: 'folgt auf eine aus consonant $+e$ bestehende haupttonige anfangssilbe derselbe. consonant + vocal, so schwindet der consonant an zweiter stelle (*sessdmá, *seadmá, *sédmá, a. a. o. s. 319)' muss als misglückt bezeichnet werden, da Loewe für dieses ad hoc statuierte 'gesetz' selbst ausnahmen zugeben muss: ae. dide, as. deda, ahd. teta (aus einem idg. aorist *dhedhóm oder, wie Hirt, Idg. abl. s. 192 will, = ai. imp. ádadhām), aisl. sera (zu sá 'säen') = got. saisō (zu saian), aisl. rera (zu róa 'rudern') u. ähnl. mehr. Auch bemerkt Janko a.a.o. s. 308 ganz richtig, dass der idg. plural *sesdamé (mit schwundstufe) und nicht *sesodamé lauten müsste.

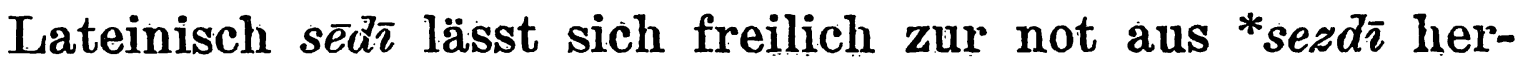
leiten; vgl. z. b. $c \bar{e} d \bar{o}$ aus ${ }^{*} c e-z d \bar{o}$ 'ich gehe einher', ce deiktische

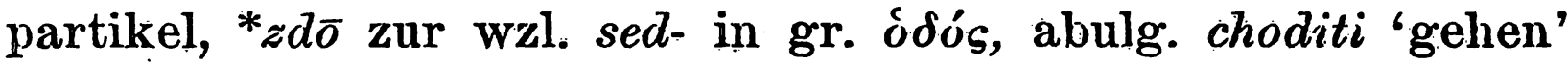
(Brugmann, IF. 13, 85). Aber es liegt doch viel näher, sēdi direct mit got. sētum zu verbinden ') und es auf eine linie mit formen wie vēnimus = got. qēmum, clēpimus = got. hlēfum, frēgimus = got. brēkum, $\bar{e}$ dimus $=$ got. fr-ëtum zu stellen und $\bar{e}$ als dehnstufenvocal der $e$-wurzel aufzufassen, über dessen entstehung freilich noch keine klarheit geschaffen ist (vgl. Hoffmann, $\Gamma$. s. 62 oder Brugmann, Kurze vgl. gramm. s. 542 und s. 544).

Wenn aber auch die gleichung ai. sēdimá = got. sētum aus unserer betrachtung ausscheiden muss, so bleibt doch genug material übrig, um den schluss zu erlauben, dass die reduplication nicht zu den unentbehrlichen kennzeichen des perfects im indogerm. gehörte (vgl. Brugmann, Grundriss 2, 2, 1208 und IF. 6, 91)); ja, das gänzliche fehlen derselben in der centralen gruppe der baltisch-slavisch-armenischen satem-sprachen führt gerádezu zu der annahme, dass der perfecttypus, den wir besonders im indischen und griechischen so consequent durchgeführt finden, erst einzelsprachlich entstanden ist, und dass

1) Es wäre dies überhaupt notwendig, wenn Lorentz a. a. o. s. 79 mit der gleichung lat. sēdit aus ${ }^{*}$ sẽdid $=$ ai. asādāt (TA) 3. sing. aor. opt. = got. sètei recht behielte. 
in der idg. grundsprache sich nur die ansätze dazu fanden. Es wird uns dies glaubhafter erscheinen, wenn wir uns des ursprungs der reduplication erinnern, aus der doppelsetzung der sog. wurzel, wie sie sich in den ai. praesentien mit intensivbedeutung findet: bhárībharti, später bärībharti zur wzl. bhar'tragen', wobei das bindevocalische $\breve{\imath}$ mit schwankender quantität (dessen ursprung wol in den auf ēi ausgehenden zweisilbigen basen $\mathrm{zu}$ suchen ist, s. Brugmann, Kurze vgl. gramm. s. 502) und die in älterer zeit noch erhaltene aspiration im anfang die selbständigkeit des ersten gliedes beweisen. ${ }^{1}$ ) Diese art der reduplication, welche die am frühesten belegte ist, kommt bei über 20 wurzeln in der älteren sprache vor (Whitney, a.a. o. $\$ 1002, c)$. Dass sie schon in idg. zeit vorhanden war, beweisen gleichungen wie av. fra-yrā-yrāyeiti 'er weckt auf'

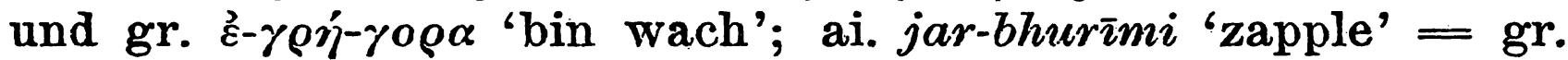
$\pi \circ \varrho-\varphi v ́ \rho \infty ~ ' b i n ~ i n ~ u n r u h i g e r ~ b e w e g u n g ' ; ~ a r m . ~ m \dot{r}-n i \dot{r} a m=g r$.

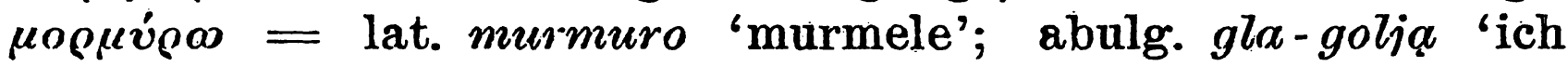
spreche' und viele andere. Daneben kommt schon im ältesten indisch auch eine verkürzte form der reduplication vor: neben badbadh $\bar{e}$ findet sich $\bar{b} \bar{a} b a d h \bar{e}$ 'er drängt'. Weiter verkürzt ist die reduplicationssilbe in den zahlreichen reduplicierten praesensbildungen besonders des indischen und griechischen mit reduciertem vocal $a$ oder $i$ in der ersten silbe: ai. dádāmi $=$ gr.

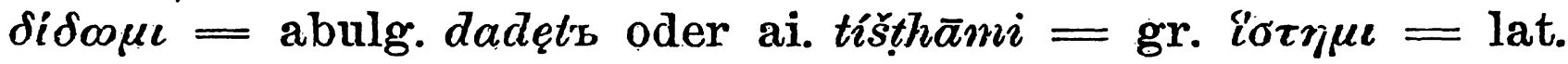
sisto oder ai. bibhémi $=$ ahd. bibêm u.s.w.

Die am weitesten fortgeschrittene lautliche entwickelung der reduplication finden wir im perfectum, das schon in idg. zeit den reduplicationsvocal $e$ besass (daneben $\bar{e}$, s. Brugmann a.a.o. s. 543 und weiter unten). Wir dürfen daher erwarten, dass auch in begrifflicher hinsicht das perfect den endpunkt einer langen entwickelung darstellt.

Von haus aus hatte die reduplication wie jede wortwiderholung steigernde (intensiv-) wirkung; mit der sich der iterative sinn verbinden konnte: ai. prīyúsprīyas 'sehr lieb' (man beachte die betonung!), lat. $m \bar{e} m e \bar{e}$, ahd. selbselbo u.s.w. Iterative bedeutung hat sich besonders bei den verben, die wirkungen

1) Auch doppelaccente wie ai. bál-baltíti oder accentschwankungen: dadhītá : dúdhīta (a.a.o. s. 481) führen zu demselben schluss. 


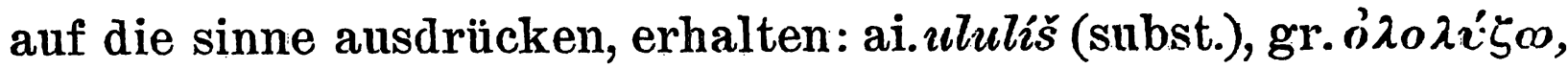
lat. ululare 'wehklagen'. Aber auch bei den präsentien mit $i$ in der reduplicationssilbe lassen sich noch spuren iterativer

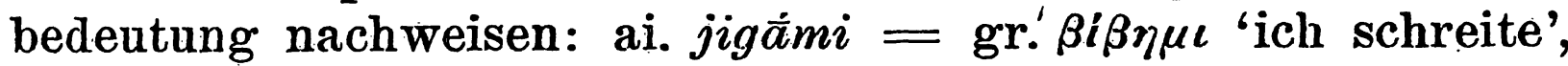
d.h. ich setze widerholt den fuss auf. Diese art verba, bei denen die iterative bedeutung in die gegenwärtig zuständliche übergegangen ist, bilden mit zahlreichen anderen: *voida 'ich habe gesehen und weiss', *memona 'ich habe widerholt im sinn gehabt und entsinne mich nun' eine brücke zur entwickèlung der bedeutung des perfects. Erstreckt sich nämlich die iterative wirkung nicht mehr bis in die gegenwart, so ist der gegenwärtig dạernde zustañd in den gegenwärtig vollendeten

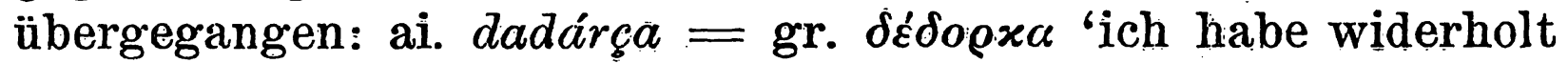
gesehen und diese tätigkeit jetzt abgeschlossen'. Loewe a.a.o. s. 277 beschränkt sich $\mathrm{m}$. e. auf ein zu enges gebiet, wenn er die entstehúng der perfectiven actionsart allein auf die verba zurückführt, die ein lustgefühl bezeichnen, und annimmt, dass dies aus der vergangenheit stammende lustgefühl in die gegenwart hineinrage (subjective intensität). Wir brauchen also durchaus nicht auf eine erklärung der bedeutungsentwickelung des perfects zu verzichten, wie Brugmann a.a. o. s. 509 es will, wenn auch dieser vorgang weit in die idg. vorzeit zurückgeht. Wann sie indes vor sich gieng, ob vor oder nach dem inkrafttreten der lautgesetze, die den idg. ablaut schufen, braucht uns hier nicht zu kümmern, obwol mit Bartholomae, Wochenschrift f. klass. phil. 17, 1223 anzunehmen ist, dass das zusammenwachsen von reduplications- und stammsilbe nicht in so früher zeit stattfand. Dafür spricht auch, dass neben kurzem $\breve{e}$ als reduplicationsvocal sich in historischer zeit auch $\bar{e}$ noch findet, das Brugmann, Grundriss 2, 2, 1208 auch für die idg. zeit ansetzt, während Hirt, Idg. abl. s. $195 \bar{e}$ als dehnstufe von $\breve{e}$ auf die 3. plur. beschränkt. Langen reduplicationsvocal finden wir in ai. jāa $\bar{a} r a, d \bar{a} \bar{d} \bar{a} r a=$ gathav. $d \bar{a} d r \bar{e}$ von wzl.

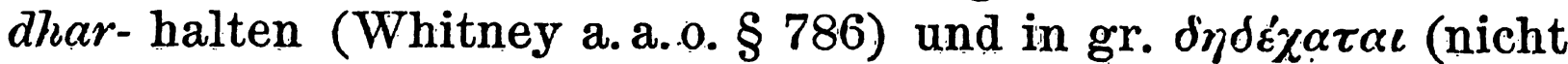

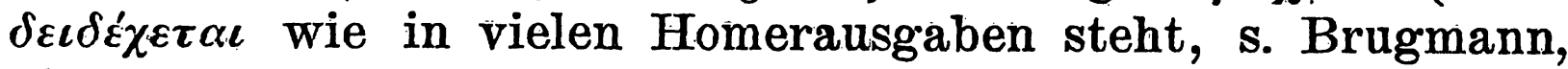
Kurze vgl. gramm. s. 482). Das auftreten des langen vocals kann doch nur unter dem einfluss des accents erfolgt sein; wir haben also wie im ai. praes. bálbalîti auch für das perfect ursprünglich einen doppelten accent anzusetzen: einen accent 
auf der reduplicationssilbe und einen zweiten auf dem stamm bez. der endung. Den beweis hierfür wollen wir in folgendem zu bringen versuchen.

Der singular des idg. perfects hatte o-vocalismus: griech.

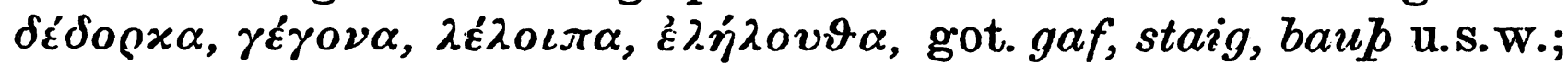
der plural besass die schwundstufe ai. dadrcmá, gr. $\gamma \varepsilon \dot{\gamma} \alpha \mu \varepsilon \nu$ (aus $\gamma \varepsilon \gamma \cdot z \mu \varepsilon \nu), \tau \varepsilon \dot{\vartheta} \nu \alpha \mu \varepsilon \nu, \tau \varepsilon \dot{\tau} \lambda \alpha \mu \varepsilon \nu$ (Hirt, Idg. abl. s. 186), ai. vidmá $=$ gr. $i \delta \mu \varepsilon v=$ got. witum; got. bundum, waurpum u.s.w. Im sing. entspricht die gr. betonungsweise, die allerdings secundär infolge des dreisilbengesetzes entstanden sein wird, eher dem zustand, den wir für die uridg. zeit voraussetzen dürfen, als die indische stammbetonung. Denn allgemein wird jetzt angenommen (Hirt, Idg. abl. s. 155 ff. oder Brugmann, Kurze vgl. gramm. s. $145 \mathrm{f}$.), dass $o$ in der $e$-reihe kein hochstufenvocal war, und bei stammbetonung dadárça eher der vocal $e$ zu erwarten ist, vgl. $\gamma \varepsilon \gamma \varepsilon v a$ bei de Saussure, Mémoire sur le système primitif s. 12 f. Formen wie *bhéresi und *génesos (e trotz des nachtons), anderseits *dedórîa und *bhóros lässt Hirt, Idg. abl. s. $155 \mathrm{f}$. als unerklärt aus dem spiel und hält für *dedorka speciell eine tonfolge dédòrर́ka für unmöglich, da $e$ in der reduplicationssilbe schwaches $e$ sei. Dies halte ich für weniger beweiskräftig als das aisl. sera $=$ got. saiso, dessen $r$ für urgerm. $z$ auf stammbetonung hinweist. ${ }^{1)}$ Aber wenn auch in der zeit vor der sprachtrennung der accent im sing. perf. auf der stammsilbe ruhte, so muss dies von anfang an durchaus nicht so gewesen sein. Im gegenteil! die entstehung der reduplication aus doppelsetzung des stammes wie in ai. bálbaltiti mit doppeltem accent weist gerade auf ursprüngliche betonung der reduplicationssilbe hin. Hirt, Idg. abl. s. 158 umgeht die schwierigkeit durch die annahme, die o-formen stammten von enklitischer betonung her; also *dedérk̂a, aber *pródòrk̂a (vgl. lat. velim, ae. voille neben nōlim aus *névolim, ae. nelle). Weiterhin (s. 159) kommt Hirt dann zu der hypothese, für den sing. perf. doppelte vocalisation, einen wechsel von $e$ und $o$ anzunehmen; endlich (s. 160) glaubt er eine frühzeitige accentverschiebung dafür verantwortlich machen zu sollen. Damit

1) Got. sciizlēp neben saislēp möchte ich hier aus dem spiele lassen; vielleicht entstand $z$ nur unter dem einfluss des benachbarten stimmhaften $l$. 
kommen wir zu der annahme einer ursprünglichen betonung der reduplicationssilbe, die ja Hirt s. 195 für die 3. plur. perf. postuliert und die ich mit rücksicht auf formen wie ai. jāa $\bar{a} r a$, hom. $\delta \eta^{\prime} \delta \varepsilon x \tau o$ für höchst wahrscheinlich halte.

Diese stufe ist für uns natürlich nur hypothetisch zu erschliessen; die reconstruction der idg. betonungsverhältnisse im perfect ergibt im sing. *dedórîka, im plur. dedrîmé. Ja, Hirt hält a.a.o. s. $194 \mathrm{f}$. den auf die stammsilbe fallenden ton für so stark, dass $e$ in der reduplicationssilbe zu schwachem $e$ wurde und unmittelbar vor dem ton schwand, so dass die got. formen gaf u.s.w. lautgesetzlich wären gegenüber ai. dadárça, gr. $\delta \varepsilon \dot{\varepsilon} \rho \varrho x \alpha$. Er setzt also ein idg. perfectparadigma wie folgt an: sing. *sóda (= got. sat 'sass'), *sodtha, *sode, plur. *sezdmé, sezdé, *sēzdr. Dagegen wendet sich Brugmann, Kurze vgl. gramm. s. $543 \mathrm{f}$. mit recht, wie mir scheint, und nimmt an, dass im perfect reduplicierte und nicht reduplicierte formen, ähnlich wie im praesens, nebeneinander standen, und dass in den verschiedenen sprachen verschieden ausgeglichen wurde. Dieser ansicht, die sich mit der oben s. 462 vorgetragenen deckt, schliesse ich mich an.

Die verhältnismässig spätere ausbildung des perfects zum eigenartigen und festgefügten tempus ist übrigens von verschiedenen seiten anerkannt. So widmet ihm Hirt, IF. 17, $66 \mathrm{ff}$. eine betrachtung, an deren schluss er meint: ¿dass sich im perfectum ein altertümlicherer zustand erhalten hat, als in den übrigen verbalformen, stimmt zu dem, was wir sonst beobachten können'. Er citiert ferner Wundt, Völkerpsychologie 1,2,142: 'Nachdem das praesens und andere an seine bildung sich anschliessende zeit- und modusformen längst zu wahren, mit dem persönlichen pronomen oder personalsuffixen gebildeten verbalformen differenziert sind, bleibt für das perfectum vielfach noch ein ausdruck bestehen, der sich in seiner struktur widerum als ein mit dem possessivpronomen verbundenes nomen aufweist.' Hirts annahme, dass im perfect der reine stamm ohne endung gebraucht wurde, findet von seiten des germanischen in formen wie saiso, waivō u. ähnl. jedenfalls eine stütze.

Bei der noch wenig gefestigten struktur des perfects im indogermanischen, wie wir sahen, halte ich es für unnötig, 
neben den germ. perfecten noch mit Hoffmann, $\boldsymbol{I}$. s. 54 f. unsere zuflucht zu imperfecten bez. dehnstufigen, geschleift betonten praeteriten zu nehmen, oder mit Janko s. 262 urgerm. praeteritalformen ohne reduplication, d.h. mit aoristischem stamm und angefïgten perfectischen endungen anzunehmen. Das fehlen der reduplication haben wir, wie ich hoffe, genügend gerechtfertigt - hier spielen die praeteritopraesentia wait, man u. a., die schon im urgerm. ohne reduplication waren, als vorbilder auch eine gewisse rolle - (s. weiter unten) - und in der erklärung der vocalischen verhältnisse der verba des $\bar{e}^{2}$ und eo-typus gehe ich andere wege wie die beiden genannten gelehrten. Doch darüber später.

Auf der im vorhergehenden geschaffenen grundlage weiterbauend, wollen wir nunmehr an die betrachtung der german. reduplicierten perfectbildungen gehen.

\section{Urgermanische und gotische roduplicierte perfecta.}

Schou in der ursprache ist die vereinheitlichung der perfectbildung nur unter der annahme weitreichender analogiewirkungen $\mathrm{zu}$ verstehen; die germ. dialekte sind den analogischen einflïssen auch in der gemeinsamen urgerm. periode wie in ihrem sonderleben gerade bei der perfectbildung in hervorragendem masse zugänglich gewesen.

Ausgehend von den schon im indogerm. vertretenen reduplicationslosen perfectformen hat das urgermanische die reduplication in weitem umfang aufgegeben und sich zur charakterisierung des perfects mit dem ablaut begnügt. Von dem grossen reichtum der idg. ursprache an zeitformen der vergangenheit (imperfect, aoriste verschiedener bildungsweise, perfect, plusquamperfect) hat das urgermanische nur das perfect als einzige zeitform der vergangenheit bewahrt!), gleichwie das altslavische ausser dem aorist und einem neugebildeten imperfect keine von den vielen zeitformen der grundsprache bewahrt und moderne slav. dialekte (z. b. russisch) sogar auf eine zeitform der vergangenheit reduciert sind.

Die einschränkung der reduplication auf verhältnismässig

1) An die von Hoffmann und Janko angenommene erhaltung von idg. aoristformen (s. oben) im germ. glaube ich nicht. 
wenige verba (21 belegte reduplicierte perfecta im gotischen, wovon manche aber ihre reduplication erst secundär erhalten haben, s.w.u.; 2-3 im altisländischen; 5 sichere, daneben auch einige $z u$ erschliessende [s. w. u.], im alt'englischen) geschah sicher unter dem einfluss der in den germ. mundarten zahlreich vertretenen sog. praeteritopraesentia, von denen eines idg. *voida schon in der ursprache keine reduplication hatte, während z. b. dem germ. man das reduplicierte gr. $\mu \varepsilon \varepsilon^{\prime} \nu^{\prime} \alpha$, lat. momini entspricht. Solche praeteritopraesentia besitzt das gotische 13, das altisländische 10, dàs altenglische 12, das althochdeutsche 11; ihre zahl ist so ansehnlich, dass. sie auf die gestalt der übrigen perfecta, mit denen sie gleiche ablautsstufe aufweisen, beeinflussend wirken konnten, zumal sie zu den häufigst angewendeten verben gehören.

Die erhaltung der reduplication bei einer anzahl verben erklärt sich daraus, dass sie entweder keinen ablaut im perfect besassen (slēpan : saislëp) oder, wenn sie einen solchen noch aufwiesen, keiner der bestehenden ablautsgruppen sich einreihen konnten (lètan : lailot, saian : saisō; ein ablaut $\bar{e}$ bez. $a i$ : $\bar{o}$ besteht nur bei den reduplicierend-ablautenden verben). Ausserdem ist bei den verben lētan, -rédan und grêtan mit rücksicht auf nord.-westgerm. perfecta (ae. as. lèt, aișl. as, rëd, aisl. grêt) auch ein urgerm. perfect mit $\bar{e}^{2}$-vocal (also entsprechend got. *lailet, *rairêp, *gaigret) anzusetzen ${ }^{1}$ ), so dass die erhaltung der reduplication auch aus dem fehlen des ablauts erklärt werden könnte. Die $\bar{e}$-formen im perfect hätten alsdann die $\bar{o}$-formen zur annahme (bez. beibehaltung) der reduplication veranlasst. Nur für got. tēcan-taitōlk kann dieser umstand nicht ins feld geführt werden, da dieses zeitwort keine nebenformen mit $\bar{e}$-vocal im perfect aufweist; vielmehr war das $\bar{o}$-perfect auch im nordischen so fest, dass vom tiefstufigen praesens taka aus dies zeitwort ganz in die ablautklasse $a-\bar{o}$ übertrat: aisl. taka-tók. Dieses zeitwort ist somit einer der unantastbaren belege für den ablaut $\bar{e}-\bar{o}-a$ im urgermanischen. Denn bei den vocalisch auslautenden verben got. saian - saiso und waiwan - waiwō weist letzteres

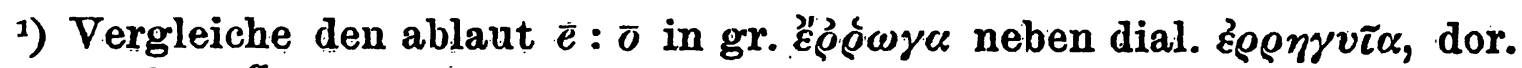

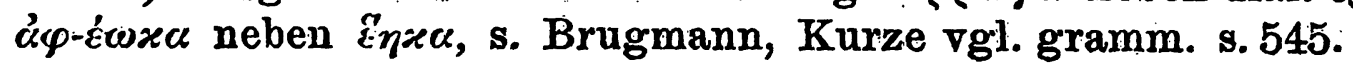


wenigstens mit altwfrs. $w \bar{c}$ und mndl. wicy auf ein urgerm. $e^{2}$-perfect (Janko a.a. o. s. 285); saian - saiso verlangt mit aisl. sá-sera aus *sézo, *sesó dagegen auch ein urgerm. $\bar{o}$-perfect, so dass wir hier ein weiteres beispiel des ablautes $\bar{e}$ (bez. $\bar{e} i$ ) - $\bar{o}$ hätten, das die reduplication bewahrte, weil keine formenkategorie olnne dieselbe vorhanden war, an die es sich hätte anschliessen können. Das auslautende $\bar{o}$ im sing. sais $\bar{o}$, waivūo ist allerdings restituiert aus dem plural saisōum, waiwōun, denn idg. $\bar{o}$ im auslaut hätte zu got. $a$ werden müssen.

Die got. perfecta lailōt, rairōp, taitōli u.s. w. bewahren die vocalstufe des singulars auch im plural gleichwie die verba der $a-\bar{o}$-klasse. Das ist natürlich nicht der ursprüngliche zustand; wir sollten im plural die tiefstufe der wurzel erwarten, den vocal $a$ also (mit rücksicht auf got. lats, garapans, aisl. taka): *lelatmé, *reradmé, *tetalimé u.s.w. In der tat liegt die lautgesetzliche entwickelung dieser formen mit synkope des mittelvocals nach kurzer silbe (vgl. Dieter, Laut- und formenlehre 1, 91 und Weyhe, Beitr. 30, $84 \mathrm{ff}$. und 31, $43 \mathrm{ff}$.) in ae. leort fïr *leolt, reord (ondreord dagegen ist nach reord gebildet), ferner in ae. lcolc zu lácan = got. lailean (uud ae. heht $\mathrm{zu}$ hátan = got. haitan) vor. Die pluralformen sind auf den singular übertragen, co für $e$ durch sog. brechung (Sievers, Ags. gramm. ${ }^{3} \S 79.80$, s. 36 ff.). $\left.{ }^{1}\right)$ Diese formen beweisen auch, $^{\circ}$ dass im urgermanischen die reduplication noch nicht verloren war, besonders im plural bei regulärer tiefstufe der wurzel, und hier wol erst infolge der übertragung der hochstufe des singulars auf den plural geschwunden ist. ${ }^{2}$ )

Die tiefstufe im plural ist auch bei den langvocalischen perfecten der $a-\bar{o}$-klasse einst vorhanden gewesen: aisl. uxom aus *unısum, vielleicht ein urgerm. redupl, plural *u(e)uhsmié zu wahsan (Kluge, Grundriss der germ. phil. 12, 437); ae. perf. wéoc, plur, wéocum aus *ucukmé (?) neben wóc zu wcecnan. Besonders zahlreich sind im nordisch-westgermanischen tiefstufige plurale bei langvocalischen reduplicierenden verben: ae. (leolc nach) leolcum aus *lélilcum. zu lácan und (heht nach)

1) Anders (durch $\iota$-umlaut) von Weyhe, Beitr. 31, 48 erklärt.

2) Janko s. $268 \mathrm{f}$. lässt die sing. leolc, heht aus *lélaika, *lelaik, *lelēk, *lelk und *héhaita, *hehait, *hehet, heht sich regelrecht entwickeln. Ich halte obige deutung (iibertragung aus dem plural) für richtiger. 
hehtum aus *hehitum zu hátan; aisl. svipom zum sing. sueip zu sueipa (Noreen, Altisl. gramm. ${ }^{3} \$ 492$, s. 300), litom zum sing. leit zu láta (ibid. $\$ 166,2$, s. 129); hlupom zu hlióp von hlaupa (ibid. § 493) = wn. (h)lupu, mschw. lopu (Noreen, Altschwed. gramm. $§ 542$, s. 446) $=$ mhd. luffen (vgl. auch das on. part. lopin mit nhd. dial. geloffen); agutn. liko zu laika (ibid. § 541, anm. s. 444); mschwed. fullo zu falla aus *fllmé? (ibid. § 543, s. 447). Natürlich fallen diese vereinzelten reste ablautender plurale dem gleichmachungstriebe der sprache zum opfer; der hochstufenvocal des singulars, der den tempuscharakter deutlicher zum ausdruck bringt, siegt gleichwie im griechischen, wo $\pi \dot{\varepsilon} \pi \lambda \gamma_{\gamma} \alpha$ : $\pi \varepsilon \pi \lambda \dot{r} \gamma \alpha \mu \varepsilon \nu$ genau dem got. faiflōk : faiflökum entspricht, während wir im idg. einen sing. *pcpl $\dot{a} g a$ neben dem plur. * peplagmé(n) anzusetzen haben (vgl. dor. aor. pass. $\dot{\varepsilon} \pi \lambda \dot{\alpha} \gamma \eta \nu)$.

Von der vocalabstufung im perfect ist im gotischen keine spur mehr erhalten; wie diese durch ausgleichung untergieng, so ist auch der vocal der reduplicationssilbe, wo sie erhalten blieb, durch analogie zu gleichförmigen ai geworden. Dieses $a i$ für lautgesetzlich zu erwartendes $i$ aus idg. $e$ war berechtigt vor $h$ und $r$ und ist von hier aus auf die anderen verba mit reduplication übertragen worden. Belegt sind im gotischen von verben, die mit $h$ oder $r$ anlauten, folgende perfecta: haihait zu haitan, haih $\bar{a} h$ zu hāhan, hwvaihwōp zu hwvōpan; nicht beleg't sind die perfecta von haldan und hlaupan. Zwair hält Wilmanns, Deutsche grammatik 3,23 es für wenig wahrscheinlich, dass der gotische reduplicationsvocal ai von den verben, die mit $h$ und $r$ anlauten, herstammt; aber er vermag keine bessere erklärung zu geben. Wir haben keinen grund, uns der allgemeinen ansicht nicht anzuschliessen (vgl. z. b. Bethge in Dieters Laut- und formenlehre der altgerm. dialekte $\$ 22, \mathrm{~b}$, anm. 4, s. 27 oder Streitberg, Got. elementarbuch ${ }^{2} \S 50$, s. 63) und an der analogischen weiterverbreitung des $a i$ von den genannten verben aus nicht festzuhalten, zumal wenn wir einen blick auf die tabelle s. $450 \mathrm{ff}$. werfen. Wir ersehen daraus, dass die verba mit $h$ und $r$ als anfangsconsonanten nicht nur der zahl nach stark vertreten sind (14 auf 81 redupl. verba), sondern auch z. t. zu den weitverbreitetsten und gebräuchlichsten gehören (hähan, haitan, haldan, haurvan, hlaupan). Es ist 
daher durchaus nicht unwahrscheinlich, dass das got. ai der reduplicationssilbe von diesen zeitwörtern aus verallgemeinert worden ist.

Diese übertragung wird uns noch glaubhafter dünken, wenn wir sehen, dass der ausgleichende trieb im gotischen in einem fall sogar die ganze reduplicationssilbe betroffen hat. Ich meine bei den mit st, sk (und sp) anlautenden verben. Belegt sind die perfecta -staistald von -staldan und skaiskaid von skaidan; dem perfect skaistaaid entspricht ai. cichéda, plur. cichidmá; die idg. wurzel ist sîkhait-, sk̂khaid- (vgl. verfasser, Grundriss der got. etymologie s.102; anders Hoffmann, Г. s. 42 ff.), deren tiefstufe sikhid- sich im av. als siz reflectiert; daher av. hisizyāt aus *si-shihlid-iēt (Hübschmann, Zs. d. d. morg. ges. 35, $425 \mathrm{f}$. und Burg, Kuhns Zs. 29, $358 \mathrm{ff}$.). Im lateinischen finden wir das perfect scicidi gebildet wie steti, d.h. mit erleichterung der stammsilbe, während das indische und griech. die reduplicationssilbe erleichtern: ai. tasthāi, plur. tasthimá

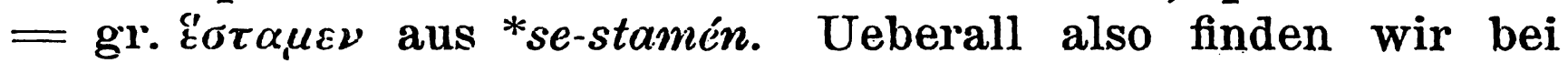
den mit sk und st anlautenden verben in den reduplicierten formen dissimilation, sei es im anlaut der reduplicationssilbe, sei es im anlaut der stammsilbe, nirgends treffen wir den gotischen typus an. Brugmann, Kurze vgl. gramm. $§ 625$, s. 484 meint nun, 'man habe bei den wurzeln mit $s+$ consonant im altindischen, italischen und germanischen eine grössere übereinstimmung zwischen reduplications- und wurzelanlaut dadurch bewirkt, dass man den verschlusslaut auch in der reduplication aufnahm, worauf dann freilich, ausser im gotischen, wider dissimiliert wurde.' Da nach dem ursprung der reduplication, der doppelsetzung der wurzel, von anfang an die verbindung: $s+$ verschlusslaut an beiden stellen vorhanden gewesen sein muss, so nimmt demnach Brugmann für die idg. urzeit zuerst einen act der dissimilation und später wider einen act der gleichsetzung an. Die genannten indogerm. sprachen hätten dann sämmtlich, mit der alleinigen ausnahme einer mundart des germanischen sprachzweigs, wider dissimiliert. Statt einer so umständlichen und unwahrscheinlichen erklärung nehmen wir doch einfacher an, dass die ursprüngliche gleichheit von reduplications- und stammanlaut schon in indogerm. zeit durch dissimilation, sei es des ersten, sei es des zweiten gliedes, be- 
seitigt wurde und den tatsächlich vorhandenen formen platz machte. Das gotische hat - ob übereinstimmend mit den anderen germ. mundarten lässt sich mangels sicherer beispiele ${ }^{1}$ ) nicht entscheiden - den ursprünglichen' idg. zustand wider hergestellt und zwar infolge des ausgleichenden triebes, der diese mundart auch zur verallgemeinerung des reduplicationsvocals $a i$ veranlasste. ${ }^{2}$ ) Diese annahme wird auch durch den umstand begünstigt, dass wir bei dem nächsten nachbar des germanischen, dem keltischen, den im griechischen und iranischen vertretenen reduplicationstypus antreffen: air. sescaind (= ai. caskánda) 3. sing. perf. zu scendim 'spring'e' (Fick, Idg. wb. 24, 307) oder sescaing zu mir, scingim 'springe heraus' (weitere beispiele s. bèi Brugmann, Grundriss 2,2, 1245).

Osthoff, Zur reduplicationslehre, Beitr. 8, 543 sieht sest-, sesk- und sesp-als den idg. typus der reduplication an; daneben aber findet er vier typen (a.a.0. s. 541): test-, stet-, stes- und stest- in den einzelnen sprachen vertreten, die er, ähnlich wie Brugmann, aus einem ausgeglichenen reduplicationstypus stestwider einzelsprachlich dissimiliert sein lässt (s. 546). Der typus stes- sei allerdings nur in einer germ. mundart, im althochdeutschen, vertrèten: *stestaúta wurde zu *stesaúta, weiter zu *stezaúta, *stérōt $=$ ahd. steroz; $s$ in den germ. mundarten als $z$ nach Veiners gesetż, vgl. an. serc aus *sezō, *sesó; dies $z$ finde sich in den sog. $r$-formen des ahd. (steroz, pleruzzun u.s.w.) wider. Obwol sich viele spätere forscher dieser ansicht anschlossen (Ottmann in der im literaturverzeichnis genannten schrift; Loewe a.a.o. s. 344; Janko a.a.o. s. 272), so kann ich mich doch von der richtigkeit dieser erklärung nicht überzeugen (ebenso Holz a.a.o. s. 28; Zarncke, Beitr. 15, 350 ff.; Wilmanns, Deutsche gramm. 3, 38). Darüber s. näheres weiter unten.

Ich érkenne vielmehr drei idg. typen an: sest-, test-, stet-, die sich entweder einzelsprachlich aus dem ursprünglichen typus stest- entwickelten oder vielleicht schon im indogerm. als rivalen vorhanden waren, da ja das perfect kein schon

1) Doch siehe weiter unten zweifelhaftes north. blefla.

2) Ueber ähnliche vorgänge im griechischen vgl. Brugmann, Kurze vgl. gramm. $§ 625$, s. 484 . 
ursprachlich fest gefügtes tempus war, wie wir oben (s. 466) sahen. Welcher von den drei typen im urgerm. der herschende geworden war, lässt sich nicht sagen, keinesfalls aber glaube ich an eine ununterbrochene überlieferung eines uridg.typus stestbis ins gotische. Dies ist übrigens auch Osthoffs ansicht a.a.o.

Freilich lässt sich ausser den beiden got. perfecten staistald und skaislaid in den germ. mundarten kein beispiel für ein redupliciertes perfect eines mit $s+$ consonant anlautenden zeitworts finden. Für das reduplicierte praesens des idg. typus

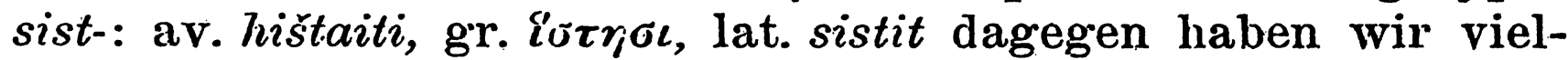
leicht ein beispiel in ahd. sestōm, falls Kluges erklärung dieser form als redupliciertes praesens (Beitr. 8, 513 ff.) das richtige trifft. Dieser umstand spricht natürlich auch nicht $\mathrm{zu}$ gunsten der ursprünglichkeit des got. typus stest-. Loewe a.a.o. s. 261 stellt sich auf Brugmanns standpunkt und sieht stest- für den idg. typus an, der im gotischen erhalten geblieben sei.

Indessen ist auch noch ein anderer umstand zu erwähnen, der gegen eine directe überlieferung der reduplicierten perfectformen vom idg. ins gotische $\mathrm{zu}$ sprechen scheint. Hätte nämlich eine solche stattgefunden und wäre reduplicationsund stammsilbe überall eng zusammengewachsen gewesen, so müssten wir wie in aisl. sera (ạus *sezó) oder got. saizlēpp (neben saislepp) doch noch mannigfache nachwirkungen von Verners gesetz bei den got. redupl. perfecten anzutreffen erwarten. Aber wie bei dem dem aisl, sera entsprechenden got. saisō das stammanlautende $s$ unter dem deutlichen bewusstsein der zusammengehörigkeit dieser form mit den nicht reduplicierten formen des verbums saian wider hergestellt ist, so finden wir ebenso wenig bei anderen got. reduplicierten perfecten (ausser saizlēp neben saislēp, s.s.465) eine spur von Verners gesetz im stammanlaut. Freilich auch nicht im stammauslaut. Denn ausser bei den zwei praeteritopraesentien parf, plur. paurbum und ail, plur. aigum ist der sog. grammatische wechsel im gotischen (im stammauslaut) üiberall zu gunsten der stammbetonten formen ausgeglichen. Die zu erwartenden perfecta got. ${ }^{*} f c \iota l \bar{l}=$ gr. $\pi \varepsilon^{\prime} \pi \lambda_{\gamma} \gamma \alpha$ oder ${ }^{*} f e b a h=$ lat. pepigi sind durch ausgeglichene faifloti und faifat ersetzt und ebenso sind die meisten anderen reduplicierten perfecta keine directen nachkommen idg. formen. 
Dass Verners gesetz bei den im gotischen reduplicierenden verben im auslaut einmal lebendig gewesen sein muss, ergibt sich aus den übrigen germ. mundarten. , So steht im ahd. halthan neben haldan, gifaltan neben gifaldan, viangum, hiangum neben vianc, hianc, kisceitain, zasceitan neben skeidan. Ebenso finden sich spuren des grammatischen wechsels bei den sog. reduplicierenden zeitwörtern im altisländișchen: $f a ́$ (aus *fanhan) 'fangen', plur. pèrf. fingom, fengom, part. perf. fingenn, fengenn, ferner das schon öfter genannte ser'a, pl. serom (aus *sezo, *sezamá) zu sú 'säen'; hell, plur. heldom (aus *help, heldom) zu halda 'halten'; fell (aus *feip), plur. feldom zu falda 'den kopf bedecken' (vgl. Noreen, Aisl. gramm.' $\$ 307,2$, a und 3, s. 200 f. und Altschwed. gramm. $§$ 340, 2, a und 3, s. 268 f.). Im altenglischen sind es ebenfalls die beiden verben fón (aus * fanhan) und hón (aus *hanhan) die in den perfecten fenz, henz und den participien fonzen, honzen grammat. wechsel zeigen. Das altsächsische weist die gleiche erscheinung auf in fâhan, perf. plur. fengum und in bi-hâhıan, part. bihangan. Demnach war der sog. grammatische wechsel auch bei den reduplicierenden verben, einst im germanischen vorhanden.

Ist der im vorhergehenden entwickelte entstehungsgang des urgerm. perfectums richtig, so musste eine so grosse mannigfaltigkeit von formen: singular und plural mit oder ohne reduplication; bei letzterem eintreten des sog. grammatischen wechsels; hochstufe der wurzel im singular, tiefstufe im plural; vielleicht auch die wirkung des Vernerschen gesetzes im stammanlaut - notgedrungen zur analogischen ausgleichung führen, wie es übrigens auch im griechischen geschah (G. Meyer, Griech. gramm. ${ }^{3} \S 543$, s. 622 und Brugmann, Griech. gramm. ${ }^{3}$ $\S 385$, s. 324). Das ergebnis dieser ausgleichungen stellt sich am deutlichsten im gotischen dar: wo das perfect nicht durch den ablaut gekennzeichnet ist, wird die reduplication erhalten bez. neu hergestellt; der nur vor $\hbar$ ( $h v v$ ) und $r$ berechtigte reduplicationsvocal ai wird, infolge des häufigen gebrauchs der betr. verba (s. tabelle s. 450 ff.), verallgemeinert; der hochstufenvocal des singulars ( $\bar{C}, \bar{o}, a i, a u$, vielleicht auch $a$ ) wird auf den plural übertragen.

Zwei schwierigkeiten bei der erklärung der gotischen reduplicierenden verben sind im vorhergehenden besprochen 
worden: der auffallende reduplicationssypus stest- und die verallgemeinerung des reduplicationsvocals ai. Eine dritte schwierigkeit bieten die ablautsverhältnisse der stammvocale des praesens und des perfects.

Alggesehen von den schon erwähnten zeitwörtern des ablauttypus $\bar{e}$ bez. $a i-\bar{o}:$ lētan - lailot, saian-saiso ist bei sämmtlichen gruppen der reduplicierten perfecta der vocal gleich dem praesensvocal. In betracht kommen folgende vocale:

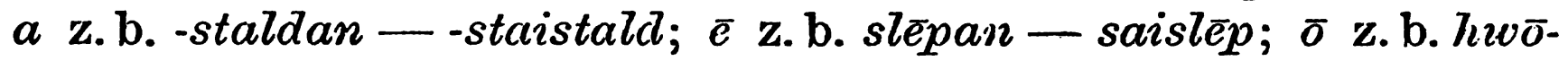
pan - hwaihwoop; ai z. b. fraisan - faifrais; au z. b. autcan aiauk.

Betrachten wir zunächst die verba mit dem stammvocal $a$. Nur zwei perfecta mit dem vocal $\breve{a}$ sind belegt: -staistald und faifall; von anderen verben kommen vor: saltan, haldan, waldan, -alpan, Ulandan, -praggan (?), gaggan; ferner mit ersatzdehnung des $a$ für ausgefallenes $n$ : făhan, perfect faifāh und hāhan, perfect haih $\bar{a} h$.

Die erklärung der ablautsverhältnisse wird dadurch erschwert, dass nicht alle hierherfallenden verba etymologisch sicher deutbar sind. Haldan zu abulg. lilada 'lade', saltan zu lat. sallo aus *saldo, waldan zu abulg.vlada, lit.valdýti 'walten' '), falpan zu ai. puta- 'falte', gr. $\delta \iota \pi \lambda \alpha ́ \sigma \iota \varsigma_{s}$ 'doppelt', alpan zu lat. aleo, fähan zu lat. pango sind zwar mehr oder minder sicher etymologisiert; indes ist das ablautsverhältnis der hier überall anzusetzenden wurzel mit $a$-vocal bis jetzt nicht aufgeklärt. Es ist zweifelhaft, ob wir einen ablaut $\breve{a}$ - o annehmen dürfen, dessen gegentoniges $o$ dem $a$ der germ. perfectformen zu grunde liegen würde, entsprechend dem ablaut $e-o$ (vgl. Hirt, Idg. abl. s. 161 f.; Brugmann, Kurze vgl. gramm. s. 146). Haben wir aber eine starre $a$-wurzel anzunehmen, so ist die erhaltung oder analogische widerherstellung der reduplication zur kennzeichnung des perfects notwendig gewesen.

Dagegen gehen auf eine $e$-o-wurzel zurück: Llandan zu abulg. blęda 'irre, schweife umher', lett. Ulinda 'unstät' u.s.w. (Hoffmann, I'. s. 58) ${ }^{2}$ ); ferner gangan zu lit. žengiì,

1) Uhlenbeck, Beitr. 30, $323 \mathrm{f}$. sieht die balto-slav. verba als entlehnt ans dem germanischen an; dagegen spricht die ableitung' abulg. v'lusts 'macht' $\mathfrak{u}$. a.

2) Ebenso Uhlembeck, Beitr. 30, $268 \mathrm{f}$., der auch Ulinds heranzieht. 
žeñti 'schreiten', pražanga 'überschreïtung, sünde'; vielleicht auch das schon oben genannte waldan, wenn Hoffmann a.a.o. mit der zusammenstellung mit lit. wéldu, wéldzu 'regieren, besitzen', pa-véldu 'ererbe'; velde-tojis 'érbe' u.s.w. recht hat. Aber Hoffmann geht noch weiter; er behauptet auf s. 57: 'der weitaus grösste teil dieser stämme [d.h. mit dem praesensvocal $a]$ folgt dem $e$ : $o$ ablaute.' Das dürfte nach der oben gegebenen liste, wenigstens für das indogermanische, nicht erwiesen sein. Auch bei den nü im nordisch-westgermanischen belegten verben: fallan, skaldan, spaldan, spannan, walkan, wallan, waltan ist idg. $e-o$ ablaut nicht nachzuweisen; für fallan zu lat. fallo, spaldan zu ai. wzl. sphutt-, sphat- aus *sphaltist sogar eher eine idg. $a$-wurzel anzunehmen. Innerhalb des germanischen ist freilich bei vielen dieser verben $e$-vocalisation nachweisbar; so bei wallan neben aisl. vella, stcaldan neben afr. scelda, ahd. skeltan 'schelten'; spaldan ist vielleicht mit got. spilda verwant; waltan stellt sich zu aisl. velta u.a.m. Sie ist aller wahrscheinlichkeit nach aber secundären, erst einzelsprachlichen oder gar mundartlichen uirsprungs, gleichwie sich z.b. aus einem ae. perfect zan $\bar{z}$, das ich als gleichartig mit einem urgerm. redupl. perfect * gegang żu gaggan auffasse, nachträglich ein praesens zinzan einstellte; denn an eine directe abstammung von ae. zinzan aus der idg. wurzel ğhengh- glaube ich nicht.

Bei den verben mit $a$-vocal im praesens geben uns die etymologischen beziehungen folgendes bild: die grösste anzahl zeigt in anderen idg. sprachen ebenfalls $a$-vocalisation im praesens; einige haben auswärtige beziehungen, bei denen $e$-vocal im praesens sich findet (das einzig sichere beispiel ist gangan: lit. $\check{z} e \tilde{n} k t i$, das aber mit rücksicht auf germ. ${ }^{*} g \bar{e}^{\prime} m i,{ }^{*} g \bar{e}^{2} m i=$ ahd. $g \hat{a} m, g \hat{c} m$ noch selbst der erklärung bedarf $\mathfrak{l}$ ), andere solche innerhalb der übrigen germ. dialekte. Bei diesen letzteren ist der $a$-vocal des perfects kaum aus idg. $o$ zu erklären; wahrscheinlicher bei den verben, denen eine idg. e.-o wurzel entspricht. Dann kann aber das a des praesens schwer erklärt werden; an ein tiefstufiges $a$ aus idg. a wie in daddja

1) Hirt, Idg. abl. s. 158 erklärt gangan neben lit. žengiùı, blandan neben lit. blendziı́s 'ich verfinstere mich' aus idg. 0 -vocalisation. 
aus idg. *dhajō (vgl. ai. dhciyāmi; Bremer, Beitr. 11, 55) ist nicht zu denken, da dieser reductionsvocal nur bei schweren basen nachgewiesen ist (vgl. z. b. Brugmann, Kurze vgl. gramm. § 213, s. 141). Es fiele also das $a$ aus idg. 0 der praesentien gaggan, Ulandan $u$. ähnl. in die kategorie unerklärter $z$ in basen mit grundvocal $\breve{e}$, zu denen Brugmann a.a.o. s. 146 die literatur angibt, wenn wir nicht etwa die gleichheit dieses idg. $\check{~ m i t}$ dem des perfects annehmen wollen.

Die 9 germ. verba mit dem wurzelvocal ai hat Hoffmann, $\Gamma$. s. $38 \mathrm{ff}$. einer eingehenden etymologischen untersuchung unterworfen. Im gotischen sind 7 belegt, dabei 6 perfecta: haitan - haihait, maitan - maimait, skaidan - skaiskaid, fraisan - faifrais, laikan - lailail, -aikan, -aiaik und -plaihan ohne belegtes perfect; dazu aus anderen mundarten *taisan (ahd. zeisan) und *swaipan (ae. sucipan, an. sveipa). Ueber allen zweifel sicher etymologisiert ist nur skaidan : ai. chinádmi, gr. $\sigma \chi i \zeta 0$, lat. scindo, caedo, lit. skëda = lett. skaida 'span' u.s.w. Es liegt absolut kein grund vor, mit Hoffmann a.a.o. s. $44 \mathrm{f}$. (s. daselbst auch die einschlägige literatur ${ }^{1)}$ ) lat. caedo

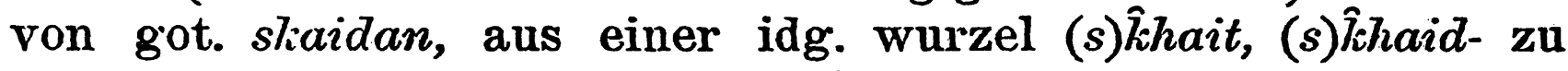
trennen, um stacidan in die ei/oi-reihe zu zwängen, zumal bei laikan zu lit. láigyti auch kein sicherer beweis für dessen zugehörigkeit zu ihr vorliegt, denn air. lóeg 'kalb' stellt sich nur vermutungsweise hierher, ebenso wie ai. réjatē 'hüpft, bebt' und gr. '̇ $\lambda \varepsilon \lambda i \zeta^{\circ}{ }^{\circ}$ 'erschüttere'. Wenn aber *taisan wirklich mit Fick, Vgl. wörterbuch 14, 450 zu gr. dxioo 'zerteile' zu stellen ist, so haben wir natürlich auch eine ai-wurzel *dai(s)- anzusetzen. Nichts beweisend, weil nur problematisch, sind die etymologien von -aikan, die bei den verschiedenen forschern ganz widerspruchsvoll lauten (s. die literatur weiter unten s. 499, anm. 1), von fraisan $\mathrm{zu}$ gr. $\pi \varepsilon \iota \rho \alpha \dot{\alpha} \omega$, lat. ex-perior nach Hirt, Idg. abl. s. 121, aus fra-isan zu ved. iccháti 'sucht', gr. 'i $\mu \varepsilon \varrho o \varsigma$ 'sehnsucht', abulg. iskati 'suchen', ahd. eiskōn u. s.w. nach Hoffmann a.a.o. s. 38, wider anders Brugmann, Grundriss 12,920; *swaipan hat keine auswärtigen beziehungen; maitan nur sehr unsichere (Hoffmann a.a. o. s. 4.5).

1) Auch Uhlenbeck, Beitr.30,380 ist nicht gegen die trennung von caedo und got. skaidan, ohne indes nähere gründe anzugeben. 
Es ist also keineswegs ausgemacht, wie Hoffmann a.a.o. s. 46 will, dass die reduplicierenden verba mit ai als stammvocal zur eiloi-reihe gehören. Alles, was wir von ihnen wissen, ist, dass neben dem stammvocal ai auch $\check{\imath}$ als ablautsstufe vorkommt, wie es Osthoff, Morph. unters. 4, $323 \mathrm{ff}$. schon nachgewiesen hat. $\mathrm{Ob}$ jenes $a i$ auf idg. $a i$ oder $\bar{a} i$ zurückgeht, lässt sich nicht erweisen; oi ist bei den sicher etymologisierten beispielen als ursprung ausgeschlossen.

Aehnlich liegen die verhältnisse bei den verben mit au als stammvocal. Das gotische kennt nur drei: aukan zu lat. augeo, lit. áugu 'wachșe', ai. ójas 'kraft', also idg. au-wurzel '); die tiefstufe $u$ ist in ai. ugrás 'kräftig' belegt; stautan $\mathrm{zu}$ ai. tudä́mi, lat. tundo 'stosse'; endlich hlaupan ohne sichere etymologie. Vermutungsweise wird *lauan als praesens zu dem perfect 3. pl. lailoun angesetzt (Bremer, Beitr. 11, 56); doch hätte au hier nicht diphthongischen wert, sondern den eines offenen $\bar{o}$, und deshalb kann dies verb hier ausscheiden. Ebenso können wir bauan übergehen, da es zwar in den übrigen mundarten nach art der sog. reduplicierenden verba perfect und particip (aisl. bió, buenn) bildet; aber im gotischen schwach flectiert wird; auch ist der lautwert des au nicht sicher (s. verf., Grundriss der got. etymologie s. 17), Aus den anderen germ. mundarten sind folgende verba mit dem stamm-

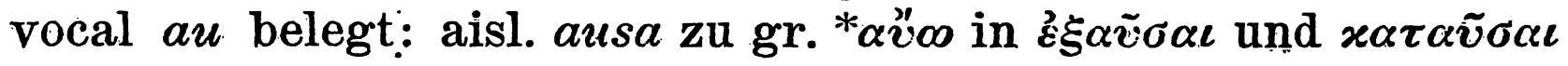

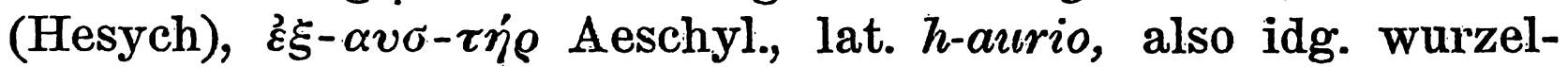
vocal au; hauqvan (as. hauwvan, ahd. houwan, ae. héawan, aisl. hoggua) wird zu abulg. kova, inf. kovati, lit. káuju 'schmiede' gestellt; also ist auch hier wahrscheinlich idg. au als wurzelvocal anzusetzen. Die verba germ. *aupan, *bautan, *hnaupan, *nauan, *skrautan (s. liste s. $448 \mathrm{ff}$.) sind entweder gar nicht oder nur sehr unsicher etymologisiert (s. Hoffmann a.a.o. s.48ff.). können also zur entscheidung der frage, ob idg. au oder ou $\mathbf{z u}$ grunde liegt, nichts beitragen.

Das resultat ist also bei den verben mit au als stammvocal das gleiche wie bei denen mit ai, nämlich, dass nichts dafür spricht, dass sie einst zur idg. $e / o$-reihe gehörten, und dass die sicheren beispiele vielmehr für idg. au als wurzel-

1) Weitere beziehungen zur basis ałege- s. bei Hirt, Idg. abl. s. 133. 
vocal sprechen. Wir gelangen also bei ruhiger prïfung des etymologisch durchsichtigen materials zu dem entgegengesetzten resultat wie Hoffmann, der s. 54 sagt: 'erstens ist nur für 2 oder 3 praesentia der sichere nachweis erbracht, dass sie ursprüngliches ai und aı enthalten, und das sind gerade die seltensten'. Warum z.b. aukan oder aisl. ausa zu den seltensten verben gezählt werden, weiss ich nicht. Dann fährt Hoffmann fort: 'ihnen stehen in gleicher anzahl solche gegenüber, deren -ai-, -au- mit sicherheit als idg. -oi-, -ou- in die ablautsreihe $e i$ : oi, eu : ou fällt'. Nach meiner ansicht ist von allen verben mit -ai- oder -au- kein einziges mit sicherheit zur $e / o-r e i h e$ zu rechnen und von denen mit $-a$ - auch nur wenige wie blandan, gaggan und waldan (s. oben s. 475 f.). Zwar schliesst sich Janko a.a.o. s. 262 rückhaltslos an Hoffmanns darlegung an und erkennt seine 'im ganzen unverrückbaren resultate' an. Aber er tut es im hinblick auf seine eigene erklärung des germ. $\bar{e}$ - bez. eo-typus, die er mittels dehnstufiger formen des e/o-ablauts *hēita bez. *höita (s. 264) und *hlēupa bez. *hlōupa zu geben unternimmt. Jankos hypothese steht oder fällt mit der annahme oder ablehnung der zugehörigkeit der verben mit $a i$ und au als stammvocal zur $e / o$-reihe. Für mich ist sie demnach verfehlt, ebenso wie Hoffmanns theorie der ge-

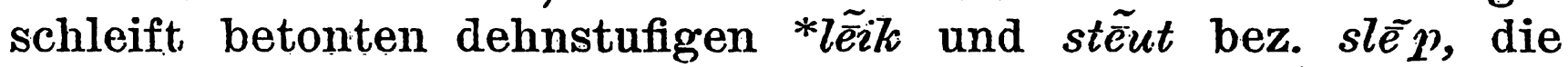
nirgends zustimmung gefunden hat, so viel ich sehé.

Demnach sind die verba mit $a_{-}$, $a i$ - und au- als stammvocal, die im gotischen ein redupliciertes perfect bilden, auch vom standpunkt des indogermanischen aus, teils als starre, nicht ablautende wurzeln ( $\alpha$-stammvocal) wie die verba mit $\bar{e}$ und $\bar{o}$ als stammvocal, teils als solche mit nur einer reductionsstufe $a i: i, a u$ : $u$ aufzufassen. Letztere sind im gotischen ebenfalls zu starren wurzeln geworden, nicht aber in den anderen germanischen mundarten, wovon s. $469 \mathrm{f}$ : die rede war.

Um das perfect als solches mit einem unterscheidenden merkmal zu kennzeichnen gegenüber dem praesens, bot sich die reduplication. Als altererbt kainn sie aber nicht bei allen reduplicierten perfecten gelten. Bei den vocalisch anlautenden aiauk, aiaik, *aiaus (aisl. iós) ist dies von vornherein ausgeschlossen, da idg. *eáuga u.s. w. zu *áă wäre, vgl. *áagom (aus *éagom, imp. zu *agō) = ai. ájam, gr. 


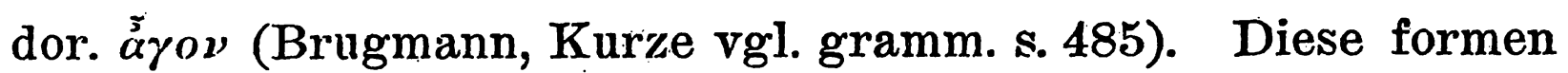
sind also als analogiebildungen nach consonantisch anlautenden wurzeln zu betrachten (Brugmann, IF.6,99). Da sie auch im altnordischen vertreten sind (aisl. iós, iók), so reichen sie in die urgerm. zeit oder wenigstens in die got.-nord. sprachgemeinschaft zurück; da aber die participien perfecti von aukan, nämlich ae. éacan, as. ôcan,·fries. äken, auch in westgerm. mundarten vorliegen, so liegt $\mathrm{m}$. e. kein grund vor, das perfect *cauk, *eok nicht auch als westgermanisch einst vorhanden anzunehmen.

Weiterhin haben wir oben s. $471 \mathrm{ff}$. zu zeigen versucht, dass auch die reduplication der perfecta -staistald und skaiskaip nicht als altererbt gelten kann. ${ }^{1}$ ) Ferner ist meist analogisch umgebildet die reduplicationssilbe, die eigentlich den vocal $i$ = idg. $e$ aufweisen sollte, nach dem muster der sehr gebräuchlichen mit $h$ und $r$ anlautenden verba (vgl. tabelle s. $450 \mathrm{ff}$.).

Alle diese umstände drängen uns, im verein mit den schon oben s. $473 \mathrm{f}$. angeführten tatsachen, zu dem schlusse, dass die reduplicierten gotischen perfecta durchaus nicht alle auf so hohe altertümlichkeit anspruch haben, wie öfters angenommen wird. Ein gewisser stamm wird als urgermanisch und daher wol als altererbt gelten können; doch beweist die übereinstimmung mehrerer mundarten noch durchaus nicht die überlieferung einer form aus idg. zeit, da gemeinsame neubildung vorliegen kann, wie wir oben an den beispielen got. aiauk = aisl. iók u.s. w. zeigten.

Als im urgermanischen vorhandene reduplicierte perfecta dürfen wir vom standpunkt des germanischen aus folgende ansetzen: haitan, haihait wegen ae. hcht; -rēdan, -rairōph wegen ae. reord; lētan, lailōt wegen ae. leort; laikan, lailaik wegen ae. lcolc; saian, saiso wegen an. sera ${ }^{2}$; hwaihwōp wegen ae. hwvéop aus *hwéhwop. Damit ist natürlich nicht gesagt, dass nicht noch viele andere reduplicierte perfecta schon im urgerm. vorhanden waren, oder dass von den oben genannten

1) Auch faifrais ist, falls fraisan als fra-isan aufzufassen ist (Hoffmann a.a.o. s. 38. Brugmann, Grundriss $\left.1^{2}, 920\right)$ natürlich als spätere analogiebildung anzusehen.

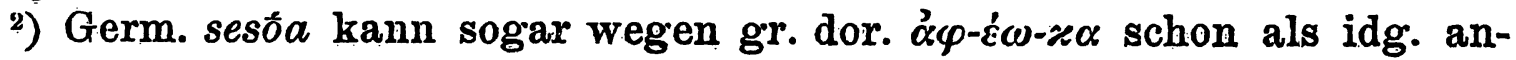
gesetzt werden (s. weiter unten). 
alle aus idg. zeit ererbt waren; unser material reicht nicht weiter und wir müssen daher alle weiter gehenden schlüsse unterlassen.

Vom gesichtspunkt des indogermanischen aus können wir als altererbt ansetzen: saisō $=$ gr. dor. $\alpha \dot{\alpha} \varphi-\varepsilon \omega-\varkappa \alpha$; faiflokk= gr. $\pi \dot{\varepsilon} \pi \lambda \bar{\alpha} \gamma \alpha$; faifah = lat. pepagi, pepigi; skaiskaid $=$ ai. $c i$ chéda, lat. scicidi (abgesehen von der art der reduplication, s. oben s. 471). Weitere sichere vergleiche fehlen; aber das mag zufall sein, ebenso wie anderseits nicht mit sicherheit zu sagen ist, ob die 4 verglichenen perfectgruppen überall aus der urzeit stammen oder einzelsprachliche bildung sind.

Dass neben den im gotischen abgelauteten und reduplicierten perfecta lailōt, gaigrōt und rair.ōp auch urgermanische formen mit $\bar{e}^{2}$-vocal anzusetzen sind, ist schon oben $s .468$ erwähnt. Die übereinstimmung aller germanischen mundarten weist darauf hin; so entspricht dem got. lailōt aisl. ae. lét, ahd. liaz, liez, dem got. gaigrōt aisl. grét, dem gotischen rairō̄b aisl. rép, ahd. riat. Daher sind èntweder urgerm. doppelformen im perfect anzusetzen: ${ }^{*} l \bar{e}^{2} t:{ }^{*} l \bar{o} t,{ }^{*} g r \bar{e}{ }^{2} t:{ }^{*} g r \bar{o} t,{ }^{*} r \bar{e}^{2} \boldsymbol{b}$ : ${ }^{*} \overline{o p}$ (vgl. Janko a.a.o. s. 263 f. u. 277 f.), die in dem gleichen verhältnis zu einander stehen wie gr. dial. - und diese annahme ist wegen aschwed. $l \bar{o} t^{1}$ ) die wahrscheinlichere, zum mindesten für das got.-nordische (Janko s. 278) - oder wir müssten die $\bar{o}$-formen als einzeldialektische neuerung des gotischen bez. altostnordischen ansehen. Das zeitwort got. tēkan, perf. taitōk, aisl. taka, perf. tók ist bekanntlich in den anderen germ. mundarten nicht vertreten (ae. takan ist lehnwort aus dem dänischen); es ist ein beleg für das vorhandensein der tiefstufe idg. $a$ des ablauts $\bar{e}-\bar{o}$ auch im praesens (aisl. $t a 7 a$ ), während sie sich bei den übrigen zeitwörtern dieser ablautsgruppe nur im particip perfect oder in adjectivischen bildungen nachweisen lässt (ga-rapans zu rēdan, lats = lat. lassus zu lētan, aisl. taka zu tëkan, ndd. slap = abulg. slabb zu slēpan). Zu slēpan ist bekanntlich nur das perfect saislēp (saizlepp), also ohne merklichen ablaut belegt; ob indes die beiden got. $\bar{e}$ ursprünglich identisch waren, ist nicht sicher. Brugmann, Kurze vgl. gramm. $§ 101$, anm.; s. 14 erkennt zwei

1) Noreen, Altschwed. gramm. \$ 544, s. 448. 
got. $\bar{e}$ an, von denen $\bar{e}^{-1}$ (in letan z. b.) oft als ei auftritt, $\bar{e}^{2}$ dagegen (in $\bar{\epsilon}_{\bar{e}}$ z. b.) niemals. Das $\bar{e}$ in saislēp (saizlēp) fasst man vielfach mit rücksicht auf ahd. sliaf als $\bar{c}^{2}$ auf, und doch findet sich anasaisleip Luc. 8,23 (mit allérdings nachträglich wegradiertem $i$, aber das geschah auch in manaseidai Luc. 9, 13) mit $e i$ für $\bar{e}^{2}$ wie bei $\bar{e}^{1}$. Es ist also fraglich, ob das gotische, zur zeit der niederschrift der codices natürlich, also im 5 . bis 6. jh. n. Chr., noch eine unterscheidung zwischen den beiden ursprünglich ungleichen $\bar{e}$ machte; darüber näheres weiter unten. Hat es aber auch früher schon keinen unterschied mehr gekannt; so würde dieser umstand die bevorzugung der $\bar{o}$-formen im perfect erklärlich machen.

Bei den verben saian und waian ist das $\bar{o}$ des perfects wegen gr. áç-\{́co-xa als idg. anzusehen. Freilich kann das auslautende $\bar{o}$ in saiso und waiwo nicht lautgesetzlich sein, da auslautendes $\bar{o}$ im gotischen $\ddot{z} u$ wird; vgl. baira aus idg. *bher $\bar{o}=$ gr. $\varphi \varepsilon ́ \rho \omega$. Das $\bar{o}$ des singulars ist aus dem plural saisoum wider hergestellt, wo es aber wahrscheinlich auch nicht ursprünglich ist, sondern schon in urgerm. oder gar vorgerm. zeit aus dem singular eindrang, da der plural des reduplicierten perfects tiefstufe der wurzel im idg. aufwies.

\section{Die nordisch-westgermanischen perfecttypen.}

Während im gotischen der perfecttypus der reduplicierenden zeitwörter ein einheitlicher ist, wenn auch viele verba eîn redupliciertes perfect erst durch analogie, nicht durch vererbung aus idg. zeit erlangt haben, wie wir im vorstehenden bewiesen zu haben glauben; so liegen in den anderen germ. mundarten bei den verben, die im gotischen ein redupliciertes perfect bilden, und solchen, die mit ihnen auf eine stufe zu stellen sind, folgende vier perfecttypen vor:

1: ein redupliciertes perfect (aisl. sera),

2: ein perfect mit hochstufe des stammes im singular und und tiefstufe im plural (aisl. leit [lít], pl. litom),

3: e̊in perfect mit dem vocal $\bar{e}^{2}$ (aisl. ae. é, ahd. $i a, i e$ ),

4: ein perfect mit dem vocal eo.

Diese 4 kategorien werden wir nacheinander ins auge fassen und dabei die nord.-westgermanischen mundarten einheitlich 
betrachten, da sie alle dieselben typen aufweisen und daher wol gemeinschaftlich an der entwickelung derselben teilgenommen haben. Altererbt waren nur die typen 1 und 2, für die wir entprechungen in den anderen idg. sprachen finden; gemeinsame neubildung der nord.-westgerm. mundarten sind die typen 3 und 4. Diese beiden letzteren werden häufig auch als 'contractionstypus' bezeichnet, da man annahm und noch vielfach annimmt, dass der vocal $\bar{c}^{2}$ und der diphthong $c o$ durch contraction des $e$ der reduplicationssilbe mit dem $a, \bar{e}$ (aus $\bar{e}$ oder $a i$ ) bez. $\bar{o}$ (aus $\bar{o}$ oder au) der stammsilbe entstanden seien.

An diesem entwicklungsgang nehmen auch die angelsächsischen mundarten teil; es bestand also eine ununterbrochene räumliche continuität zwischen den nordischen und festländischen Germanen. Da nun in der ersten hälfte des fünften jahrhunderts durch die auswanderung der angelsächsischen stämme nach Brittannien eine lücke entstand, die sich später und noch heute durch die schroffe dialektspaltung an der deutsch-dänischen grenze im gegensatz zu dem sonst zu beobachtenden allmählichen übergang von einer mundart. zur andern zu erkennen gibt, so müssen wir die ausbildung des nordisch-westgermanischen contractionstypus um $400 \mathrm{n}$. Chr. etwa als abgeschlossen ansehen. ${ }^{1}$ )

Damit hätten wir einen terminus ad quem. Einen terminus a quo gewinnen wir durch den umstand, dass das gotische an dieser entwickelung nicht mehr teilnimmt; sie muss also nach der zeit der trennung des gotischen von den übrigen germ. mundarten angesetzt werden. Um $200 \mathrm{n}$. Chr. ungefähr haben die Goten ihre neuen wohnsitze am Schwarzen meer erreicht. ${ }^{2}$ ) Demnach muss die entstehung des sog. contractionstypus in die zeit zwischen 200 und $400 \mathrm{n}$. Chr. fallen.

Wie ist nun dieser typus zu stande gekommen? - Der name 'contractionstypus' spiegelt die ältere ansicht über seine entstehung wider. Man gieng von der voraussetzung aus, die oben schon erwähnt wurde, der perfectvocal $\bar{e}^{2}$ und -diphthong

1) Bethge in Dieters Laut- und formenlehre s. 363 meint, dass er während und nach der völkerwanderung entstand und vom nordischen ausgieng.

2) Vgl. Sievers, Got. sprache in Pauls Grundr. 1 (1. aufl.), $40^{\prime}$ ff.; Streitberg, Got. elementarbuch ${ }^{2}$ s. 7. 
eo seien 'contractionsproducte'. Das wäre freilich eine ganz plausible erklärung, wenn nicht der zwischen reduplication und stammsilbe stehende stammanlautende consonant bez. die consonantengruppe einige schwierigkeiten machte. Ihr ausfall muss lautgesetzlich erklärt werden: Früher half man sich mit Scherer (Zs. f. d. östr. gymn. 24 (1873), 296) durch die annahme: 'diese perfecta reduplicata sind ein ganz exceptionelles gebiet, worin dinge geschehen, die anderwärts in der sprache nicht möglich wären'. Heute kann man sich mit einer solchen erklärung nicht mehr zufrieden geben. Trotzdem sind auch noch anhänger des consonantenausfalls vorhanden, so Loewe in seinem genannten aufsatż, der den ausfall des stammanlautenden consonanten durch haplologische dissimilation zu rechtfertigen sucht. Wir haben diese annahme ob. s. 459 f. abgelehnt.

Eine zweite möglichkeit, zu einer erklärung des $\bar{e}^{2}-$ und eo-typus zu gelangen, erörterten Brugmann, IF. 6, 89 ff. und gleichzeitig. Wood, Germ. Studies 2, $27 \mathrm{ff}$. Zunächst ausgehend von den verben mit stammvocal ai und au (haitan, stautan), sahen sie in den reduplicationslosen perfecten des nordischwestgermanischen hochstufige stammformen dieser verba (*hēit, * stāut), die sich zu jenen verhielten wie got. tēkan zu an. taka. $\mathrm{Zu}$ erklärren bleibt dann noch das perfect- $\bar{e}$ der verba mit $a$ als praesensvocal (waldan) und das perfect-eo derjenigen mit $\bar{o}$ im praesens (*hrōpan). Sie werden als analogiebildungen

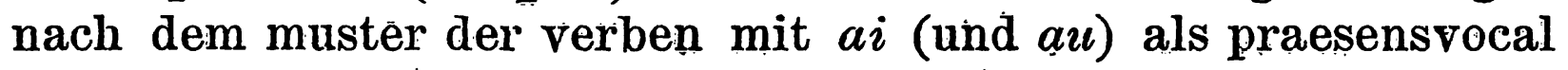
erklärt, unter anlehnung an ein dehnstufiges $\bar{e}=$ nord-wgerm. $\bar{a}$ der verba des $e / o$-ablauts (gangan, waldan). Dem gegenüber hat van Helten (Beitr. 21, 445) eingewendet, dass die numerisch schwächere ai-klasse kaum im stande gewesen sei, die an zahl weit beträchtlichere $a$-klasse zu beeinflussen. Ob dieser einwand stichhaltig ist, werden wir später zu erwägen haben. Ebenso haben wir die auf der von Brugmann geschaffenen basis fussenden erklärungsversuche von Hoffmann, $\Gamma$. s. 33 ff. (grundformen léike, *stéute, woraus *lẽèit, *stẽ $u t$ mit schleifton) sowie von Janko, IF. 20, 252 ff. (grundformen *hēita, *höita und *hlëupa, *ht̄̄upa) später noch einer eingehenderen betrachtung: zu unterwerfen, wenn wir an die erklärung des nord.-westgerm. $\bar{e}^{2}-$ bez. eo-typus herantreten werden.

Hier will ich zunächst nur meine principiellen bedenken 
gegen diese neuerdings beliebt gewordenen methoden äussern. Es scheint mir der weg verhängnisvoll zu sein, bei der äusserst verwickelten und durch analogische beeinflussungen in weitgehendem masse veränderten perfectbildung der sog. reduplicierenden zeitwörter $\mathrm{zu}$ viele formen auf die lautgesetzliche entwickelung hypothetischer grundformeu zurïckzuführen. Die ansetzung einer grundform *hlëupa oder *hlöupa entbehrt doch jeder realen unterlage; sie ist ein rein constructives gebilde noch dazu auf ungewisser grundlage (c/o-ablaut). Wenn wir im gotischen schon beobachtet haben, wie wenige perfectformen als altererbt gelten können, wie das ganze system von mannigfachen analogiebildungen durchkreuzt wurde, so dürfen wir bei den erst aus einer weit späteren zeit (400 jahre später und noch mehr) überlieferten formen des nordisch-westgermanischen der analogiewirkung eine noch weit grössere rolle $\mathrm{zu}$ erteilen. Alle vorhandenen perfectformen erklären $\mathrm{zu}$ wollen, ist überhaupt eine vergebliche mühe, da uns ja nur ein beschränktes material zu gebote steht und viele bedingungen der gegenseitigen beeinflussung von perfectformen naturgemäss uns entgehen miissen. Unsere aufgabe kann in der hauptsache nur diejenige sein, die haupttypen lautgesetzlich oder auf analogischem wege $\mathrm{zu}$ erklären und ihre ausbreitung zu verfolgen. Wir beginnen mit den altererbten typen.

\section{A. Reduplicierte perfecta im nordisch- westgermanischen.}

I. Das altisländische besitzt folgende reduplicierte perfecta: 1) sera zu sá 'säen' = got. saisō zu saian. Das altisl. ist in doppelter beziehung ursprünglicher wie das gotische: a) es zeigt mit $r$ für urnord. ${ }^{*} z$ die regelrechte entwickelung eines urgerm. sesó $(a)$, während das gotische für lautgesetzliches $z$ das wurzelanlautende $s$ eingesetzt hat; b) auslautendes $a$ in sera ist die reguläre entwickelung eines urgerm. $\bar{o}$, nachdem der accent auf die reduplicationssilbe getreten war; das gotische auslautende $\bar{o}$ ist aus dem plural widerhergestellt. - 2) rera zu róa 'rudere'. - Ferner finden wir das perfect 3) snera zu snuia 'wenden'. Noreen, Altisl. gramm. ${ }^{3} \S 496$, s. 302 erklärt snera aus *snezo, ohne weiteres über die entstehung dieser form zu sagen; er schliesst sich also an Zarncke, Beitr. 15, 353 
an, der snera analogiebildung nach sera sein lässt. Osthoff, Beitr. 8, 554 nimmt folgenden entwickelungsgang an: *sesnáua, *snesnárva, *snesáiva, *snezán, *snézō. Aber mit recht hebt Loewe a.a.o. s. 340 f. hervor, dass gegen' Osthoffs entwickelungsgang das ganz gleichartige got. saizlepp spricht, das ebenfalls *slaizēp hätte ergeben müssen, wenn Osthoffs a.a.o. formulierte gesetz: 'folgten sich in zwei unmittelbar benachbarten silben eines wortes identische und mit $s$ beginnende consonantengruppen, so fielen aus der zweiten alle hinter dem zischlaut stehenden consonanten aus', haltbar wäre. Loewè setzt folgende proportion an: *séo (got. saia) : * sézōa = * snútō: (*seznaía, später) séznōa. In *sézōa wurde $s$ als wurzelhaft, *ezōa als endung empfunden, daher fügte man ebenso *ezōa, später -era an das als wurzel aufgefasste sn- von snía an. Wider anders erklärt Janko a.a.o. s. 289 das perfect snera aus ursprünglichem *se-zn⿳亠े(n) zum ehemaligen infinitiv *snóa (= ae. snówan), mit analogischer schwundstufe snía (vgl. wn. biia neben seltenem anorw. bóa; Noreen, Altisl. gramm. ${ }^{3} \$ 125$, anm. 2 und 3). - Auch 4) grera zu gróa 'grünen' erklärt Janko a.a.o. aus *gre-rò $(n)$, sagt aber dabei nicht, ob er diese form als lautgesetzlich ansieht oder als analogiebildung (róa : rera $=$ gróa : grera), wozu ich neige, und die Janko bei 5) gnera zu gnúa 'schaben' und 6) bnere (3. sing.) zu bnúa 'reiben' (Noreen, Altisl. gramm. ${ }^{3} \S 496$ und anm. 2) anerkennt. - Aber liegt es nicht näher, bei snera auch von vornherein analogiebildung nach sera und rera anzunehmen, statt sich auf complicierte und nicht beweisbare constructionen einzulassen? Das element -era wurde im altisländischen fast als suffix aufgefasst; es ergibt sich dies daraus, dass die ablautenden verba kiósa (perf. kaus) 'wählen' und friósa (perf. fraus) 'frieren' auch in dessen bannkreis gezogen werden. Nach dem plural korom und frorom (mit tiefstufe und gramm. wechsel) stellt sich ein sing. kera und frera ein (schwach flectiert, s. Noreen a.a.o. $\S 478$, anm. 1, s. 291), neben dem sich die formen. kera und frera unter offenkundiger anlehnung an obige entsprechende perfecta einfinden.

Sicher redupliciert, wenn auch erst infolge urgerm. neubildung, sind 7) aisl. iólk = got. aiauk zu auka 'vermehren' und 8) aisl. iós zu ausc 'schöpfen' aus urgerm. *éausa (urgerm. 
au in unbetonter silbe wird im westgerm. und nord. zu $\bar{o}$ ). Wie sera und rera manche neubildungen nach sich zogen, so haben auch iók und iós analogisch beeinflussend gewirkt, worüber weiter unten; - 9) aisl. hió zu hogg(u)a 'hauen' kann nach der gleichung *aukan : *éaulia = *hanıvan : *héauıa neu gebildet sein, kann aber auch auf ein urnord. redupliciertes *héhauwa, *héhōrv, *héōv, *héō, hió zurückgehen (Noreen, Altisl. gramm. $\left.{ }^{3} \S 97.224 .227, d\right)$.

II. Das altenglische, speciell das anglische und die poesie, weist eine beträchtliche anzahl reduplicierter perfecta auf: 1) heht zu hátan 'heissen'; - 2) reord zu rádan 'raten'; - 3) leort zu látan 'lassen'; - 4) leolc zu lácan 'springen'. Da das schwinden des langen stammvocals im singular nicht zu erklären ist ${ }^{1}$ ), so sieht man meist (vgl. z. b. Kluge, Pauls Grundriss $1^{2}, 437$ ) die singularformen als übertragen aus dem plural an, ein vorgang, den wir bei got. saiso und waiu $\bar{o}$ ebenfalls annehmen mussten (s. 482). Als pluralformen sind anzusetzen urgerm. *hehitum zu haitan, *lelikum zu lailian (vgl. agutn. liko bei Noreen, Altschwed. gramm. § 541, s. 444); *lelatum zu látan, vgl. got. lats oder *lelitum, vgl. aisl. lito, agutn. litu; *reradum zu ródan, vgl. got. garapans. Die synkope von mittelvocalen darf mit Weyhe, Beitr. 30, 84 ff. auch nach kurzem stammvocal für erwiesen gelten. So kommen wir zu ae. urformen *hehtum, *lelkum, *leltum, *rerdum. Während die erste form unverändert in $h e h t^{2}$ ) fortlebt, liegen die drei letzteren als leolc, leort und reord vor. Man nimmt meist an, dass $e \mathrm{zu}$ co wurde infolge von 'brechung' vor $l c$ und $r+$ consonant (Sievers, Angelsächs. gramm. ${ }^{3} § 79$ ff.); leort für *lelt zeigt dissimilation des zweiten $l$. Weyhe, Beitr. 31, 48 dagegen lässt co durch $\iota$-umlaut aus dem plural *lelaikum, *lelăkun, *lelucun entstehen. Zwei bedenken stellen sich dieser annahme entgegen: erstens ist eine tiefstufe *lelitiun anzusetzen (s. oben); zweitens wäre dann bei heht auch umlaut $\mathrm{zu}$ *heoht $\mathrm{zu}$ erwarten. Auch Janko s. 269 bleibt lieber bei der 'brechung' des $e$ zu eo. Freilich ist noch

1) Doch s. Janko (a.a.o. s. 268), der die entwicklungsreihe *lelaik, *lelęl, *lelěk, *lelli ansetzt und ae. swelc $=$ got. swaleiks und hwilc $=$ got. lnvileiks vergleicht (nach Kluge in Pauls Grundriss $1^{2}, 1068$ ).

2) Warum hier die brechung zu eo unterblieb, ist strittig; s. darüber Janko a.a. o. s. 269 und weiter unten. 
zu erklären, weshalb heht nicht der brechung unterlag. Ten Brink, Anglia 1, 514 und 524 postulierte zwar mit rücksicht auf me. hihte, highte ein ae. *heoht; doch scheint mir Bülbrings deutung; Altengl. elementarbuch s. 58 zutreffender, dass wegen des helleren timbre von $h$ in *hehitrum (nicht *hehĕt wie Bülbring will) die brechung unterblieben sei; - 5) ae. ondreord (Ps. und North.) von on $=d r a ́ d a n$, ist analogiebildung nach dem muster ródan. : reord $=$ ond-raedan : ond-reord ${ }^{1}$ ); - 6) ae.

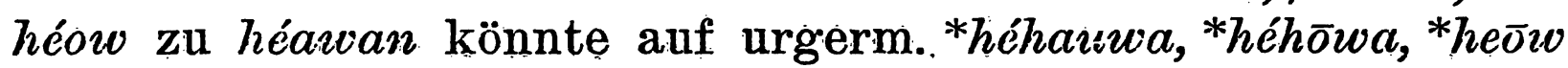
zurïckgehen (Sievers, Ags. gramm.3 \$ 218, s.111); - bei 7) heold $\mathrm{zu}$ healdan; - 8) weold $\mathrm{zu}$ vealdan; - 9) veolc zu wealcan; - 10) veoll zu weallan; - 11) wéow zü wáwan und 12) wéop zu wépan ist die möglichkeit vorhanden, auf reduplicierte bil-

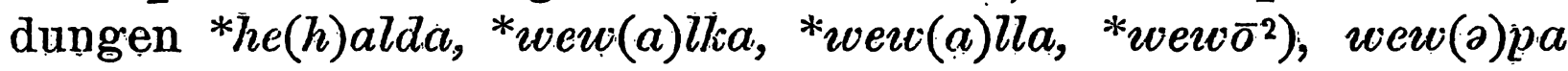
zurückzugreifen; bei weolc könnte man auch an brechung aus * welk denken; das wahrscheinlichste ist, dass analogische beeinflussung eine ebenso grosse rolle spielt wie ursprüngliche reduplication, ohne dass wir bei dem mangel an belegten zwischenstufen die grenzen beider bestimmen können.

Eine umstrittene form ist 13) north. blefla (Lindisfarne Gospels, Joh. 20, 22), das Füchsel, Anglia 24, 75 als redupliciertes perfect von ae. bláwan anspricht. Es übersetzt an der betr. stelle lat. insuflavit; daneben aber findet sich eine zweite, aus der ersten corrigierte übersetzung zebleou (d.h. zebléouv), die Sievers, Beitr. 26,557 für die richtige ansieht und blefla als schreibfehler. verwirft. Immerhin aber besteht die möglichkeit, dass ein jüngerer schreiber die alte, nicht mehr verstandene form übersetzt hat, wie Loewe a.a.o. s. $321 \mathrm{ff}$. will. Freilich würden wir eher eine form *befla (vgl. got. saislēp) erwarten. Wir kommen höchstens zu einem non liquet. ${ }^{3}$ )

III. Das althochdeutsche besitzt ein perfect; das als redupliciert angesehen werden muss: iar, iarum zu einem $j$-praesens erien, erren $=$ got. arjan 'pflügen', part. perf. gi-

1) [Vgl. Pogatscher, Anglia Beiblatt14, $182 \mathrm{ff}$., der ondr'cédan als wahres compositum von rotedan erklärt. - W. B.]

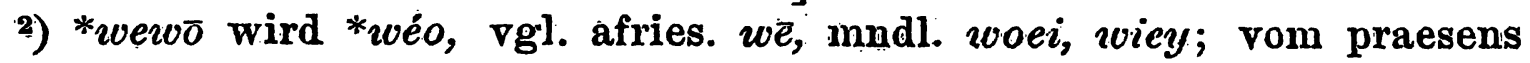
aus tritt stammauslautendes $w$ an *quéo an.

3) S. den nachtrag am schluss. 
aran. Ahd. iar aus *ear') wie aisl. iók = got. ciank aus urgerm. éauk; daneben findet sich das perfect uor, das nach Kögel, Beitr. 16, 502 nach der gleichung swerien : swuor = crien : uor gebildet sein soll; indes hindert nichts, uor: *aran aufzufassen wie aisl. tól : taka, also entstanden durch übertritt in die $a / \bar{o}$-klasse.

Was sich sonst noch von reduplicierten formen im ahd. finden soll, muss als zweifelhafte vermutung hingestellt werden. Es sind in erster linie die sog. $"$-perfecta, die hier zu erwähnen sind: 1) ana-steroz Gl. 1,282, glosse zu inipingebant (statt impingebat) im Reichenauer codex; in der Murbacher abschrift desselben ist deshalb anastcrozun verbessert; - 2) ki-slcrerot Gl. 1, 281, glosse zu incidit; - 3) pleruzzun Gl. 1, 409, glosse zu adolerent, aus dem Reichenauer codex und 4) ca-pleruzzi G]. 1, 312, glosse zu inımolavet (hs. St. Paul in Lavandthal, Kärnten). - Auf bairischem sprachgebiet finden sich (nach Kögel, Beitr. 26, 500 f.) in den Prudentiusglossen (Gl. 2, 542, 7) stiriz = prosıbigit, auch verkürzt als stivz (Gl. 2, 444,22), das der schreiber selbst durch ahd. spurnta übersetzt. Durch das regelmässige sticz ist es ersetzt Gl. 2,508, 1 und 536,34; Gl. 2, 542, 19 findet sich stiriz = pupugerat. Ferner die form steraz (in den Vergilglossen $2,669,50$ ) $=$ arietat, die der schreiber nachträglich in stiaz verbesserte; in derselben handschrift (Gl. 2,670,16) lesen wir farsterc = proterret. Zweifelhaft ist ein $r$-perfect in einer Trierer handschrift (Gl. 2, 33, 1) anage-lierzon indulsere; das ie legt nahe, $r$ nur als schreibfehler für $z$ anzusehen. - Auf fränkischem boden findet sich bei Otfrid von bîan : bivnıı 4, 4, 59 und birunuis 2, 7, 18. Auch bei verben, die nicht zu den reduplicierenden zählen, findet sich der $r$-typus: ahd. scrivun (daneben eine $\boldsymbol{w}$-form erscriuun in den Mainzer glossen), ferner part. perf. giscrivan (das Zarncke, Beitr. 15, 351 f. nicht nachweisen kann ${ }^{2}$ )); anschliessend an letzteres in späterer zeit (11./12. jh.) pe-spiren Denkm. 90, 23.

Wie die älteren germanisten Grïmm, Lachmann und Müllen-

1) Vgl. Loewe a.a.o. s. 308; dazu Janko a.a.o. s. 313 und Brugmann, Kurze v.l. gramm. s. 544; eine grundform *ēr wie *ēt 'ass' ist nicht denkbar, da sie *âr ergeben hätte.

2) Doch findet sich z. b. G1.2, 775, 6 er.scrivena = conclamata. 
hoff sieht Zarncke, Beitr. 15, $350 \mathrm{ff}$. in dem $r$ dieser formen einen hiatusdeckenden laut, und noch neuerdings schliesst sich Wilmanns, Deutsche gramm. 3, 38 dieser ansicht an, da er es fiir sehr zweifelhaft hält, ob man einige dieser formen durch reduplication (s. weiter unten) erklären dürfe; allgemein ahd. sei $r$ nur in scrivın, giscrivan. In diesen formen sehen jüngere forscher (Streitberg, Urgerm. gramm. s. 281 oder Brugmann, Kurze vgl. gramm. s. 541) reste eines idg. $s$-aorists. Gegen diese erklärung wendet sich Loewe a.a.o. s. 266, und Brugmann selbst vermutet a.a.o. an anderer stelle (§ 798 anm., s. 598) zusammenhang mit den $r$-endungen des arischen und italokeltischen (ai. 3. pl. vidúr, lat. videre $=$ vidèrunt).

Einen ganz anderen weg zur aufhellung dieser vielgedeuteten ahd. $r$-formen hatte Osthoff, Beitr. 8, 540 ff. beschritten. Er sah in ahd. steroz eîne reduplicierte perfectform, deren entwickelungsgang er folgendermassen ansetzt: *stantan, perfect *stestaita (vgl. got. -staistald), *stesaúta, *stezaúta (nach Verners gesetz), *stérōt $>$ ahd. steroz. Dementsprechend construiert Loewe a.a.o. s. $344 \mathrm{f}$. die entwickelung von ahd. ki-skverot zu *skraidan aus *skeskraúda, *skesraúda, *skresaúda, *skrezaúida, *skivérōd > ahd. skrerot; scrirun aus *skeskrimé, *skezrimé, *skrizimé u. s. w., oder gar mhd. spiren aus *spespumé, *spesumé, *spezumé u.s.w. ${ }^{1)}$ Ảber jeder unbefangene muss zugeben, dass Osthoffs erklärung von steroz zwar recht annehmbar aussieht, aber den fehler aufweist, dass sie sich auf ein ad hoc angenommenes 'dissimilationsgesetz' stützt, das sonst nicht nachweisbar ist; Loewes entwickelungsreihen aber nelhmen sich auf dem papier vielleicht ganz gut aus; in wirklichkeit wird niemand überzeugt sein, dass sie im leben der sprache vorhanden gewesen sind. Wir haben ferner schon oben s. $471 \mathrm{f}$. nachzuweisen versucht, dass der gotische reduplicationstypus -staistald u.s.w. secundär ist und nicht olıne weiteres auf die übrigen germ. dialekte ausgedehnt werden darf.

Das $r$ endlich, das sich in ahd. biruun, birunuis findet, wird wider auf eine andere art erklärt. Kluge, Pauls Grundriss $1^{2}, 436$ vergleicht ai. babhüva und lässt ein urgerm. *bebriıva

1) Auch Janko a.a.o. s. 274 steht auf ähnlichem standpunkt. 
zu *Zezúwa dissimiliert werden; aus letzterem entsteht durch weiterentwickelung ahd. birun (= urgerm. *bezunmé). ${ }^{1}$ )

Lautgesetzlich erklärt werden bei allen diesen versuchen nui nicht die formen pleruzzun und ca-plervzzi zu ahd. bluozan. Hier muss auf jeden fall entweder nach der älteren annahme ein hiatusdeckendes $r$ eintreten oder wir müssen an analogische neuschöpfung nach einem der obigen muster denken. Da fragt es sich jedenfalls, ob es nicht richtiger ist, wie bei dem altisländischen (s. oben s. $485 \mathrm{f}$.), bei allen $r$-formen des althochdeutschen an analogische entstehung zu denken, anstatt sich auf complicierte und unbeweisbare constructive erklärungen einzulassen. Zarncke meinte am a.a.o., dass alle $r$-formen in Reichenau im 8. jh. von ein und demselben schreiber gebraucht worden seien, doch wies Kögel, Beitr. 16,500 nach, dass sie sich auch auf bairischem gebiet finden, und inzwischen sind sie auch aus rheinfränkischen glossenwerken nachgewiesen worden. Wir müssen sie also für allgemein ahd. ansehen.

Vielleicht gehen wir bei der erklärung der $r$-formen durch analogische schöpfung gerade von dem sonst nicht deutbaren pleruzzun aus. Das ahd. mag wie das altisländische (und gemeinsam mit den anderen germ. dialekten) einst ein redupliciertes perfect von *sē(j)an 'säen' und *rōan 'rudern' besessen haben: *sero und *rerō (got. saisō $=$ aisl. sera und aisl. vera). ${ }^{2}$ ) Nach der proportion *rōan : *rerō $=$ blôzan : blerôz wurde ausser diesem geschaffen stôzan : sterôz ( $\hat{o}$ erst ahd. aus germ. au vor $t=$ ahd. $z$ ), ebenso slirôtan : slcrerôt. Bair. steraz mag die lautgesetzliche entwickelung eines gekürzten steroz sein, stiriz mit $i$ in der stammsilbe aus tiefstufigem *stivuzun (u-umlaut, vgl. Kögel a.a.o. s. 501) entstanden sein; stirz endlich aus *stiruz wie hirz aus hiruz. Erkennen wir die möglichkeit an, dass einst im westgermanischen ein *sero und ${ }^{*}$ rer $\bar{o}$ vorhanden war, so bietet die analogische weiterverbreitung eines perfectischen -ero- keine anderen schwierigkeiten als die gleiche erscheinung in aisl. snera zu snúa,

1) So auch noch nenestens Janko a. a. o. s. 276.

2) Vgl. Holz, Urgerm. geschl. e s. 45; Loewe a. a. o. s. 348. Auch Janko, 1F. 20, 285 vermutet ein 'verschollenes westg'crm. perf. *sesī(a.).' Franck, Zs. fla.40,25 vertrat ebenfalls die ansicht, dass die redupl. perfecta gemeingut aller germ. mundarten gewesen seien.

Beiträge zur geschichte der deutschen sprache. $\mathrm{XXXII.}$ 
gnera zu gnía, grera zu grúa und bnere:zu biúa (s. auch oben s. 485 f.).

Aus einer anzahl derartiger formen mit innerem $r$ konnte sich allerdings die vorstellung eines hiatusfüllenden $r$ im vergleich mit eo-perfecten von demselben stamme (steroz : steoz, *bleroz : bleoz u.s.w.) entwickeln und zur weiterverbreitung dieses $r$ auf formen wie scrirun neben scriun, giscrivan neben giscrian, pe-spiren nebèn spienn führen. Otfrids bivunn und biruwîs fügen sich ebenso leicht hier ein, da wir ein perfect *beo, biu (vgl. aisl. bió), pl. *biuwum (aisl. biuggom) zu erwarten haben ${ }^{1}$ ); ein *biuum fordert aber geradezu, wenn ich so sagen darf, ein hiatusdeckendes $r$ heraus.

Sind die vorstehenden ausführungen rỉchtig, so wären wir, teilweise wenigstens, zu den anschauungen der älteren ger= manisten zurückgekehrt, unter ablehnung der complicierten und unwahrscheinlichen erklärungsversuche jüngerer forscher, und damit scheiden die $r$-perfecta aus der reihe ursprünglich reduplicierter perfecta aus.

B. Der hochstufentypus im nordischen und althochdeutschen.

Während die gotischen reduplicierten perfecta keine $a b$ stufung zwischen singular und plural aufweisen, sind im nordisch-westgermanischen noch vereinzelte fälle von tiefstufigen pluralen bei langvocalischen wurzeln erhalten. Wir haben dieselben schon oben s. $469 \mathrm{f}$. betrachtet; hier erübrig't uns noch, die zu diesen tiefstufigen pluralen vorliegenden hochstufigen, reduplicationslosen singulare aufzuzählen. Hoffmann, $\Gamma$. s. 57 erkennt 'delnnstufige, geschleift betonte praeterita' an, wie auch Janko, IF. 20, 262 'dehnstufige formen' ansetzt. Letzterer vergleicht die delinstufigen $s$-aoristformen des altindischen und griechischen, die nach Brugmann, Kurze vgl. gramm. § 703, s. 538 bei den leichten basen im ind. sing. act. dehnstufe, im plural schwundstufe aufwiesen: ai. sing. aor. act. cirāut-s-am zur wzl. rudh- 'hemmen', civākș̆-am = lat. vēxĭ, aksl. věs zur

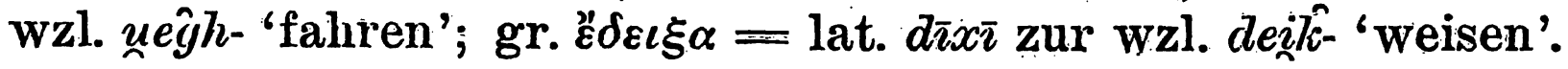

1) Vgl. haunaan, perf. hiu (oberdeutsch) und hio (fränkisch) s. Braune, Ahd. gramm. ${ }^{2}$ § 354, anm. 2, s. 250. 
Die schwundstufe liegt noch vor in gr. $l \sigma \alpha \nu$ neben analogischem

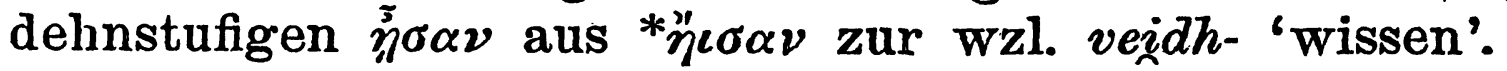

Die in den germanischen mundarten vorliegenden beispiele verlangen nun nicht unbedingt dehnstufe der wurzel; bei fast allen kommen wir mit der normalhochstufe aus. Es liegt deshalb kein grund vor, mit Janko a.a.o. s. 263 neben dem vom praesens nur durch die reduplication unterschiedenen perfect ein durch $\bar{e}$-färbung (sic!) ausgezeichnetes dehn- und ein schwundstufiges praeteritum anzusetzen. Das fehlen der reduplication im perfect haben wir oben $\mathrm{s} .461 \mathrm{ff}$. schon für das indogerm. erwiesen, und zur ansetzung von grundformen wie *(he)hoita oder *hoita zu einer wzl. hait- sind wir durch nichts berechtigt. Prüfen wir nunmehr die einzelnen beispiele.

Aisl. heit 'hiess' zu heita stellt sich neben ahd. ca-heiz (Gh. 3; s. Singer, Beitr. 11, 294); dem aisl. leit, plur. litom vergleicht sich aschwed. lèt, plur. litu und ahd. fur-leiz (Fuldaer beichte z. 11 in $\mathrm{MSD}^{3}, 73,241 \mathrm{f}$. im text $\mathrm{A}$ aus Göttingen; die texte $\mathrm{B}$ in Fulda und $\mathrm{C}$ in Rom haben ie) und fir-leizssi (Isidor 25, a, 23). ${ }^{1}$. Es geht wol nicht an, in ahd. ei mit Braune, Ahd. gramm. ${ }^{2} \S 36$, anm. 3 nur eine ältere schreibung von $i e$ zu sehen, obwol sich in derselben Fuldaer beichte; aus der die ei-form stammt und in demselben text A z.16 auch gihiezi ebenso. wie in den beiden anderen texten findet, weil das aisl. heit eine stütze für ahd. -heiz abgibt. Germ. *haita nun mit 'imperfectischer' wurzelstufe hat sich ursprünglich vom praes. *haito genügend unterschieden, um als charakteristische form der vergangenheit empfunden zu werden; in historischer zeit aber, als die endung $a$ geschwunden war, fiel es mit dem imperativ des praesens, einer vielgebrauchten form, zusammen. So erklärt es sich, dass ein ersatz für das perfect *hait geschaffen werden musste. Doch darüber später.

Schwieriger zu erklären ist das germ. perfect *laita, neben dem sich *lèta (aisl. lét, ae. lét, as. lêt, ahd. liaz), *lāta (aisl. lít, aschwed. līt) und *lōta (got. laitōt, aschwed. lōt) finden. Die tiefstufe *lelitmé des plurals liegt in aisl. litom, aschwed. litu mit abfall der reduplication und in ae. leort, leortom (s. oben s. 487) vor. Das perfect *laita (aisl. leit, aschwed. lêt,

1) Vgl. Persson, Bezz. Beitr. 19, 280. 
ahd. -leiz) als nachbildung eines *haita aufzufassen, wie Janko s. 283 und passim es tut, halte ich für unannehmbar. Die etymologie von germ. lêtan ist nicht ganz feststehend; einerseits vergleicht man lit. léidžı, léidnii 'lasse', laidinti 'laufen lassen', palaidas 'lose', was uns zur annahme einer schweren einsilbigen wurzel lêìl- berechtigt (Hirt, Idg. abl. s.36); anderseits zieht man lat. lassus aus *lad-tos heran, was neben got. lats, air. lesc, gr. $\lambda \eta \delta \varepsilon \tilde{i} \nu \cdot x о \pi \iota \tilde{\alpha} \nu, x \varepsilon x \mu \eta x \varepsilon \dot{v} \alpha \iota$ (Hesych) $\left.{ }^{1}\right)$, alb.

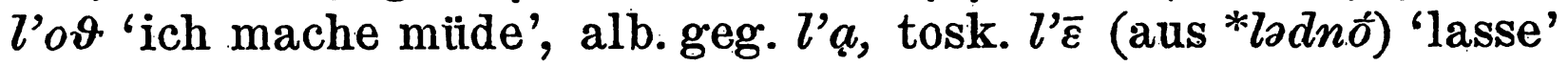
eine wzl. $l \breve{e} d-$ und den $\breve{e}-\bar{o}-\partial-a b l a u t$ voraussetzt. Alle schwierigkeiten, auch die verschiedenen perfecta des germanischen, erklären sich am besten durch die annahme zweier

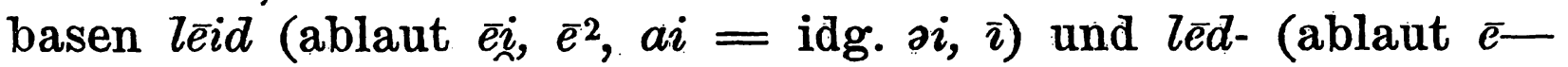
$\bar{o}-e-\partial)$, die sich im germanischen kreuzten. Das gotische kennt nur die basis lêd- (lêtan : lailōt : lats); das nordischwestgermanische hat daneben die basis leid- bewahrt, aber sie auf das perfect beschränkt: gèrm. ${ }^{*}$ lait $(a)$ ist idg. *lēi-da (oder *loida); *le $t(a)$ ist aus idg. *le( $(i) d-t h a$ entsprung:en; *litt(a) und *litum entsprechen der reductions- bez. schwundstufe idg. leid, līd-, lǔd-. Natürlich wäre es vergebliche mühe, heute noch ermitteln zu wollen, unter welchen bedingungen jede einzelne form entstanden ist; es muss uns genügen, die verschiedenen typen lautgesetzlich zu rechtfertigen. (vgl. die tabelle bei Hirt, Idg. abl. s. 33).

Auch für haitan ist eine ähnliche erklärung möglich wie für lētan. Es gibt nur eine etymologie von haitan, die einige wahrscheinlichkeit hat, nämlich von Brugmann, IF. 6, 89 f. $\mathrm{Er}$ verbindet es mit lat. ac-cio, ac-ci-re, ch-tare und weiterhin mit

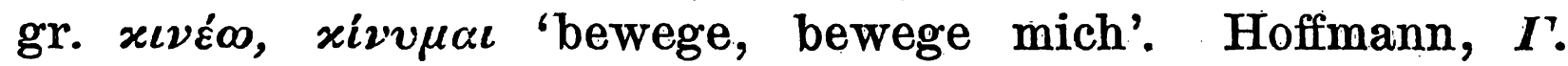
s. 40 f. erkennt nur den vergleich mit lat. accio u.s.w. an. Ich halte auch diesen für $\mathrm{zu}$ weit hergeholt. Nehmen wir haitan als tiefstufe *kəįd- einer wzl. kāid- an, so könnte das perfect *haita die fortsetzung der reductionsstufe *kaid- sein (s. Hirt a.a.o.). Eine etymologische anknüpfung lässt sich an

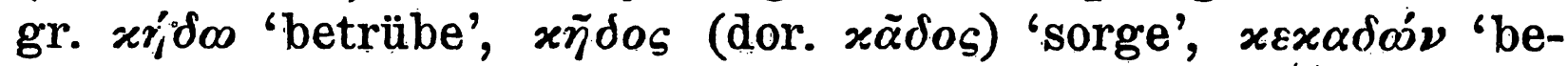

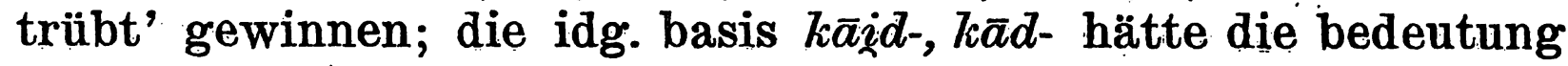
'schelten' gehabt, aus der sich einerseits die bedeutung 'betrüben', andererseits 'rufen, heissen' entwickelte.

1) Sütterlin, IF. 6, $99 \mathrm{f}$. 
Ich will diese erklärung aber nur als eine möglichkeit hinstellen, wie ich überhaupt auf die möglichkeit hinweisen will, dass in den praesentien der sog. reduplicierenden zeitwörter oft tiefstufige praesentia (vgl. Brugmann, Kurze vgl. gramm. \$ 655 ff., s. 509 ff.) langvocalischer wurzeln vorliegen mögen, an die zuweilen 'formantien' antraten, wie sie z.b. Brugmann bei der oben angeführten etymologie von haitan annimmt. Dann wäre auch das perfect ursprünglich nicht ablautlos gewesen, wie es jetzt den anschein hat. Nehmen wir als beispiel fāhan aus *fanthan, dem nach Hirt, Idg. abl. s. 31 eine idg. basis p $\bar{a} \hat{i}$ - zu grunde liegt. Wie lat. pango ist auch germ. *fantza ein tiefstufiges praesens mit nasalinfix

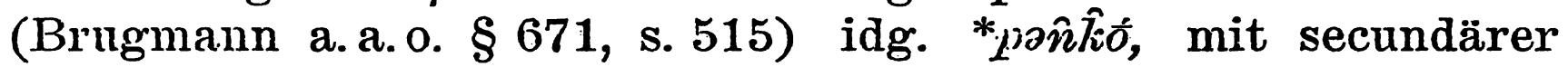
wurzelbetonung (im gotischen in allen zeiten, in den anderen germ. dialekten noch mit sog. grammatischem wechsel im perfect und part. perf.). Die schwundstufe liegt auch vor in got. fagrs aus idg. pokrós (Brugmann a. a.o. s. 141). Das perfect aber hat im sing. die reductionsstufe a nicht besessen; das

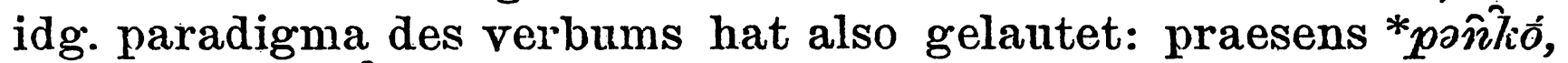
perfect pepcínkia. Da reductions- und schwundstufe im germanischen $a$ zusammenfallen, so war der unterschied im tempusvocal verwischt, wie das gotische zeigt.

Ansser -heiz und -leiz finden sich vereinzelt im ahd. noch einige ei-perfecta, die Singer, Beitr. 11, 294 aufzählt. Es sind us-sceit $\mathrm{Sb}$ zu skeidan, bi-heilt und int-pheing im text $\mathrm{B}$ der Fuldaer beichte (MSD ${ }^{3}$ s. $241 \mathrm{f}$ ), pi-heialt $\mathrm{K}$ zu haltan bez. fâhan; endlich untar-feille $\mathrm{Rb} \mathrm{zu}$ fallan und reitun $(\mathrm{O}$ 4,28, $9 \mathrm{P})$ zu râtan. Von allen diesen fasse ich nur -sceit als organische form auf, dem Janko s. 270 ein ersćhlossenes ws. *scád (?), palatalisiert scéad vergleicht. $\left.{ }^{1}\right)$ Aber auch die übrigen beispiele nur als graphische varianten der regulären $i e$-perfecta aufzufassen, geht nicht an, da sich auch im nordischen $e i$-formen finden. Im aisl. findet sich heilt (neben hélt) für helt (Noreen, Altisl. gramm. ${ }^{3} \& 494$, anm. 1, s. 301); reiph für rép, greit neben grét (ibid. $\S 495$, anm. 1, s. 302). Entsprechende formen sind aschwed. lēe, rē $\bar{p}$ und grêt (Noreen, Altschwed. gramm. § 544, s. 448). Ja, es findet sich sogar aisl. geingu zu ganga (Noreen,

1) Sievers, Ags. gramm. 3 § 76, 2, s. 35. 
Altisl. gramm. ${ }^{3} \S 98$, s. 81 ), das auch im altsächsischen -geing (Ess. gloss.) auftritt.

Alle diese fälle sprechen für die annahme, dass im nordischwestgermanischen einmal ein nicht zur entfaltung gelangter ei-typus sich auszubilden begann, der dem siegreichen $\bar{e}^{2}-$ typüs allerdings frühzeitig unterlag und nur einzelne spuren seines daseins hinterliess. Der ursprung dieses ei-typus ist natürlich in lautgesetzlichen perfectformen wie *hait, *lait, *skaid u. ähnl. zu suchen.

Als vertreter dieses ei-typus sehe ich auch das aisl. perfect sueip, plur. suipom zu sueipa 'fegen, wickeln' an, das aber hauptsächlich schwach flectiert wird. Also auch hier ist die $e i$-form in den hintergrund gedrängt worden.

Hochstufenvocalismus zeigen auch folgende perfecta: runschwed. $h a(u) k \rightleftharpoons$ aschwed. hogg zu runschwed. ha(u)kua= aschwed. hogg(u)a 'hauen'; aschwed. valt zu valda, fal zu falla (vgl. Noreen, Aschw. gramm. $§ 542$, s. 445 und $\S 543,2$, s. 447 und anm. 7, s. 448). Ferner ae. zanz zu zanzan und die reihe éo-perfecta, die sich in der liste s. 456 findet. ${ }^{1}$ )

Nicht unerwähnt bleibe eine ansicht, die das ei-perfect (aisl. leit, heit, sueip u.s.w.) aus analogieschöpfung nach den tiefstufigen pluralen litom, *hitom, suipom unter anlehnung an die $\bar{\imath}$-klasse (gripa u.s.w.) entstehen lässt; also gripom : greip = litom : leit (vgl. Loewe, Kuhns Zs. 40,325 f.). Diese auffassung lehnen wir nach obigen ausführungen natürlich ab; wol aber bewirkte der tiefstufige plural die entstehung seltener singularformen mit pluralvocal, wie aschwed. lupp, auch lop, lopp, mschwed. ful, aschwed. fiul, ulte (zu valcla), aschwed. liog, mschwed. hıg u. a., die bei Noreen, Altschwed. gramm. § 541 ff., s. 444 ff. und Altisl. gramm..$^{3} \S 493$ ff., s. 300 ff. aufgezählt sind.

\section{Der $\bar{e}^{2}-t y p u s$ des perfects.}

Im vorhergehenden haben wir gesehen, dass der aujs idg. zeit übernommene, im gotischen noch productive reduplicationstypus in den nordisch-westgermanischen mundarten erstarrt ist und ausstirbt; wir haben ferner gesehen, dass der wurzel-

1) Vgl. dazu Hoffmann, T.s. 55 f., wo auch as. griot zu as. griotan = ae. zréotan gestellt und hierher gezogen wird. 
vocaltypus im perfect sich wegen der gleichheit des stammvocals im praesens und perfect und der dadurch bewirkten geringen unterscheidung dieser beiden zeiten - allein durch die endungen, und auch da nur zum teil, da in manchen mundarten die endungen einzelner personen des praesens und perfects zusammenfielen, wie im nord. bei der 1.plur. - ebenfalls nicht zu erhalten vermag; endlich fanden wir im nordischen und althochdeutschen ansätze zur entwickelung eines ei-typus, herrührend von idg. bildung gelangte.

Productiv ist in allen deutschen mundarten dagegen der . $e^{2}$-typus geworden; er ist auch - mit alleiniger ausnahme des altenglischen - der ausgebreitetste in historischer zeit. Die älteren und auch neuere versuche, ihn zu erklären, gehen aus von einem intervocalischen consonantenschwund. Das ur-

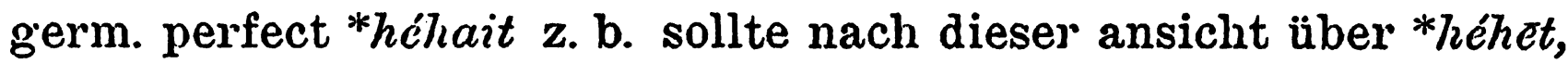
*hćct (mit ausfall des intervocalischen $h$ ) zu het contrahiert werden. Diese erklärung stimmt für das altnordische, wo inlautendes $h$ (ausser zwischen kurzem vocal und $s$ und vocal und $t$ ) schwindet: aisl. sici = got. saihvan, auch für das altenglische: séon = got. saitrvan. Dagegen bleibt im althochund -niederdeutschen inlautendes $h$ erhalten: schan, wenn es auch zum schwachen hauchlaut geworden ist. Da wir schon oben ausgeführt haben, dass eine erscheinung, die gleichmässig in den westgerm.-nordischen mundarten auftritt, auch eine einheitliche erklärung verlangt, so können wir mit dem schwund des intervocalischen $\hbar$ in den nordisch-angelsächsischen mundarten nichts anfangen. Zudem setzten wir s. 483 die entstehung des nordisch-westgermanischen $\tilde{e}^{2}$ - bez.eo-typus zwischen 200-400 an, und $\mathrm{zu}$ dieser zeit ist das intervocalische $h$ auch im altenglischen noch erhalten, wie die Epinaler glossen aus dem anfang des 8.jh.'s beweisen, die es noch besitzen: thóhae $=$ ws. đó, wlóluum = ws. wló(u)m u.s.w. (Sievers, Ags. gramm. ${ }^{3}$ $\S 218,2$, anm. 3). Ebenso zeigen nord. runeninschriften aus der älteren zeit noch das intervocalische $h$, so der stein von Einang: aus dem 4. jh., dessen inschrift lautet: Đazar par runo faihido - aisl. Dagr pár rúnar (für lautgesetzliches *rina) fápa (lautgesetzlich *fápba zu fá 'malen' = urgerm. *faitrjan zu got. faihs 'bunt'). Wenn wir also an einer einheitlichen er- 
klärung des nordisch-westgermanischen $\bar{e}^{2}$-typus festhalten, können wir an. ae. hét auch nicht mittels schwund des intervocalischen $h$ aus *hehet ableiten.

Ebensowenig können wir das von Lóewe a.a.o. s. 319 gègebene gesetz annehmen: 'folgt auf eine aus consonant $+e$ bestehende haupttonige anfangssilbe derselbe consonant + vocal, so schwindet der consonant an zweiter stelle', also z. b. lètan, perfect *lélêt, *léêt, lèt. Wir haben bereits s. 462 gezeigt, dass dieses angebliche gesetz für: das germanische nicht haltbar ist, was auch Loewe indirect durch die zulassung zahlreicher ausnahmen zugeben muss (aisl. sera aus *sesó, reva, ae. dide u.s.w.); es ist natürlich für das germanische gänzlich irrelevant, dass ein solches dissimilationsgesetz für das keltische aufgestellt worden ist.

Ottmann, Die redupl. praeterita in den germ. sprachen, 1890, steht auf dem gleichen ablehnenden standpunkt gegenüber der ausstossung innerer consonanten; aber um die entstehung des $\bar{e}^{2}$-typus zu erklären, greift er zu einem in der germ. lautlehre ganz vereinzelt dastehenden fall, dem nebeneinander von got. mizdo, ae. meord und ae. méd, as. mêda, mieda, ahd. miata, mieta 'miete, lohn'. Germ. mizdo geht auf

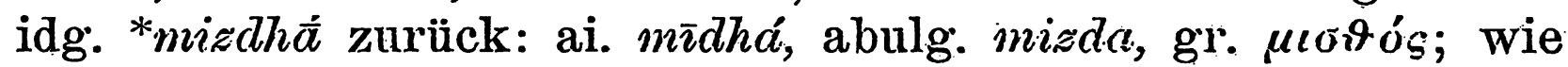
das germ. *méd̄ zu erklären ist, untersucht Ottmann weiter nicht. Er nimmt einfach in allen perfecten, die $r$ vor stammauslautendem consonant aufweisen, ausfall des $r$ und ersatzdehnung an: ae. $*_{r e r d}>*_{r} \bar{e} d$, *leri $>*^{*} \bar{c} t$; auch in Osthoffs reduplicationstypen skes-, spes-, stes-, also: *sterld (zu skaldan) $>*^{*}$ skèld, ${ }^{*}$ sperlt (zu spaltan) $>{ }^{*}$ speelt u.s.w. Es liegt auf der hand, dass diese erklärung noch unhaltbarer ist wie die oben abgelehnte durch den ausfall innerer consonanz, da sie sich nur auf ein vereinzeltes beispiel stützt, das zudem in keiner. beziehung $\mathbf{z u}$ den in frage kommenden verben steht.

Einen weiteren erklärungsversuch macht Zarncke, Beitr. 15,352. Er leitet den $\bar{e}^{2}$-typus ab von einem lautgesetzlich

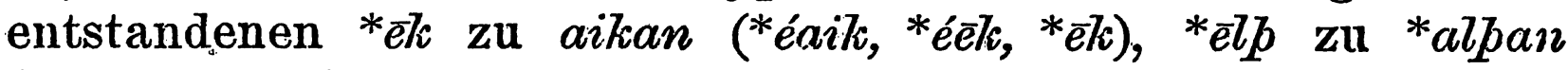
$\left({ }^{*} e ́ a l p<*^{*} \bar{e} l p\right)$ und *het zu haitan. Das letzte beispiel haben wir oben abgelehnt; got. us-alphans hat kein belegtes perfect (es hätte aber vermutlich *aialp gelautet) und im aisl. kommt auch nur das part. perf. aldenn vor. *Alpan war demnach im 
germanischen wol ein unvollständiges zeitwort, das wir nicht in einem erschlossenen perfect $* \bar{e} l p$ als muster für neubildungen gebrauchen dürfen. Es bleibt also nur got. -aiaik als sicheres beispiel, von dem aber nur feststeht, dass es auch im althochd. vorkam (ahd. eilhan); das aisl. eilienn 'rasend' gehört der bedeutung wegen kaum dazu.') Uebrigens hätte Zarncke noch germ. *éar zu asjan (ahd. iar) hinzufügen können.

Holz, Urgerm. geschl. $\bar{c}$ s. 36 will den $\bar{e}^{2}$-typus aus diesem

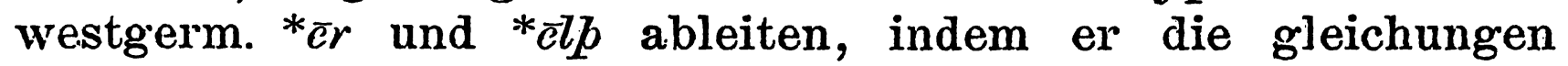

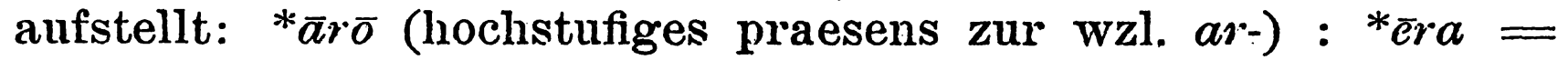

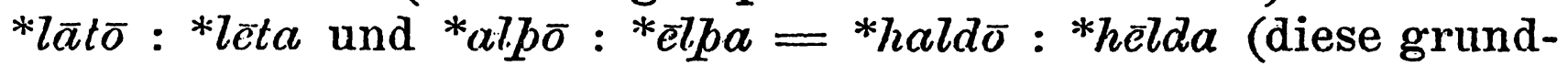
form ist nicht über allen zweifel, vielleicht ist schon urgerm. * hěla anzusetzen, s. weiter unten). Seine aufstellungen haben anklang gefunden bei Bethge in Dieters Laut- und formenlehre s. 361 ; s. dagegen Loewe a.a.o. s. 317.

In ein neues stadium tritt die erklärung des $\bar{e}^{2}$-typus mit Brugmanns aufsatz IF. 6, 89 ff. Dieser forscher und gleichzeitig mit ilım Wood, Germanic Studies 2, $27 \mathrm{ff}$. trennen. die nord.-westgerm. $\bar{e}^{2}$-perfecta (und co-perfecta) ihrem ursprunge nach ganz von den reduplicierten formen got. haihait: und aiank und sehen darin urgerm. reduplicationslose perfecta *heita und *stênta (nord.-westgerm. *hèt und *steot), die sich zum praesens haita und stauta verhalten sollen wie got. tēkan zu aisl. taka. Natürlich kann alsdann das $\bar{c}^{2}$-perfect der $\breve{a}$-stämme nur durch übertragung von den $a i$-wurzeln herrühren (a. a. o. s. 94 f.). 2)

Gegen die theorie Brugmanns und Woods wante sich Hoffmann, $\Gamma$. s. 33 ff. Zunächst zeigt er, dass der langdiphthong $\bar{e} u$ nur unsichere und spärliche belege aufzuweisen hat (ahd. giumo aus *gheূnımo neben ahd. goumo und guomo = aisl. gōmr oder ahd. stiuri aus *stēuvi-?). Dagegen ist $\bar{c} i \underline{\text { gut }}$ beglaubigt (vgl. Jellineck, Beitr. 15, 297 ff. und Sievers, ibid. 18, 409 ff.). Aber die entwickelung dieses $\bar{e}_{\hat{2}}^{i}$ in den einzel-

1) Vgl. zur etymologie von aikcan: Osthaff, Beitr. 13, $395 \mathrm{f}$. und 14,319f.; Kögel, ibid. 16, 512; Uhlenbeck, ibid. 30, 253; Hoffmaun $\Gamma$. s. 39.

2) Die doppelte entwicklung des $\bar{e} i$ zu $l \bar{e}^{1} t a n$ im praesens und $l \bar{e}^{2} t$ im perfect erklärt Brugmann aus einer verschiedenheit der silbengrenze: idg.

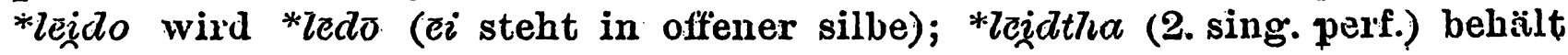
das $\bar{e} i$ in geschlossener silbe (Grundriss $1^{2}, 203$ ). 
sprachen ist nicht die von Brugmann angenommene; das gegenteil ist der fall: in geschlossener silbe fällt der zweite component aus (ai. $r \bar{a} s, r \bar{a} n=$ lat. $r \bar{e} s,{ }^{*} r \bar{e} m>$ rem, stamm $r \bar{e} i$,

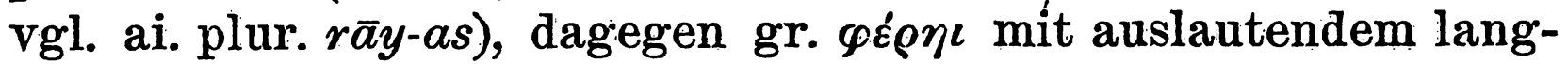
diphthong. Wenn wir das nebeneinander von germ. $l \bar{e}^{-1} t$ - und $l \bar{e}^{2} t$ - erklären wollten, so könne das nur durch eine verschiedene idg. betonungsweise geschehen; $l \bar{e}^{1} t$ - sei gestossen, $l \bar{e}^{2} t-$ geschleift betont gewesen. Um nun die $\bar{e} \hat{n}_{-}$- (bez. $\left.\bar{e} u-\right)$ diphthonge auch bei den ai- (und au-) stämmen nachweisen zu können, versucht Hoffmann alle $a i$ - (und $a u$-) verben in die $e / 0$-reihe zu bringen, wogegen wir uns schon oben s. $478 \mathrm{f}$. erklärt haben. Die perfectformen *léike (zu laikan) und *stéute (zu stautan) sollten mit verlust des auslautenden vocals zu geschleift betonten $l \tilde{\bar{e}} i \hbar$ und st $\tilde{\bar{e}} u t$ werden, aus denen westgerm.-nord. $* l \bar{e}^{2} \eta_{i}$ und *steut erwuchsen. Die verba mit dem praesensvocal $a$ werden ebenfalls für die e/o-reihe reclamiert (s. oben s. 475 f.), und das $\bar{e}^{2}$-perfect hier durch dehnstufiges, unter dem schleifton als $\bar{e}$ erhalten gebliebenes idg. $\bar{e}$ (praesens gangan, perfect

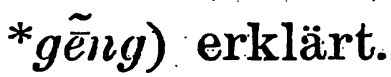

Auf einem ganz entgegengesetzten standpunkt steht Loewe, Kuhns Zs. 40,266 ff. Er kehrt zu der alten contractionstheorie zurück, sucht aber den ausfall des stammanlautenden consonanten durch sog. 'haplologie' zu erkläran. Wir haben den versuch bereits $\mathbf{s . 4 5 9} \mathrm{ff}$. als verfehlt bezieichnet.

Als letzter in der reihe ist Janko zu erwähnen, der in den IF. 20, 229 ff. das wort ergreift. Nachdem er zuerst über das germ. $\bar{e}^{2}$ gehandelt hat (s. darüber weiter unten), wendet er sich s. 252 ff. zu den sog. reduplicierenden zeitwörtern des germanischen. Er setzt neben den reduplicierten perfecten (got. haihald, aisl. sera, ae. heht u.s.w.) reduplicationslose hochstufige aoristformen an: *hēita, *höita und *hlëupa, *hlouupa, aus denen sich der $\bar{e}^{2}-$ bez. eo-typus entwickeIt habe. Bei den verben mit dem stammvocal $\bar{e}^{-1}$ (got. lètan) lässt er das $\bar{e}^{2}$ des perfects in nebentoniger stelle (*lélèt) erhalten geblieben und von da in die tonstelle eingerückt sein. Bei den verben der $a$-klasse (haldan) wird widerum ein dehnstufiges perfect *helda angesetzt, das zu *held verkürzt wurde; vor nasal + consonant gieng dies $e$ in $i$ über (*fing zu fanzan); daneben wird ein *hōlda angesetzt, das sich zu *halda verkürzte. Das 
perfect-eo der verben mit $\bar{o}$ als stammvocal will Janko ebenfalls lautgesetzlich erklären (s. 290); es ist ihm dies nur auf sehr gezwungene weise möglich (urgerm. *hఒvélıwōp, *hwéhwőp, *hwé(h)wrip, *hwéup mit schwinden des intervocalischen $w$ wie in $*_{n e w u n}=$ got. niun).

Jankos theorie beruht auf den von ihm bedingungslos anerkannten (s. 262) darlegungen Hoffmanns, wonach die verba mit $a$, $a i$, au im praesens für die $e / 0$-reihe reclamiert werden. Da wir oben die haltlosigkeit dieser behauptung bewiesen haben, so fallen auch Jankos erklärungsversuche des $\bar{e}^{2-}$ und co-typus in sich zusammen.

Die frage nach der entstehung des $\bar{e}^{2}$-typus hängt eng zusammen mit der frage nach der herkunft des germ. $\bar{e}^{2}$ überhaupt, wie schon Holthausen in Kuhns Zs. 27,618 f. richtig erkannt hat. Die meisten forscher sind jetzt einig darin, dass $\bar{e}^{2}$ aus dem idg. langdiphthongen $\bar{e} i$ abzuleiten ist und geschlossen ausgesprochen wurde (Jellineck, Beitr. 15, 298 ff.; Sievers, ibid. 16, 238 ff. und 18, 403; Brugmann, IF. 6, 89 f.; Franck, Zs. fda. 40, 51 ff. u. a.m.). Zuletzt hat über $\bar{e}^{-2}$ ausführlich gehandelt Janko, IF. 20, 229 ff., wo auch die einschlägige literatur in grosser vollständigkeit verzeichnet ist.

Germ. $\bar{e}^{2}$ liegt vor in got. aisl. ae. ahd. hêr 'hier'; got. ahd. fêra 'seite'; got. mès, ahd. mias 'tisch'; got. Krëks 'Grieche', ahd. Chrêchi; ahd. mêta, as. mêda, ae. méd 'miete'; ahd. zêri 'schön'; ahd. kiêin, ae. cérı 'kien'; ahd. skêri 'schnell'; ahd. Wêlant, ae. Wéland 'Wieland' u. a., auch in vielen meist aus dem lateinischen stammenden fremdwörtern (s. Streitberg, Urgerm. gramm. § 79; Braune, Got. gramm.5 § 8, s.6; Braúne, Ahd. gramm.2 § 36, s. 24; Sievers, Ags: gramm. ${ }^{3} \S 58$, s. 28).

Dass germ. $\bar{e}^{2}$ in engem zusammenhang mit einem $e i-d i-$ phthong steht, ergibt sich schon aus den germ. mundarten. So hat ahd. mêta eine nebenform meida, afr. mêde steht neben mîde, meide; ahd. stiaga wechselt mit stîga; got. weis, ahd. vir entspricht aisl. vér; ahd. zeari gehört zu aisl. tírr, ae. as. tír 'ruhm'; neben ahd. wiara 'goldschmuck' steht aisl. virr, ae. vir dass.; mhd. viege gehört zu weigen 'schwanken'; got. $\hbar \overline{e r}$ steht im ablautsverhältnis $\mathrm{zu}$ hi-mma, hi-na, hi-ta, hi-dre und neben ahd. hêr steht $h \bar{\imath} r$ (bei Tatian 91, 2, vgI. Sievers, Beitr. 16, 246) und ȟrr; ahd. skêri 'scharfsinnig, helle' g:ehört 
zu got. słeirs, an. skírr, ae. as. skir 'klar, hell'; ae. cén, ahd. kền stellt sich $\mathrm{zu}$ ae. cinan 'sich spalten' u. a.m.

Aber auch die etymologien der germ., wörter mit $\bar{e}^{2}$ neisen auf idg. $\bar{e} i$-diphthong. Nehmen wir die sicheren beispiele zuerst: ahd. skêri, got. skeirs, an. skïrr, ae. as. skîr neben got. skeinan, aisl. stiina, ae. as. skinan gehören zu einer idg. wzl.

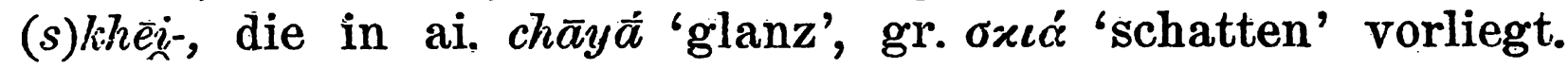
Ahd. zêri, ziari neben an. tîrr, ae. as. tîr ist eine $r$-erweiterung einer idg. basis dēi-, die sich in av. dōivra 'auge', daềma 'gesicht', ai. sudūtés̆ 'schönen glanz habend' widerfindet; der demonstrativstamm germ. $h i$ - ( $h \bar{e} r, h \breve{r} r, h i-t a)$ steckt in lat. cis, ci-tra, gr. ov'-xi, alb. si-viét 'heuer', lit. szis, abulg. sb 'dieser'; die idg. basis ist also $\left.\hat{k}_{\bar{e}} \bar{i}-{ }^{1}\right)$ Andere etymologien sind unsicher. So wenn Uhlenbeck, Beitr. 30, 275 got. fêra, ahd. fras a aus idg.

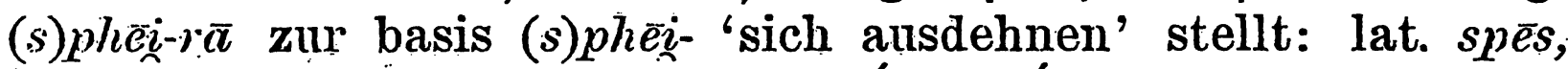
abulg. spéti 'erfolg haben', lit. spéju, spéti 'musse haben', ai. spliirás 'reichlich, gross' (vgl. auch Hirt, Idg. abl. s. 30).

Schwierigkeiten macht die erklärung von germ. ${ }^{*} m \bar{e} d \bar{o}$ (ahḍ. mêta, as. mêda, ae. méd), *meid̄ (ahd. meida, afr. meide) und *mizdö (got. mizdo, ae. meord). Nur der stamm *mizdofindet sich in anderen idg. sprachen: abulg. mьzda, gr. $\mu \propto \sigma \vartheta o ́$, ai. mĩăhám (aus *mizdhám, Brugmann, Kurze vgl. gramm. § 278, s. 196), av. mž̃da. Eine vermittlung ist nur denkbar, wenn wir neben der idg. basis *nizdho- eine zweite basis *mēidhoansetzen; diese beiden basen fasse ich als erweiterungen mit dem gleichen wurzeldeterminativ $d h$ von zwei idg. wurzeln, die 'messen' bedeuten, auf: mizdho- zur wzl. med- (gr. $\mu$ '́o, lat. meditari, air. midim, got. mitan) ${ }^{2}$ ) und méidho- zur wzl. meì(in ai. màttrā, lat. métior, abulg. mèra, ahd. mâa, s. Hirt, Idg. abl.s. 30). Diese beiden wurzeln med- und méi- haben sich schon im idg. gekreuzt, und so wurde die tiefstufe mi- (ai. mitás) der letzteren auf jene und umgekehrt die wurzelstufe med- der ersteren auf diese übertragen (gr. $\mu \varepsilon ́ \tau \rho o v)$. Aus idg. *mezdhóentstand durch diese beeinflussung *mizdhó-, das wie *méc(i)dhodie bedeutung. 'die zumessung' gehabt hat. Die seltẹere form

1) Ahl. stiega neben stîga gehört zu germ. stîgan, idg. wzl. steighh, gr. $\sigma \tau \varepsilon i \chi \omega$ etc.; bei der die ein-stufe nicht belegt ist.

2) Ueber den idg. lautwandel *med-dho- über *medzdho- zu *.nezdhovgl. Brugmann, Kurze vgl. gramm. \$ 261, 4, s. 179. 
ahd. afries. meida, meide geht auf idg. *məidhơ zurück oder ist wahrscheinlicher ursprünglich ein endbetonter casus des hochstufigen $m e ́(i) d h \bar{o}$.

Mit dem im vorstehenden untersuchten germ. $\bar{e}^{2}$ (ahd. ea, $i a$, $i e)$ aus idg. $\bar{c} i, \bar{e}^{i}$ ist das $\bar{e}^{2}$ des sog. $\bar{e}$-typus der reduplicierenden zeitwörter identisch und macht die gleiche weitere entwickelung mit jenem durch. Elie wir aber zu dessen betrachtung übergehen können, müssen wir noch einen blick werfen auf das auch im gotischen im perfect auftretende $\bar{e}$, wofür allerdings nur ein beleg vorhanden ist: sleppan : saislēp (saizlēp), da die übrigen verba mit $\bar{e}$ im praesens den ablautvocal $\bar{o}$ im perfect haben (lêtan : lailot, grētan : gaigrōt, -rēelan : -rairōp, tēkan : taitōk). Nach dem verhältnis von ae. slóepan : slép, ahd. slâfan : sliaf wurde nun auch für das gotische ein unterschied zwischen den beiden $\bar{e}$ des praesens und des perfects statuiert, indem man got. saislēp und ae. slép, ahd. sliaf einfach gleichsetzte. Dem gegenüber ist zunächst zu betonen, dass sich aus den gotischen handschriften kein unterschied zwischen den beiden $\bar{e}$ herausfinden lässt, da sie beide gleichmässig mit $e i$ wechseln, wie das got. $\bar{e}$ überhaupt, was auf eine geschlossene aussprache bei beiden hinweist (perfect anasaisleip Luc. 8, 23, allerdings mit nachträglich wegradiertem $i$, was aber auch z. b. in manaseidai Luc. 9, 13 geschah). Eine gleichsetzung des got. perfects saislepp und des westgerm. slēp ist aber weder nötig noch überhaupt wahrscheinlich. Der nordisch-westgerm. $\bar{e}^{2}$-typus hat weder mit der reduplication, noch mit dem praesentischen $\bar{e}^{l}$ irgend welchen zusammenhang. Er ist erwachsen auf dem boden der idg. $\bar{e} i$-basen, die sicher mehr germanischen verben $\mathrm{zu}$ grunde liegen, als wir jetzt noch nachweisen können. Wir haben schon oben eine idg. wzl. $l \bar{e} d$ - behandelt und daneben eine idg. wzl. lēendwahrscheinlich zu machen gesucht (s. s. 494). Die hochstufe im singular des perfects musste germ. $l \bar{e}^{2} t$ ergeben, die tiefstufe im plural lait- oder lit- (aus idg. laid- bez. leid-) lauten (vgl. Hirt, Idg. abl. s. 33). Schon in idg. "zeit standen neben den $\bar{e} i$-wurzeln vielfach $\bar{e}$-wurzeln, die entweder selbständigen ursprungs gewesen oder aus jenen durch ausfall des $i$ unter gewissen. noch näher zu erforschenden bedingungen (vgl. Brugmann, Grundr. 12, 206; Streitberg, Urgerm. gramm., nachträge 
s. 371 f.; Hoffmann, $\Gamma$. s. 35; Bezzenberger, ibid. s. 163 und s. 169, anm.2) sich secundär entwickelten und in den einzelsprachen zu selbständigem dasein gelangten. So hängt got. rëdan, ai. ráadhyate, abulg. raditi wol mit ai. räs, lat. rés (basis rēi- im ai. plural ráajas) zusammen; bei dieser etymologie würde auch das ahd. reitıın bei Otfrid eine gute erklärung finden. Die verba got. saian und waian gehen mit ziemlicher sicherheit auf $\bar{e} \dot{i}$-wurzeln zurück (s. Hirt, Idg. abl., no. 52, anm., s. 30 und no. 383, s. 101 f.), wenn wir formen wie abulg. séjă, lit. séju

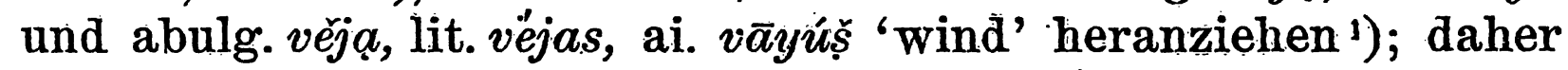
ist auch hier ein $\bar{e}^{2}$-perfect etymologisch berechtigt, das die ndd. perfecta as. obar-se-u (Hel. 2545 C), mnl. sie-u und wie $u$ in der tat aufweisen. ${ }^{2}$ ) Bei ihnen wurde aus dem praesens (van Helten, Beitr. 20, 524) die endung der ersten person -u (as. sâju) angefügt; oder vielleicht ist ein einmal vorhandener verbalstamm mit dem wurzeldeterminativ $w$ (ae. sáwan, wáwan) ${ }^{3}$ ) anzunehmen. Nicht unmöglich ist auch, dass $-u$ aus dem perfect as. gi-heu, mndl. hieu herstammt, wo es wurzelhaft ist (ahd. as. hauwan, ae. héawan, vgl. abulg. kova, lit. káuju 'schmiede, schlage'). Ueberhaupt war im niederdeutschen die perfectendung -(i)eu productiv, vgl. grieu $\mathrm{zu}$ groeien und crieu $\mathrm{zu}$ craien (Kögel, Beitr. 16, 501 f. und Franck, Mndl. grämm. s. 154).

Es ist nicht zu beanstanden, dass wir bei den verben rédan, saian, waian u. a. mit sog. wurzeldeterminativen operieren. Ein solches liegt z. b. sicher vor in got. blēsan, aisl. blása, ahd. blâsan neben ahd. blâen ${ }^{4}$ ); ae. blávvan hat an stelle des $s$ ein $w$ als wurzelerweiterung. Als idg. wurzel ist daher *bhle- anzusetzen, die mit ${ }^{*} b h l \bar{a}$ - in lat. fläre in einem noch unaufgeklärten zusammenhang stehen muss. Vielleicht ist eine gemeinsame wzl. bhel- anzunehmen, die dem ahd. as. ae. belgan 'aufschwellen' ebenfalls zu grunde liegt. Wir können bis jetzt noch wenig sicheres über die wurzelerweiterungen sagen; man vgl. z. b. Brugmanns ansicht in Kurze vgl. gramm. $\S 367$, s. 296 f. Es ist nicht ausgeschlossen, dass an die wzl.

1) Vgl. auch ahd. as. sâjjan, ahd. wâjan, afries. wâjja.

2) Rein erhalten im afries. perf. opt. wê zu *wia, s. Siebs, Pauls Grundriss $1^{2}, 1321$.

3) Vgl. lat. perf. $s \bar{e}-v-i$.

4) Aostfries. *blia - perfect blê, Siebs in Pauls Grundriss $1^{2}, 1321$. 
bhet- neben $\bar{e}$ und $\bar{a}$ auch ein determinativ $\bar{e} i$ antrat, so dass wir auch $b l \bar{e}(s) a n$ zu den ei

Denn das nebeneinanderbestehen von $\bar{e}$ - und $\bar{e} i$-basen ist ausser bei den sog. reduplicierenden zeitwörtern auch noch sonst im germanischen nachweisbar. So finden wir neben gewöhnlichem ahd. feili 'feil' auch fâli (im Voc. St. Galli) und in aisl. falr haben wir die tiefstufe der anzusetzenden idg.

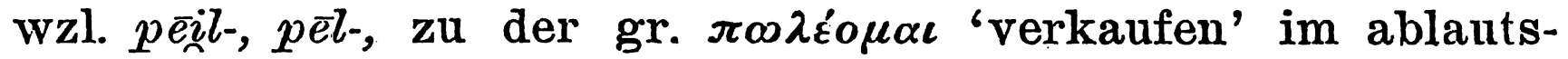
verhältnis steht (vgl. Hirt, Idgl. abl. s. 36).

Die verbreitung der $\bar{e} i$ - und $\bar{a} i$-basen war im indogermanischen wol noch grösser, als wir jetzt nachweisen können; vgl. die liste bei Hirt, Idg. abl. s. 34 ff., die sich noch im laufe der zeit wird vervollständigen lassen. Eben deshalb wird es auch nicht möglich sein, die ausdehnung dieser basen unter den sog. reduplicierenden verben des germanischen gânz zu überschauen; es muss daher der nachweis genügen, dass wir bei einer anzahl verben wie lètan, rēdan, saian, waian die zugehörigkeit $\mathrm{zu}$ alten $\bar{e} i$-basen annehmen müssen und bei anderen sie wenigstens vermuten dürfen.

Neben dem $\bar{e}^{2}$-typus war in allen mundarten auch ein $\breve{e}$-typus vertreten:

Aisl. blett zu blanda, fell zu falla, felt zu falda, helt (selten hell) zu halda. Vor nasal + consonant wurde diesses $\breve{e}$ schon urgermanisch zu $\breve{\imath}$, daher aisl. fekk (aus *fink, vgl. Noreen, Aisl. gramm. ${ }^{2} \S 257,3$, s. 169), plural fingom zu fá, gekk, plur. gingom zu ganga und helk, pl. hengom (e nach dem sing:) zu hanga. Im altenglischen finden wir blend zu blandan, fenz zu fón, henz zu hón 1); im altfriesischen treffen wir aofr.

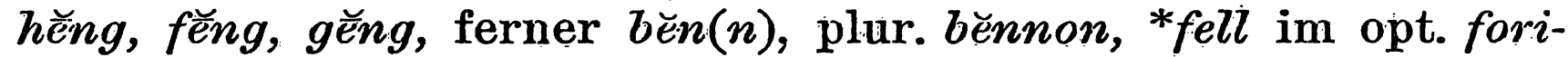
felle; awfr. $g(h)$ eng $(h)=$, -fong, aber daneben $g(h) i n g(h)$, (out)fingh (vgl. Siebs, Pauls Grundriss 12, s. 1218 f́.).

Das altsächsische besitzt fel(l), feng, geng, held, spenn, giweld, wel(l), aber keine $i$-formen $\left.{ }^{2}\right)$; das althochdeutsche weist kenc, leengun (gengun), - fenc, fengun - henc in der Fragmenta

1) Ae. feoll, zeonz, heold, steold (auch weolc, weold, weoll?) setzen ebenfalls kurzformen mit $\breve{e}$ voraus, das aber zu eo gebrochen ist, vgl. Janko a. a. o. s. $300 \mathrm{f}$.

2) Die $\breve{e}$-formen überwiegen bedeutend die $i e$-formen (180 gegen 24, wovon 20 im anfang). 
Theodisca und dem Isidor auf; andere beispiele wie pi-fel Ra. oder helt Gl. R. lassen nicht ersehen, ob $\breve{e}$ oder $\bar{e}$ vorliegt.

Das mittelniederländische zeigt vel, plur. vellen, helt, plur. helden; indes nur $i$-formen bei vinc, vinghen, hinc, hinghen, ghinc, ghinghen (Franck, Mittelniederl. gramm. § 153).

Seit Sievers, Beitr. 1,504 ff. die ansicht äusserte, dass die $\breve{e}$-formen bei den wurzeln auf doppelten consonant die ursprünglicheren sind, hat sich die forschung stets auf diesen boden gestellt, aber die $\breve{e}$-formen aus $\bar{e}$-perfecten entstehen lassen; so Franck; Zs. fda. 40, 30 f. und Mittelniederl. gramm. a.a.o.; Loewe, Kuhns Zs. 40, 327. Janko a.a. o. s. 298 sieht die $\breve{e}$-kurzformen als ältere selbständige bildungen an, worin wir ihm aber nicht folgen können, da wir seine und Hoffmanns annahme, den stämmen mit $a+$ doppelconsonanz lägen durchgehends $\breve{e}$-wurzeln zu grunde, áls unbewiesen abgelehnt haben.

Wir nehmen vielmehr folgenden entwickelungsgang an: Als infolge des schwindens beż. nichtvorhandenseins der reduplication im perfect sich im nordisch-westgermanischen ungefähr um 300 n. Chr. geburt (s. oben s. 483) das bedürfnis nach einer schärferen charakterisierung der zeit der vergangenheit bemerkbar machte, da wählte man das in mehreren beispielen vorliegende $\bar{e}^{2}$, das schon frühzeitig von den $\bar{e} i$-wurzeln auf die $\bar{a} i$-wurzeln übergegriffen hatte: ${ }^{*} l \bar{e}^{2} t,{ }^{*} r \bar{e} d,{ }^{*} w \bar{e}^{2},{ }^{*} s \bar{e}^{2},{ }^{*} h \bar{e}^{2} t$ und vielleicht noch andere. Vor doppelconsonanz wurde $\bar{e}^{2}$ entweder verkürzt: ${ }^{*} h \bar{e}^{2} l d$ wurde also zu held und vergleicht sich der kürzung von germ. *winda aus idg. *vēntó- - vgl. ai. vàtas - oder germ. *férsnō aus idg. *pérsnā, vgl. aị. párṣṇiṣ (Brugmann, Vgl. kurze gramm. s. 218) u. a.m.; oder eine andere möglichkeit ist, dass in *held von vornherein kurzer vocal vor-

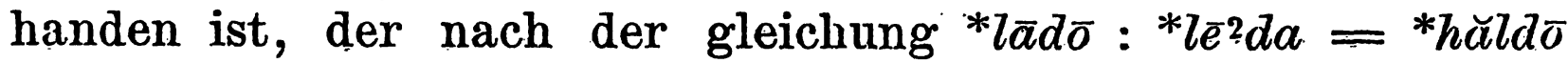
: *hělda eingetreten war. Später tritt in den meisten mundarten wider langer vocal ein, so im altfriesischen: aofries, hêlld, wêld; im altsächsischen: hield (für *hêld), gieng u.s.w.; im althochdeutschen: fiang, gianc, hiang, und zwar nach dem muster der langsilbigen verba. Das mittelniederländische hat nur selten ie angenommen, meist nur in den grenzdialekten (Franck, Mndl. gramm. § 153); das altnordische überliaupt nicht, und das altenglische hat, wie schon gesagt, von vorn- 
herein hier meist eo-perfecta'), wovon noch später die rede sein wird.

Ueberblicken wir nummehr die ausbreitung des $\bar{e}$-typus in den einzelnen mundarten. Im altnordischen hat er nicht wesentlich über seine anfänglichen grenzen hinausgegriffen: aisl. heét $\mathrm{zu}$ heita, lét zu láta, réb zu rába, blés zu llása, grét zu graita und lék zu leiłia; aschwed. $7 \bar{\omega} t$ zu heta, grāt zu grāta,

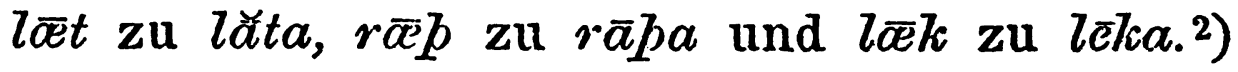

Die dem nicht zur entialtung gelangten ei-typus (s. oben s. 496) angehörigen aisl. Theit $=$ mschwed. hēt, aisl. leit $=$ mschwed. lett, aisl. reip $=$ aschwed. réph, aisl. greit $=$ aschwed. grêt, aisl. heilt und mschwed. leck sind bereits besprochen; ebenso haben wir die nebenformen aisl. agutn. līt, plur. lito bezw. litu, agutn. hīt u.s.w. bereits (oben s. 470) als lautgesetzliche tief- bez. schwundstufenformen der $\bar{c} i$ - und $\bar{a} i$-wurzeln zu erweisen gesucht.

Das altenglische hat den $\bar{e}^{2}$-typus ebenfalls nicht sehr ausgedehnt. Von den in allen mundarten vertretenen und daher wol altertümlichsten formen sind hier belegt: hét $\mathrm{zu}$ haitan, lét zu lótan, réd zu rádan, léc zu lácan, slép zu slcépan, ferner -dréd zu ondródlan und scéd zu scádan.

Das altfriesische weist als zum $\bar{e}^{2}$-typus gehörig auf: afries. hêtt, lêt, awfries. rêtd, nordfries. slêp. Hier bemerken wir nun zum ersten mal ein weitergreifen des $\bar{e}^{2}$-typus, wenn wir perfecten wie aofries. hêld und wêld begegnen; ja sogar in das gebiet des sonstigen eo-typus ist $\bar{e}^{2}$ eingedrungen im fries. hlêep zu hlopa 'laufen' (s. auch weiter unten s. 512). Daneben finden wir die tiefstufigen $\bar{\imath}$-perfecta, besonders im Rüstringer dialekt, zahlreich vertreten: hît, lît, hîld, wîld (diese beiden auch awfries.), ferner wg. lîp zu lôpa und rîp (ein afries. */hrêp voraussetzend) zu rôpa 'rufen'. Freilich kann $\hat{\imath}$ hier speciell friesische verengung von $\hat{e}$ sein (vgl. zu

1) Abgesehen von einigen e-perfecten wie zenz Gen. 626 und 834, das Sievers, Ags. gramm. ${ }^{3} \S 396$, anm. 1 zwar nicht als echt ags. gelten lassen will; das schwache perfect zenzde entstand aber doch wol durch anfïigung: von -de an jenes.

2) Aisl. Zlóta - perf. blét beweist die ausdehnung der $\vec{a}^{2}$-typus anch auf die verba mit $\bar{o}$-vocal wie im friesisehen hlêp zu hlôpa.

Peiträge zur geschichte der deutschen sprache. XXXII. 
allen hier genannten formen Siebs in Pauls Grundriss 12, 1218 f.). ${ }^{1)}$

Das altsächsische hat hêt, lêt, rêd, slêp, daneben an-drêd, for-hwwêt, -scêth. Der ĕ-typus ist vertreten mit blend, feng, fell, geng, held, weld, well; doch finden sich auch diè langformen fieng, gieng, hield, wield. Ueber heu żu ha(u)wan handelt Kögel, Beitr. 16, 501; es stellt sich neben ob̆ar-seu Hel. 2545 C, das wir schon oben s. 504 besprochen haben. Ein *hêu, wie

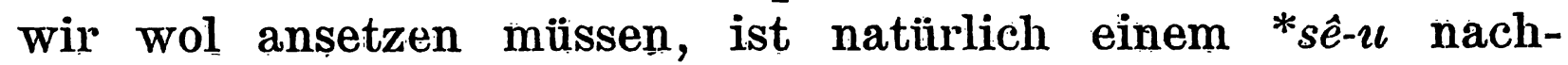
gebildet, dessen $u$ d.h, $v$ entweder wurzelerweiternd (vgl. lat. sêvi) oder *hêu entlehnt ist.

Die weiteste ausdehnung hat der $\bar{e}^{2}$-typus im althochdeutschen gefunden, vielleicht unterstïtzt durch das lautliche zusammenfallen des aus $\bar{e}^{2}$ entwickelten ia mit dem aus *a . entstandenen $i a$ in iar zu erien aus *arjan, neben dem vielleicht in vorliterarischer zeit noch perfecta wie ein dem got. aiaik entsprechendes *éék zu *eikan u. a. vorhanden gewesen sind 2) (vgl. Zarncke, Beitr. 15, 352); beweisen lässt sich diese annahme freilich nicht, aber auch nicht ganz von der hand weisen. Auch die verba mit $a+$ doppelconsonanz (haldan u.s.w.) haben sich früh im ahd. dem $\bar{e}^{2}-$ bez. $i a$-typus angeschlossen; formen wie feng, geng, heng sind nur in ältester zeit und selten auf fränkischem boden, also dem niederdeutschen benachbart, zu belegen (s. oben s. $505 \mathrm{f}$.).

\section{Der eo-typus des perfects.}

Alle erklärungsversuche, die für den $\bar{e}^{2}$-typus aufgestellt worden sind, die contractionstheorie, Brugmanns deutung aus idg. langdiphthong, Hoffmanns geschleift betonter und Jankos der $e$-reihe angehöriger $\bar{e}$-diphthong, kehren bei dem eo-typus wider. Wir haben oben s. $497 \mathrm{ff}$. gesehen, dass keiner dieser versuche voll befriedigt. Wir werden zunächst eine andere theorie prüfen und dann den tatsächlich vorliegenden bestand

1) $\mathrm{Zu}$ erwähnen ist noch allerdings unsicheres awfr. gheengh, d.h. gêng zu ganga (Siebs a.a.o. s. 1219).

2) Falsch ist natürlich die ansetzung urgerm: formen wie ${ }^{*} \bar{e} r$, *elp, $*_{\bar{e}} k_{\text {. }}$. die wie got. $-\bar{e} t=$ ahd. $\hat{a} z$, ae. $\alpha t$, an. át, im ahd. *âr; *âld und *âh ergeben hätten. Sehr gekünstelt ist die deutung von Loewe a.a.o. s. 308; vgl. auch Janko a.a.o. s. 313. 
an $e o-$ perfecten in den einzelnen mundarten nacheinander betrachten.

Hoffory, Kuhns Zs. 27, 597 und Holthausen, Kuhns Zs. $27,620 \mathrm{f}$. haben zuerst $\mathrm{m}$. w. den versuch gemacht, die eo-perfecta im nordischen wie auch im westgermanischen als analogiebildungen nach den perfecten vocalisch anlautender stämme urgerm. *éauk zu aukan, *éaus zu ausan und *éaup zu *aupan zu erklären. Holthausen meint a.a.o.: 'Nach analogie dieser drei verba bildeten sodann alle reduplicierenden verba von der form stautan ihr praeteritum mit eo, an. ió, ae. eo, ahd. as. eo, io. Dass später jene formen, die durch regelrechte entwickelung $\mathrm{zu}$ dieser neuen reihe den anlass gegeben hatten, im westgermanischen ganz oder zum teil schwanden, konnte natürlich die einmal durchgeführte bildung nicht wider beseitigen.' Gegen diese erklärung hat Behaghel, Lit.-blatt 1890, s. 284 eingewendet, dass die perfecta germ. *éauk, *éaus und *éau $p$ im westgermanischen nicht belegt seien. Obwol ich diesen einwand nicht für ausschlaggebend halte, so bin ich doch auch der ansicht, dass eine so weitgehende analogiebildung nach nur drei dazu in den westgermanischen mundarten früh ausgestorbenen formen noch einer stütze bei den consonantisch anlautenden verben bedürfe. Eine solche lässt sich in der tat finden und wir werden sehen, dass die eo-perfecta in der mundart die grösste ausbreitung gefunden haben, wo sie die meisten lautgesetzlich entstandenen formen aufzuweisen haben, nämlich im altenglischen. Ueberhaupt ist von vornherein bei den eo-perfecten, ebenso wie bei den $\bar{e}^{2}$-perfecten nicht anzunehmen, dass ihre vertreitung nur von einem punkte aus stattgefunden hat, sondern wir müssen annehmen, dass verschiedene momente zusammentrafen, um diese ausbreitung zu begünstigen. Ausser bei den vocalisch anlautenden stämmen lassen sich in allen mundarten auch sonst noch lautgesetzlich entwickelte eo-perfecta nachweisen, die meisten, wie schon gesagt, im altenglischen.

Im altnordischen liegt, ausser den schon genannten lautgesetzlichen perfecten aisl. iók = got. aiauk zu auka und iós zu ausa, noch ein perfect vor, das regulär aus einem urgerm. redupl. perfect entwickelt sein kann: aisl. hió zu hogg(u)a. Es sind folgende stufen anzunehmen: urgerm. *hehaúiva, urnord. 
*héhōw(a), *héōw (Noreen, Altisl. gramm.3 § 224, s. 147 f.), aisl. hió (ebenda, $\$ 97$, s. 80 und $\S 227$, d, s. 150). Der plural aisl. huggom, rschwed. uku = mschwed. huggo, hoggo erklärt sich aus tiefstufigem urgerm. *(he)huwmé. Zwischen singular und plural fanden dann mannigfache beeinflussungen statt; die sich in den aisl. formen plur. hioggom, rschwed. (h)iuku, aschwed. sing. hiog, hiog ${ }^{1}$ ), mschwed. hug, plural hioggo zeigen; mschwed. finden sich spät auch die sing. høg, hyg, die beeinflussung durch den infinitiv hogga, hugga verraten oder auch direct aus dem plural huggo, hoggo und dem singular hiog contaminiert sind.

Nur als analogiebildungen nach obigen mustern können wir aisl. hlaupa - hlióp und bria - bió auffassen.

Das altenglische ist reich àn eo-perfecten, die indes doppelten ursprungs sind und teils mit länge als éo, teils als $e o$ anzusetzen sind. Dass es in urgermanischer zeit auch die perfecta *éauk, *éaub besass, ist deshalb anzunehmen, weil es noch in historischer zeit die participien éacan 'gross' (= as. ôkan 'schwanger', fries. āken, aisl. aukenn 'vermehrt') und éaden 'geboren' (= as. ôdan 'bescheert', aisi. aupenn) aufzuweisen hat; ausserdem ist wie in as. ôlkian, ahd. ouhhôn ein schwach flectiertes verb iec(e)an vertreten (auch aisl. auka flectiert schwāch; vgl. Noreen, Altisl. gramm. § 493, anm. 2, s. 300).

Der langdiphthong éo kann lautgesetzlich entstanden sein in héow $\mathrm{zu}$ héawan (*héhauwa, *hehōv(a), *hēow), wéold zu rvealdan (*wewald,*weuld), wéolc zu wealcan (*wévall, *weulk), hwéop zu hwópan (*hwehwōp, *hwveōp oder nach dem plural *hwehwopum, wie Zarncke, Beitr. 15, 352 will) ${ }^{2}$ ); endlich wéow zu wáwan aus einem plur. *wewmé, *weum, contaminiert mit dem singular $* w \bar{e}$ und dem angehängten $w$.

Der kurzdiphthong eo ergab sich infolge der sog. brechung oder des $u$-umlauts (s. darüber Weyhe, Beitr. 31, 48 und Janko a. a. 0. s. $267 \mathrm{ff}$.) in den formen reord, ondreord, leort, leolc.

Weiter ergab sich der kurzdiphthong eo aus dem perfect $\breve{e}$ der verben mit $a+$ doppelconsonanz im praesens entweder

1) io statt io erst spät (seit 1350).

2) Janko a.a.o. s.300 f. nimmt eine etwas verschiedene entwickelung an mit demselben endresultat. 
durch brechung oder durch $u$-umlaut aus dem plural. Erstere findet statt von $r+$ cons., $l c$ und 77 (Sievers, Ags. gramm. ${ }^{3}$ $\S 79 \mathrm{f}$.); es käme daher nur weolc in betracht, das aber auch als veéolc aufgefasst und als ursprünglich redupliciert angesehen werden kann. $U$-umlaut kann in betracht kommen vor $l l, n n$, nd (Sievers, Ags. gramm. ${ }^{3} \S 104$ ) in feoll $\mathrm{zu}$ feallan, speon $\mathrm{zu}$ spannan, beon $\mathrm{zu}$ bannan.

Wir haben also etwa ein dutzend formen mit eo und éo Im perfect, wo dieser diphthong lautgesetzlich zu erklären ist. Dazu die hypothetisch für das urenglische vorausgesetzten ${ }^{*} c \bar{o} k$ zu *aukan und *eōb zu *aupan. Diesen zahlreichen eo-perfecten gegenüber konnten wir für das urenglische nur fünf lautgesetzlich entstandene $\bar{e}^{2}$-perfecta aufstellen (s. oben s. 506). Dies verhältnis erklärt m. e. am deutlichsten das überwiegen des eo-typus im altenglischen. Sehen wir nun im einzelnen $\mathrm{zu}$, wie die analogische weiterverbreitung der eo-perfecta erfolgt sein mag.

Urengl. *eōk zu *eakan und $*_{e \bar{o} p} \mathrm{zu} * e a p a n$ ergaben die muster für ae. béot $\mathrm{zu}$ béatan, hléap $\mathrm{zu}$ hléapan und á-hnéop zu á-hnéapan. Ferner diente hwópan : hwéop als muster für die verben mit ó im praesens: blówan : bléow, blótan : bléot, flówan : fléow, zrówan : zréow, hlówan: hléow, hrópan : hréop, rówan : réow, spówan : spéow, swózan : swéoz. Ebenso wáwan : wéow als muster für die verba mit $a$ im praesensstamm, unter denen séow zu saiwan vielleicht durch doppeltes antreten des wurzeldeterminativs $w$ sich erklärt (vgl. as. -seu, seu $+w$ - *seuw): es sind dies: bláwan: bléow, cnáwan: cnéow, cráwan : créow, máwan : méow (auf diese lässt sich obige erklärung von séow ebenfalls anwenden, auch sind perfecta wie afries. blē, mndl. crieu ebenfalls belegt, *cneu und *meu dagegen nicht), ferner swápan : swéop ${ }^{1}$ ) und dráwan : Jréow. Bei den verben mit germ. $a+$ doppelconsonanz im praesens boten sich als muster weolc, feoll, speon, beon, daher fealdan : feold, healdan : heold, sealtan : seolt, stealdan : steold, zanzan : zeonz. Endlich zog wépan : wéop noch *hwésan : hwéos nach sich; wépan aus urgerm. *wōpjan (got. as. wōpjan, ahd. wuoffen, mhd. wïefen) setzt ein älteres *wōpan voraus, wie dem got. hropjjan ein ae.

1) Scherer, Zs. f. d. östr. gymn. 24, 299. 
as. hrôpan, ahd. hruofan gegenübersteht; *ūopan aber konnte nur ein perfect *weōp aus *wéwop ergeben.

Wenn auch im altenglischen das eorperfect infolge analogischer einflüsse bei weitem das übergewicht über das $\bar{e}^{2}$-perfect erlangt hat, so sind trotzdem noch manche reste alter é-perfecta erhaltén. Blend zu blondan zeigt sogar noch die alte, urwestgerm.-nord. kürze des $e$ vor doppelconsonanz, ebenso fenz zu fón und henż zu hón (s. oben s. 505). 1) Deutlich erkennen wir im opt. séwe (altw̌s. Cura past. und merc. $\mathbf{R}^{1}$ ), sowie in der 2. sing. north. sáwe, von dem urgerm. perfectum ${ }^{*} s \bar{e}^{2}$ mittels des determinativs $v$ abgeleitete formen. Das merc. héu entspricht dem as. -heu, mndl. hieu (s. oben s. 504); north. bléuu, plur. bléwun findet sein gegenstück in aostfr. ble (Franck, Zs. fda. 40, 38 ff.); altwests. merc. north. on-cnéw, sowie north. plur. hréwun sind ebenfalls solche alte, versprengte $\bar{e}^{2}$-perfecta (s. Sievers, Ags, gramm. § 396, 2, anm. 8, s. 224).

Vereinzelte eo-perfecta wie á-bréot 'er tötete' (Beow.2931), héof zu héofan, á-hnéop 'er pflückte ab' (Leg. of Guðlác), zenéop (Exodus 475) zu got. dis-hniupan, aschwed. njūpa 'kneifen', onréod 'imbuit' (Corp. gloss. 1129) zu ae. 7rćodan 'schmücken' u. a., die Hoffmann, $\boldsymbol{\Gamma}$. s. 55 bespricht, erklären sich am leichtesten als analogiebildungen nach dem im altenglischen verbreiteten eo-typus des perfects. ${ }^{2}$ )

[Ueber north. speoft, beoft s. nachtrag.]

Die nichtwestsächsischen mundarten (kentisch, mercisch, northumbrisch), bei denen eo und ea nicht streng geschieden werden (Sievers, Ags. gramm. $\S 150,3$, s. 69 f.) haben auch den diphthong ea im perfect; so in den Lindisfarne Gospels: ondreard 19, 8, ondreardon 6,19 , feall 11, 32, beheald 1,36 , zeheald 17,12 u. a. m.

Das altfriesische ist arm an eo-perfecten; vielleicht ist awfr. hliope (opt. zum ind. hlêp von hlâpa 'laufen') und rôp (roep) zu hrôpa 'rufen' hierherzurechnen. Neben rôp ist übrigens eịn *hrêp wegen wg. rîp (Sylt rốp ?) vorauszusetzen (vgl. Siebs, Pauls Grundriss 12, 1219).

1) Auch zenz Gen. 626 und 834 sowie spenn Gen. 445 sind hier zu nennen, die Sievers, Ags. gramm. ${ }^{3}$ § 396, anm. 1 nicht als ae. gelten lässt:

2) So auch das perf. héof zu héofan und spätws. hréow zu hréowan. 
Das altsächsische besitzt von verben mit germ. $a u=$ as. $\bar{\sigma}$ im stamm: a-hliopun (M 4857) von $a$-hlopan, wo der Cott. $a$-hliepun hat; ebenso in den Oxf. glossen stiet zu stôtan. Von verben mit germ. $\bar{o}$ als stammvocal sind belegt: hriop zu hrōpan 'rufen', iviop zu wôpian (ja-praesens, vgl. got. hrôpjan) 'weinen' im Mon.; daneben hat der Mon. wie der Cott. auch eo in hreop; einmal findet sich ia in hriapun (Ess. gloss.). Ein opt. perf. ist wiopin (Cott. Mon. 5522), neben dem sich im Cott. wêpin, also mit übertritt $\mathrm{zu}$ den $\bar{e}^{2}$-perfecten findet. ')

Im altsächsischen ist durch den zusammenfall von germ. a $\iota$ und $\bar{o}$ die ïbertragung des eo-perfects von den urgerm. vorbildern *aukan : *eōk, *ausan : éōs, auzan : *éōz, *hauwan : héo auf die $\bar{o}$-stämme ermöglicht worden.

Im althochdeutschen ist derselbe process anzunehmen; hier bildeten verba wie stôzan (= got. stautan), scrôtan (aus urgerm. *skrautan) die brücke. Belegt sind die perfecta von loufan, houwan, stôzan, scrôtan (urgerm. au im stamm) und bluozan, (h)ruofan, uvofan (urgerm. $\bar{o}$ im stamm). Neben den beiden letzteren haben sich aus den germ. $j$-praesentien *hroppjan, *wopjan schwache verba (h)ruofen, wuofen entwickelt.

Versprengte reste sind (far-)fluohhan part. perf. zu germ. *flōkan; mhd. gebûwen dass. zu ahd. bûan, das sonst schwach flectiert.

Der perfectvocal eo wird später (9. jh.) zu io (ia bei Otfrid) und endlich $\mathrm{zu} i e$, wodurch er mit dem aus $\bar{e}^{2}$ entstandenen ie zusammenfällt. Oberdeutsch wird io vor labial zu iu: iiuf, riuf, wiuf; so auch hiu, plural hiuwen bei Notker.

\section{Schlussbetrachtung.}

Wir haben im vorhergehenden die perfectbildung der sog. reduplicierenden zeitwörter einer eingehenden betrachtung unterworfen, die früheren erklärungsversuche kritisch beleuchtet und sie teils $\mathrm{zu}$ widerlegen versucht, soweit sie

1) Eigentümlich ist das eo-perfect griot C, griat M 4072 zu as. *grâtan (got. grētan : gaigrōt). Hoffmann $\Gamma$. s. 56 stellt es zu as. greotan = ae. zréotan; Rödiger, Anz. fda. 20, $243 \mathrm{f}$. sieht in letzterem eine contamination von *grâtan und *eutan, ae. réotan, ahd. riozan und setzt griot $=$ got. gaigrot. 
unhaltbar erschienen, teils angenommen, wenn sie eine ansprechende deutung der sehr verwickelten verhältnisse auf diesem gebiete zu enthalten schienen. Es erübrigt nunmehr, in kurzen worten die ergebnisse der vorstehenden untersuchung zusammenzufassen.

1. Das indogerm. perfect konnte mit und ohne reduplication. gebraucht werden.

2. Die reduplication, die z.t. schon in indogermanischer zeit bei den sog. praeteritopraesentien fehlte, wurde im germanischen in grösserem umfang aufgegeben, wenn der ablaut das perfect genügend kennzeichnete.

3. In urgermanischer zeit waren in allen germ. mundarten reduplicierte perfecta vorhanden; doch nur im gotischen ist diese kategorie noch einigermassen productiv.

4. Erhalten blieb die reduplication im gotischen bei fehlendem ablaüt oder bei dem nur vereinzelt vertretenen ablaut $\bar{e}(a i): \bar{o}$, der sich keiner grösseren ablautsgruppe angliederte.

5. In der zeit zwischen $200-400 \mathrm{n}$. Chr. geburt vollzogen die nordisch-westgermanischen mundarten den übergang zum $\bar{e}^{2}-$ bez. eo-perfecttypus.

6. Zunächst lagen noch andere perfecttypen im kampf mit dem $\bar{e}^{2}$ - bez. eo-typus: der hochstufentypus (runschwed. $h a(u) k$ zu hauwan, aisl. sueip zu sueipa, ae. zanz zu zanzan u.s.w.) und der ei-typus (aisl. leit, ahd.-leisz u.s.w.).

7. Gesiegt hat bei den hellvocalischen wurzeln (germ. $a$, $a i, \bar{e}$ im stamm) der $\bar{e}^{2}$-typus, dessen erklärung von indogerm. $\bar{e} i$-wurzeln auszugehen hat. Dies ist Brugmanns theorie (IF. 6, 89 ff.), die deshalb anzunehmen ist, weil sie auch schon aus dem germanischen selbst sich ergibt; alle wörter mit $\bar{e}^{2}$ haben verwante formen mit stammhaftem $\breve{\imath}$ neben sich. Die ausbreitung dieses $\bar{e}^{2}$-typus gieng auf analogischem wege vor sich von einer beschränkten anzahl beispiele aus: urgerm. ${ }^{*} l \bar{e}^{2} t,{ }^{*} \boldsymbol{e}^{2} d$, $* s \bar{e}^{2}, * w \bar{e}^{2}, * h \bar{e}^{2} t$ und vielleicht von noch anderen verben, deren etymologie bisher nicht ermittelt ist.

8. Der eo-typus gieng ebenfalls nur von wenigen typen aus (urgerm. *éauk, *éaus, *éaup, urnord. urengl. *héo(w) aus *héhaıนwa) und erlangte, mit ausnahme des altenglischen, in allen germ. mundarten nur geringe ausdehnung. 
9. Das altenglische entwickelte neben dem allgemein-germ. éo-typus infolge seiner besonderen lautverhältnisse ein ěo-perfect, das sich ebenfalls auf analogischem wege ausbreitete. Hier nur blieb der eo-typus deshalb auch lebenskräftig;

10. in allen übrigen mundarten ist er in dem verbreiteteren $\bar{e}^{2}$-typus zuletzt aufgegangen, allerdings auch infolge regelrechter lautlicher entwickelung (im ahd.).

Bei der prüfung der ausführungen in dem vorliegenden aufsatz wird man leicht die grundsätze herausfinden, die mich bei der erklärung der perfectformen der sog. reduplicierenden zeitwörter geleitet haben. Ich will sie in einigen worten noch kurz zusammenfassen.

Ich halte es vorerst für einen methodischen fehler, von construierten indogermanischen urformen aus an die erklärung der $\bar{e}^{2}$ - und eo-perfecta in den germanischen mundarten heranzutreten. Diese erklärung muss zunächst von dem tatsächlich belegten material ausgehen; die ansetzung einer vorgerm. form ist m. e. nur dann berechtigt, wenn sie durch germ. lautverhältnisse gestützt und gefordert wird. Aus diesem grunde stimme ich Brugmanns deutung des $\bar{e}^{2}$-perfects aus idg. $\bar{e} i$-diphthong $\mathrm{zu}$, weil im germanischen selbst enge beziehungen zwischen $\bar{e}^{2}$ und dem $\bar{\imath}$-laut bestehen, wie oben s. 501 f. gezeigt worden ist. Dieses germ. $\dot{\bar{e}}^{2}$ ist auch im gotischen vertreten und wechselt auch hier mit $i$ ab (hêr, hidre $\bar{e})$; ob es in dem einzig belegten reduplicierten perfect mit $\bar{e}$ als stammvocal (saislepp) vorliegt, ist nicht zu entscheiden, aber nicht wahrscheinlich (s. oben s. 503). Wo im westgerm.-nord. der ablaut $\bar{e}^{1}: \bar{e}^{2}$ vorliegt $\left({ }^{*} l \bar{e}^{1} t \bar{c}:{ }^{*} l \bar{e}^{2} t\right)$, hat das gotische den ablaut $\bar{e}^{1}: \bar{o}$ (lèta : lailōt).

Dagegen verwerfe ich die annahme eines êu-diphthongen als vorstufe für das eo-perfect. Zunächst ist die existenz dieses langdiphthongen weder vom germanischen noch vom indogermanischen aus sicher erweisbar; sodann ist es durchaus nicht nötig anzunehmen, dass das $\bar{e}^{2}$ - und eo-perfect den gleichen ursprung haben. Das letztere kann auf einem andern boden erwachsen sein als jenes, was ich auch annehme. 
Für methodisch verfehlt (nicht nur wegen der nicht bewiesenen zugehörigkeit zur e/o-reihe bei den in frage kommenden zeitwörtern) halte ich 0 . Hoffmanns ansetzung von aoristformen *léike und *stéute. Es gibt bis jetzt keinen beweis dafür, dass im. germanischen der idg. aorist weitergelebt habe (abgesehen von einigen zweifelhaften fällen wie ahd. scrirun u. ähnl.); eine nicht sicher als vorhanden nachgewiesene formenkategorie aber zur aufhéllung unerklärter verbalformen $\mathbf{z u}$ verwenden, ist ein circulus vitiosus, ein beweis aus irrigen voraussetzungen, der abzulehnen ist.

- Nicht anders steht es um Jankos dehnstufenformen *hēita, *hōita, *hlèu pa, *hlōupa. Sie sind construiert, um die germ. $\vec{e}^{2}-$ bez. co-perfecta zu erklären; der beweis für ihr einstiges vorhandensein steht auf schwachen füssen. Altindische dehnstufige $s$-aoriște wie arāikșam, ábhāukšsam u.s.w. gehören doch einer ganz anderen formenkategorie (dem $s$-aorist) an und sind zudem so selten, dass sie nicht schlankweg auf das germanische übertragen werden dürfen, wo sie sonst nicht nachweisbai sind.

Ebensowenig vermag ich mich mit Osthoffs deutung der ahd. $r$-perfecta zu befreunden, so wenig widerspruch sich auch gegen das aus idg. *stestaúda dissimilierte germ. *stesaúta $=$ ahd. steroz erhoben hat. Eine dissimilation von *stest- zu *stesist im germanischen anderwärts nicht zu belegęn, der urgerm. reduplicationstypus *stest- zum mindesten sehr zweifelhaft (s. oben s. $471 \mathrm{f}$.).

Alle oben genannten erklärungsversuche haben den fehler gemein, construierte idg. laute und lautgesetze, deren vorhandensein bez. berechtigung unerwiesen ist und die ad hoc statuiert sind, zur aufhellung innergermanischer verhältnisse zu verwenden. Ich hoffe, in meinen ausführungen über die germ. reduplicierenden zeitwörter diesen fehler vermieden zur haben.

BERLIN N 54, 18. märz 1907.

S. FEIST. 